Pacific Northwest

National Laboratory

Operated by Battelle for the

U.S. Department of Energy

\title{
Technical Review of the Characteristics of Spent Nuclear Fuel Scrap
}

\author{
WL Kuhn JP Sloughter \\ J Abrefah JC Wiborg \\ AL Pitner DW Damschen \\ M Plys
}

December 2001

Prepared for the U.S. Department of Energy

under Contract DE-AC06-76RL01830 


\section{Technical Review of the Characteristics of Spent Nuclear Fuel Scrap}
W. L. Kuhn
J. P. Sloughter
J. Abrefah
J. C. Wiborg
A. L. Pitner
D. W. Damschen
M. Plys

December 2001

Prepared for

the U.S. Department of Energy

under Contract DE-AC06-76RL01830

Pacific Northwest National Laboratory

Richland, Washington 99352 


\section{Summary}

Nearly 2100 metric tons of metallic uranium spent nuclear fuel (SNF) are stored in two water-filled pools - the K-Basins - in the 100-K Area at Hanford. The Spent Nuclear Fuel Project is resolving the safety and environmental issues associated with continued wet storage of the deteriorating SNF in these basins. The project's fuel-handling process involves preparing, loading, and transporting fuel for drying and subsequent storage in canisters, pending suitable repository disposal.

Scrap generated from October to July, 2001, while washing the SNF to prepare it for cold vacuum drying, differed significantly from that envisioned during project design. This raised the issue that the geometric reactive surface area of particles of uranium in the scrap could be higher than allowed for the baseline process. Therefore, Fluor Hanford convened a technical review panel to evaluate the new information about the physical characteristics of scrap generated during processing. The technical review began after K-Basin staff tested the process by retrieving, weighing, and photographing the scrap that they collected during the washing process.

The review panel defined a characterization approach based on the available information; i.e., the weights and digital photographic images. They examined and interpreted video images of the scrap obtained by K-Basin staff and estimated the volume and hence the masses of inert material and of large fragments of spent fuel. The mass of the remaining spent fuel particles, viz., particles of uranium less than 5/8 inch across, was found by subtracting the difference between the total mass and the mass of inert material and large fragments. The area of these particles was estimated by fitting a lognormal distribution to the relative number particles in four size ranges and then obtaining the area-to-volume ratio from the distribution.

The panel attempted to meet three objectives, in the following order of preference:

- Based on the physical characteristics that are important to ensuring that scrap can be safely dried and stored, provide a technically defensible position that all scrap that will be generated is qualified for loading into canisters for cold vacuum drying by qualifying the existing washing equipment and process.

- Based on these same physical characteristics, qualify the examined SNF for loading into canisters for drying.

- Recommend potential improvements that could improve or accommodate the characteristics of the resulting scrap if it cannot be qualified for loading into canisters for drying.

The estimated geometric reactive surface area of the scrap is estimated to be about $0.3 \mathrm{~m}^{2}$ for the mass of scrap that could be loaded into a container for drying, which compares to a value of $4.5 \mathrm{~m}^{2}$ assumed for safe operation of the baseline process. The panel believes the results are very encouraging because the quantity of scrap generated was very small. However, the size and mass of the scrap depend both on 
processes degrading the fuel while in the basin and processes catching the scrap during washing, the latter including essentially unintentional filtration as debris accumulates. This is not a sufficiently strong technical position from which to extrapolate the results from the examined scrap to all future scrap generated by the existing process.

Therefore, the panel concluded that the estimated small surface area meets the existing criterion for loading scrap into a multi-canister overpack for drying, but because it did not attempt to evaluate the criterion itself, it is not in a position to actually recommend loading the scrap. The panel could not meet the first objective because it did not learn enough from the available information about the physical processes that generated and caught the scrap to be able to predict either the future mass of uranium debris or its area-to-volume ratio.

Apparently, the packed bed of scrap that accumulates during fuel washing acts as an unintended particle filter that can collect small particles, e.g., resulting in some cases of $85 \%$ of the observed particles being smaller than 1/4 inch. Pursuant to the third objective, the panel proposes that the SNF project modify the washing process to prevent this, such as by washing the collected scrap using a process designed to prevent unintentional capture of small particles, or by developing an alternate design for equipment collecting the scrap during washing to prevent unintentional capture of small particles. 


\section{Contents}

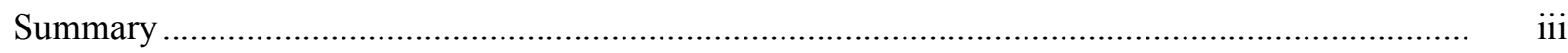

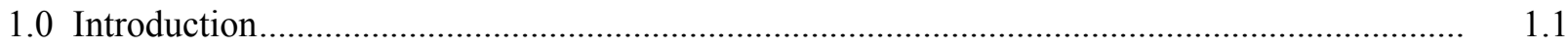

2.0 SNF Washing and Generation and Disposal of SNF Scrap ............................................ 2.1

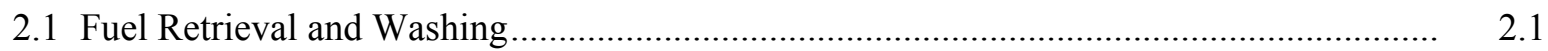

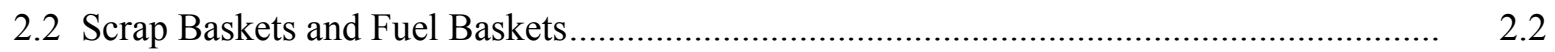

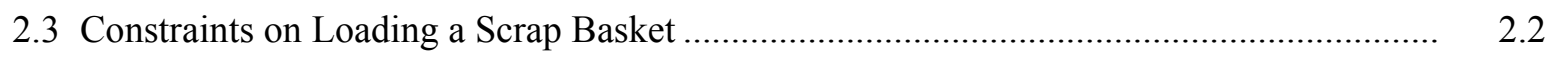

2.4 Thermal Function of the Scrap Basket.......................................................................... 2.3

2.5 Scrap Characteristics that Affect Thermal Behavior .................................................... 2.4

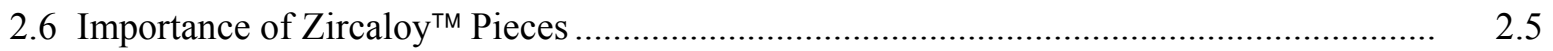

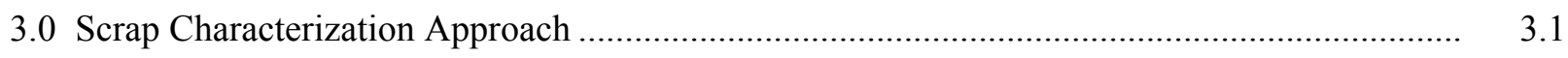

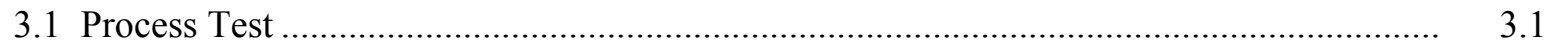

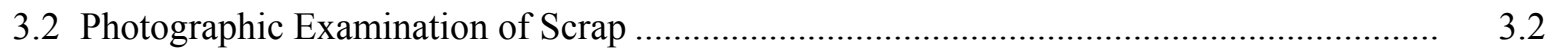

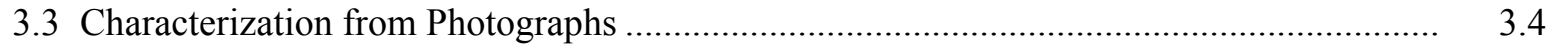

3.3.1 Estimating the Masses of Scrap Pieces ............................................................. 3.4

3.3.2 Estimating the Area of Large Uranium Pieces.................................................... 3.4

3.3.3 Sizing the Small Pieces of Uranium ................................................................ 3.5

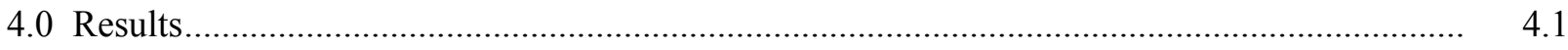

4.1 Quantitative Results from Weighing Scrap and Examining Images............................... 4.1

4.2 Zircaloy ${ }^{\mathrm{TM}}$ Mass and Volume for Each Scrap Canister................................................... 4.2

4.3 Big Uranium Pieces Mass, Volume, and Area for Each Scrap Canister........................... 4.2

4.4 Small Uranium Pieces Mass and Counting ................................................................ 4.2 


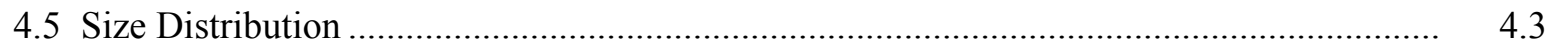

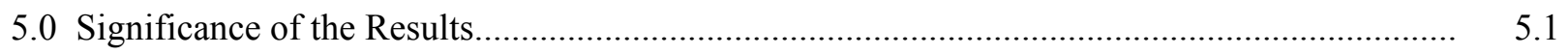

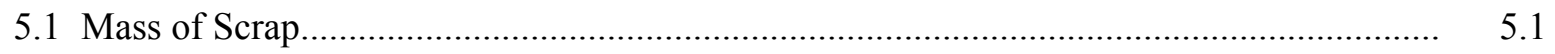

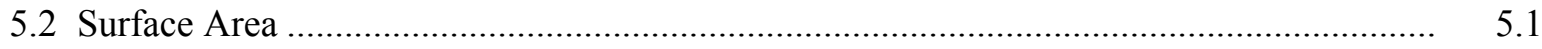

5.3 Effect of Removing Very Small Particles................................................................

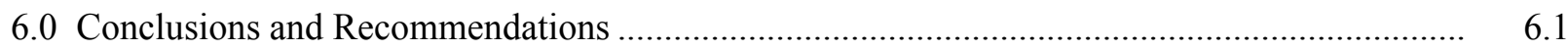

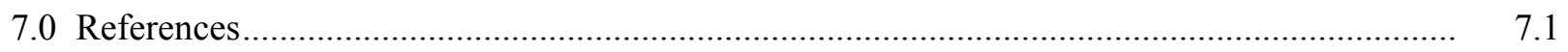

Appendix A - Details of the Spent Nuclear Fuel, Scrap, and Processing Done by the Spent Nuclear Fuel Project ............................................................................................ A.1

Appendix B - Physical Handling of Scrap Canister During the Process Test................................ B.

Appendix C - Procedure for Analyzing Photographs of K-Basin Spent Fuel Scrap Material ........... C. C.1

Appendix D - Analysis of Uncertainty in Measurements of Scrap Characteristics ........................ D. $\quad$ D.1

Appendix E - Scrap Mass, Volume, and Area Details ......................................................... E.1

Appendix F - Application of the Lognormal Distribution .................................................... F.1 


\section{Figures}

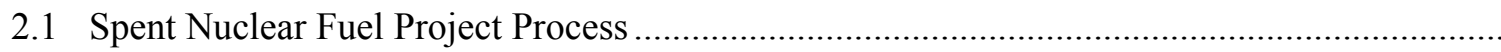

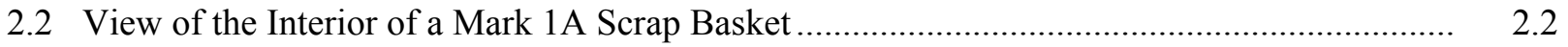

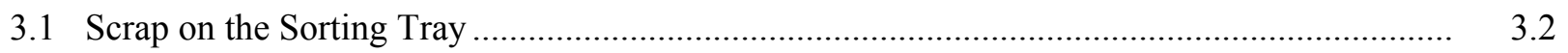

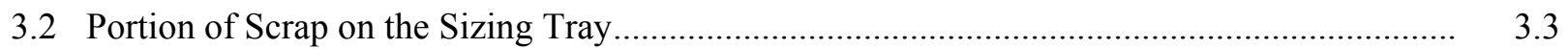

3.3 Lower Right Quadrant of Sizing Tray Shown in Figure 3.2 …............................................

3.4 Sorting Tray with Small Pieces too Close Together to Distinguish and Count Separately ....... $\quad 3.5$

5.1 Effect of Removing Particles Below Size $\mathrm{x}_{\text {removed }}$ on the Effective Particle Size of the Fitted Lognormal Distributions for the Various Canisters...................................................... 


\section{Tables}

2.1 Important Scrap Basket Loading Parameters............................................................ 2.3

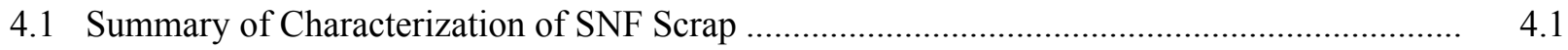

4.2 Results of Fitting a Truncated Lognormal Distribution to the Counting Data ........................ 4.4

4.3 Fitted Parameters of the Lognormal Distribution ............................................................... 4.5 


\subsection{Introduction}

Nearly 2100 metric tons of metallic uranium spent nuclear fuel (SNF) are stored in two water-filled pools - the K-Basins - in the 100-K Area at Hanford. Most of this inventory is N Reactor fuel, a lowenriched metallic uranium, clad in Zircaloy ${ }^{\top \mathrm{T}}$ jackets. Fuel in the K Basins has been in storage for 10 to 25 years and some of it is badly corroded. The Spent Nuclear Fuel Project (SNFP) is resolving the safety and environmental issues associated with continued wet storage of the deteriorating SNF in these basins. The project's fuel-handling process involves preparing, loading, and transporting fuel for drying and subsequent storage in canisters, pending suitable repository disposal.

Scrap generated from October to July, 2001, while washing the SNF to prepare it for cold vacuum drying, differed significantly from that envisioned during project design. The volume of scrap is smaller than estimated, and specifically the quantity of small scrap is very small. This is significant because the smallest scrap presents the largest reactive surface area per volume, and the reactive surface area affects temperatures during cold vacuum drying, as discussed in Section 2.0.

Therefore, Fluor Hanford convened a technical review panel of Hanford contractor experts to evaluate new information about the physical characteristics of scrap generated during processing. The panel did not attempt to evaluate the existing criteria for loading scrap. The panel examined video images of the scrap obtained by K-Basin staff, interpreted the images, and attempted to meet three objectives, in the following order of preference:

- Based on the physical characteristics that are important to ensuring that scrap can be safely dried and stored, provide a technically defensible position that all scrap that will be generated is qualified for loading into canisters for cold vacuum drying by qualifying the existing washing equipment and process.

- Based on these same physical characteristics, compare the examined SNF to the surface area criterion for loading it into canisters for drying.

- Recommend potential improvements that could improve or accommodate the characteristics of the resulting scrap if it cannot be qualified for loading into canisters for drying.

This report documents the results of the technical panel's review. Section 2.0 describes the SNFP, including SNF and scrap, the process and equipment, and issues related to meeting the scrap qualification objective. Section 3.0 presents the assumptions and approach taken to meet the above-stated objectives. Sections 4.0 and 5.0 present the results derived from the technical review, and analysis and interpretation of the results, respectively. Finally, Section 6.0 provides conclusions and recommendations for how to proceed to best qualify 1) the process and 2) the generated scrap for storage. Appendixes contain supplemental information. 
Note that a mixed system of physical units is used in this report. This is because this report references and uses prior work in which criteria are defined in terms of metric units, while many of the actual measurements were made in English units. Further, the design of much of the process is described in English units, and hence we deemed it useful to report much of our analysis in English units. 


\subsection{SNF Washing and Generation and Disposal of SNF Scrap}

This section describes the process by which SNF is washed and by which the scrap is generated, the disposal of the scrap, and the technical issues that ultimately must be addressed because of the characteristics of the scrap. Background information about the SNF and design assumptions about the scrap generated during washing of the SNF are provided in Appendix A.

\subsection{Fuel Retrieval and Washing}

SNF scrap is derived from the fuel retrieval and washing steps of the fuel handling process. Fuel retrieval systems, installed underwater in each basin, transfer fuel stored in the current basin canister configuration to a basket configuration that is suitable for loading in a multi-canister overpack (MCO). Fuel materials are separated from sludge and debris during the fuel retrieval process. Sludge removal is accomplished by inserting the fuel canisters in a primary cleaning machine (PCM), which provides mechanical agitation and flushing, slowly tumbling the fuel canisters past high-pressure water jets (Figure 2.1). This is performed in a confinement enclosure to minimize the impact of fuel washing on basin water quality.

The scrap material removed by the washing process is sieved by passing it through a basket-like strainer at the bottom of the PCM. The strainer is designed to pass debris less than $1 / 4$ inch across, to be retained as sludge. Nevertheless, as the strainer fills with scrap, the scrap forms a packed bed that can filter particles before they can pass through the bottom of the strainer. As described below, we found that the resulting scrap can include a predominance of rubble less than $1 / 4$ inch in size.

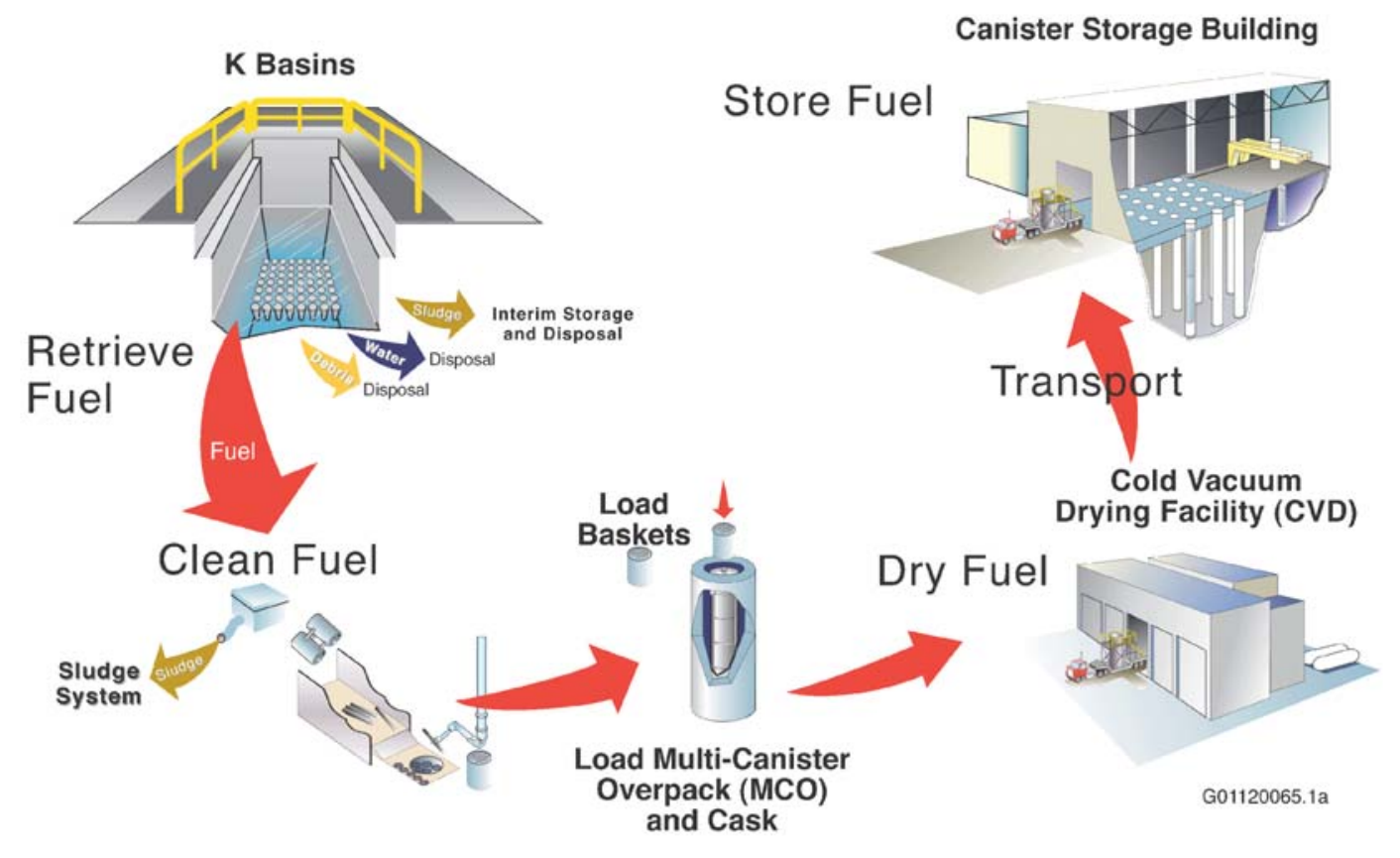

Figure 2.1. Spent Nuclear Fuel Project Process 


\subsection{Scrap Baskets and Fuel Baskets}

Two types of baskets are available for the cleaned fuel depending on the fuel condition after cleaning: 1) a fuel basket for generally intact fuel assemblies, and 2) a scrap basket for fuel fragments and pieces. The current project design allows for loading each MCO with one or two scrap baskets. The process design provides for scrap that is greater than 1 inch in size in the outer region (or coarse section) of the scrap basket. The inner region (or fine section) of the scrap basket accommodates scrap that is between $1 / 4$ inch and 1 inch in size. Material greater than 1 inch in size can be loaded in the fine section if operationally feasible. Material less than $1 / 4$ inch in size is allowable in the fine section, as long as the bounding surface area-to-volume ratio calculated for the fine section in Fuel Surface Area (Ball and Duncan 1998) is not exceeded by 10\%. Although the Spent Nuclear Fuel Project Product Specification (Pajunen 2000) is somewhat ambiguous, scrap material less than 1 inch in diameter also may be allowable in the coarse section of a scrap basket as long as the surface area per unit volume is no more than 5\% greater than that calculated for the coarse sections of a bounding scrap basket in CN-017.

The scrap basket, shown in Figure 2.2, is divided into six equally sized exterior sections bounded by the perimeter, radial spoke dividers, and an internal hexagonal divider, all of which are made from copper. An interior region is defined by the hexagonal divider and a stainless steel support tube. The interior region (fine section) is the design destination for scrap pieces that are too small to handle, i.e., less than about 1 inch in size. Exterior regions (coarse sections) are the design destination for typical fuel scrap pieces, partial fuel elements, and badly damaged whole elements.

\subsection{Constraints on Loading a Scrap Basket}

Criticality and heat transfer considerations from uranium metal reactions with water determine the quantity and characteristics of fuel scrap placed in a scrap basket. As noted previously, the scrap baskets accommodate different scrap sizes. Each basket is designed so that fine scrap (between 1/4 inch and $1 \mathrm{inch}$ ) can be loaded into the region at the center of the basket while scrap greater than 1 inch can be

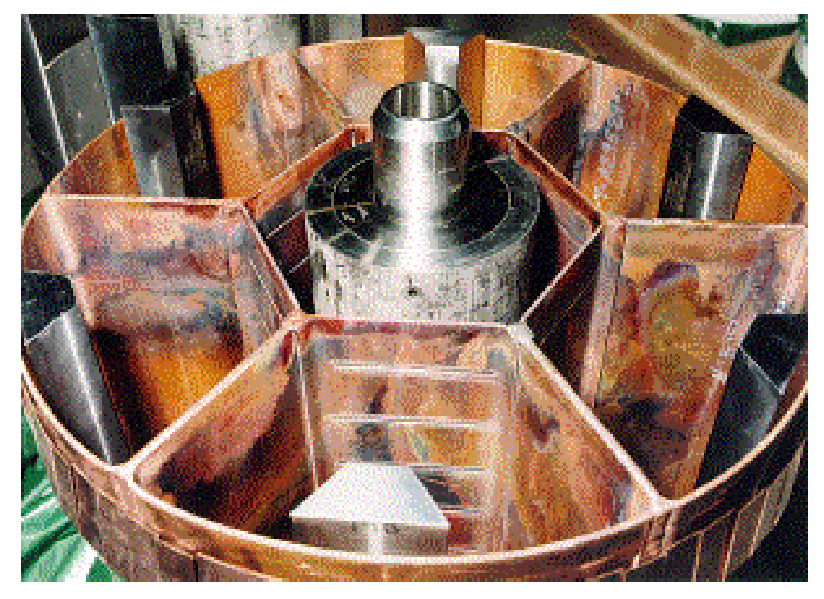

Figure 2.2. View of the Interior of a Mark 1A Scrap Basket 
loaded into six, pie-shaped segments in the outer region of the basket. The heat transfer in the basket must accommodate the heat generation associated with surface reactions whose rate is proportional to the geometric surface area of exposed fuel. A summary of key scrap basket loading parameters and limiting values is provided in Table 2.1.

\subsection{Thermal Function of the Scrap Basket}

Some scrap basket features are important to the thermal function of the basket. While there are separate Mark IV and Mark IA scrap baskets, their differences are moot for this discussion. (The scrap basket is briefly described in Section 2.2 and its characteristics are fully described in Simulation of Normal and Off Normal MCO Behavior (Duncan and Plys 1998).

Copper conducts heat generated by decay and chemical reaction to the basket periphery and minimizes the temperature rise across the basket and scrap therein. This is accomplished at least three ways:

- The conduction distance from the center of a scrap region to the copper is smaller than it would be in the absence of the radial and hexagonal dividers.

- Heat generated in the basket interior fine section bypasses the exterior coarse section.

- Fine material is both limited in volume and distributed in a known way (either confined to the interior fine section as planned, or uniformly distributed along with the coarse scrap if deemed necessary, so that large fine clusters need not be examined).

As a result, the overall resistance to heat removal essentially has only two components: conduction and radiation through the scrap itself, and conduction and radiation across the gap between the basket periphery and MCO wall. Therefore, the thermal function of the basket is to minimize thermal resistance to maximize thermal stability and make incredible the potential for a thermal runaway for normal and offnormal events, given assumed scrap parameters and known process parameters.

Table 2.1. Important Scrap Basket Loading Parameters

\begin{tabular}{|l|l|}
\hline \multicolumn{1}{|c|}{ Parameter } & \multicolumn{1}{c|}{ Limiting Value } \\
\hline Geometric fuel surface area in a scrap basket & Safety basis value: $45,000 \mathrm{~cm}^{2}$ per scrap basket \\
\hline Geometric fuel surface area in a fuel basket & Safety basis value: $7,9000 \mathrm{~cm}^{2}$ per fuel basket \\
\hline $\begin{array}{l}\text { Geometric fuel surface area in a MCO with one } \\
\text { scrap basket and four fuel baskets }\end{array}$ & Safety basis value: $80,000 \mathrm{~cm}^{2}$ \\
\hline $\begin{array}{l}\text { Geometric fuel surface area in a MCO with two } \\
\text { scrap basket and three fuel baskets }\end{array}$ & Safety basis value: $120,000 \mathrm{~cm}^{2}$ \\
\hline Scrap $<1 / 4$ inch & $\begin{array}{l}\text { Allowed in fines sector as long as the area/volume ratio } \\
\text { calculated in Fuel Surface Area } \text { (Ball and Duncan } 1998) \text { is } \\
\text { not exceeded by } 10 \text { percent }\end{array}$ \\
\hline Scrap $<1$ inch and $>1 / 4$ inch & Loaded into fine scrap region of basket \\
\hline Scrap $>1$ inch & Loaded into scrap basket \\
\hline Criticality & $980 \mathrm{~kg}$ (MkIV); $575 \mathrm{~kg}$ (Mk1A) \\
\hline
\end{tabular}




\subsection{Scrap Characteristics that Affect Thermal Behavior}

The thermal stability of reactive metals in general, and of SNF and scrap in particular, is discussed in an SNFP topical report (Plys and Duncan 2000). Here it is important to note that a simple algebraic definition of a dimensionless parameter exists that defines stable and unstable situations. This allows the scrap configuration to be evaluated using a simple formula so that its thermal stability may be judged without a detailed transient analysis. This stability formula may be used to examine tradeoffs between baseline SNFP process design parameters and parameters of the scrap in question, and to examine tradeoffs between design and process alternatives.

We define an ignition parameter, $\mathrm{B}$, as

$$
\mathrm{B}=\frac{(\mathrm{A} / \mathrm{V}) \mathrm{L}^{2} \mathrm{~K}_{\mathrm{o}} \Delta \mathrm{H} \mathrm{T} \mathrm{T}_{\mathrm{r}}}{2 \mathrm{k} \mathrm{T} \mathrm{T}_{\mathrm{dk}} \exp \left(\mathrm{T}_{\mathrm{r}}-1\right)}
$$

where $\begin{aligned} \frac{A}{V} & =\frac{6(1-\phi) \kappa_{f}}{d_{e f f}} \\ T_{r} & =\frac{T_{E}}{T_{d k}}\end{aligned}$

$\mathrm{A} / \mathrm{V}=$ reactive area per unit volume of fuel, $\mathrm{m}^{-1}$, assuming spherical particles (this assumption is unimportant compared to other sources of uncertainty)

$\phi=$ porosity in the scrap configuration

$\kappa_{\mathrm{f}}=$ mass fraction of fuel in the scrap

$\mathrm{x}_{\mathrm{eff}}=$ effective particle size, $\mathrm{m}$, which is described later

$\mathrm{L}=$ conduction distance, $\mathrm{m}$,

$\mathrm{k}=$ thermal conductivity, $\mathrm{W} / \mathrm{m}-\mathrm{K}$,

$\Delta \mathrm{H}=$ heat of reaction, $\mathrm{J} / \mathrm{kg}$

$\mathrm{T}_{\mathrm{dk}}=$ maximum temperature given decay power alone, $\mathrm{K}$,

$\mathrm{K}_{\mathrm{o}}=$ Arrhenius coefficient, $\mathrm{kg} / \mathrm{m}^{2}$-s, and

$\mathrm{T}_{\mathrm{E}}=$ normalized activation energy, $(\mathrm{E} / \mathrm{R}), \mathrm{K}$.

The critical value $\mathrm{B}=1$ divides stable, steady-state temperature solutions in the reacting medium from those that are unstable; the form of $\mathrm{B}$ was chosen so that the critical value would be unity. For $\mathrm{B}>1$, the configuration is thermally unstable; for $\mathrm{B}<1$, the configuration is thermally stable.

Because the ignition parameter is proportional to the ratio of reactive uranium area to scrap volume, this ratio, or equivalently the effective fuel particle size, directly affects the thermal stability of the scrap configuration. Specifically, during the drying operation, the exposed surfaces of the uranium metal in the scrap will react with any water initially present or released from other materials. This exothermic 
reaction will heat the scrap. If the heat generation rate per volume of scrap is large enough, the heat cannot be conducted away from the volume fast enough to prevent an increase in temperature sufficient to increase the reaction rate, causing an accelerating reaction.

If the uranium in the scrap comprised pieces of a single size, the area per volume of the uranium would vary inversely with the size of the pieces. Therefore, it is important to estimate the size of the particles of uranium in the scrap to ensure that it can be dried safely. The pertinent size is the effective particle size, $\mathrm{x}_{\mathrm{eff}}$, which represents the area-to-volume ratio of a distribution of particle sizes. As is discussed in Section 4.5, we characterized the scrap in terms of two general sizes: pieces larger than $5 / 8$ inch that we characterized by estimating the volume and area for each piece we could distinguish in the images, and pieces smaller than $5 / 8$ inch that we characterized by establishing a particle size distribution assuming a lognormal form.

The conduction length, L, is nearly constant as long as the height of the scrap filling a canister is large compared to its width because in that case the dominant path for thermal conduction is lateral and outward to the thermally conducting walls of the basket - the path of least resistance. The height of the fill affects the area and volume proportionately. Therefore, until the height of the scrap becomes small compared to its width, the height of fill has no effect on the ignition parameter. The lateral distance is about 6 inches, so one must decrease the height of the fill to about 6 inches before the conduction distance is decreased significantly. At that point the path of least resistance is to the thermally conductive bottom plate, and conduction occurs primarily axially and downward.

\subsection{Importance of Zircaloy ${ }^{\mathrm{TM}}$ Pieces}

The volume of the scrap is due both to the volume of the reactive uranium and the volume of the unreactive Zircaloy ${ }^{\mathrm{TM}}$ pieces. Therefore, to estimate the area of uranium per volume of scrap, we must estimate both the volume of the uranium and the Zircaloy ${ }^{\mathrm{TM}}$ pieces. Essentially, the Zircaloy ${ }^{\mathrm{TM}}$ dilutes the reactive material in a scrap basket by decreasing the average reactive area (uranium) per volume by increasing the volume. We did not attempt to estimate the effect of the Zircaloy ${ }^{\mathrm{TM}}$ on the effective thermal conductivity of the scrap. 


\subsection{Scrap Characterization Approach}

K-Basin staff conducted a test of the baseline fuel washing and scrap collection process that SNFP staff hoped this review could qualify as producing scrap suitable for addition to MCOs in scrap baskets. The technical review began after K-Basin staff tested the process by retrieving, weighing, and photographing the scrap that was collected during the washing process.

The review panel defined a characterization approach based on the available information, i.e., the weights and digital photographic images. This section describes the retrieval process tested by K-Basin staff, the nature of the photographic images, and the panel's approach to quantifying the geometric reactive surface area of the uranium in the scrap.

\subsection{Process Test}

K-Basin staff visually examined the scrap from the fuel washing process for the first 16 MCOs. This test allowed for visual sizing of fuel pieces to the extent possible, subject to the ability to spread the material out upon the grid plate. The grid plate was fabricated of 1/4-inch-thick 6061 aluminum alloy, and measured 24 inches by 36 inches. Lines were engraved in an orthogonal pattern at $1 \pm 0.0 .10$-inch intervals. The short edge (on one side of the plate) had letters A through X engraved within each square, while the long edge (on one side of the plate) had numbers 1 through 36 engraved within each square. One square at the D4 location had 9 lines engraved within the square, spaced equally, as a visual check of camera resolution.

The scrap for this assessment was derived from Mark 1A fuel that had a nominal enrichment of $1.25 \mathrm{wt} \%$ U-235. The outer elements of these fuel assemblies measure 2.42 inch OD by $1.70 \mathrm{in}$. ID, and the inner elements measure 1.02 inch OD by 0.40 in. ID. Fuel element lengths ranged from about 15 inch to 20 inch. Five "key dates"(a) were included in this processing: 10259, 11449, 13650, 13686, and 13859.

The fuel was processed during the period ranging from October 2000 to July 2001. Most of the scrap came from cleaning out the PCM strainer basket, which occurred nominally after each batch of 10 canisters. Most of the scrap volume coming from the strainer baskets consisted of the W-springs and spacer clips used to center the fuel elements. These springs and clips often were separated from the fuel elements during the cleaning process. Technically, these springs can be considered debris rather than fuel scrap, but there is no practical way to separate the W-springs from the fuel scrap, so all of it was spread on the grid table for size assessment of the fuel scrap.

The remaining pieces of scrap came from breakage of the fuel elements themselves during the washing process and subsequent handling. This breakage occurred almost exclusively on the outer fuel elements.

(a) A key refers to a set of fuel assemblies irradiated as a group in N Reactor and hence characterized by a characteristic date of discharge from the reactor, or "key date." 
Pieces longer than 3 inches were normally stacked around inner elements in the fuel baskets, but pieces shorter than 3 inches were considered to be scrap by definition and placed in scrap baskets.

The scrap from each fuel "key" was loaded into a separate scrap canister, resulting in five scrap canisters that are discussed in this report. After loading, the scrap canisters were placed in temporary basin storage pending future processing. Details about handling the canisters are found in Appendix B.

\subsection{Photographic Examination of Scrap}

The process was videotaped and still images were recorded during the sorting and sizing steps to document the appearance of the pieces comprising the scrap. All of this was done under 16 feet of water. Figure 3.1 shows scrap on the sorting tray. Figure 3.2 shows a portion of the scrap on the sizing tray.

The sizing tray was illuminated from several sides and photographed using the video camera. Principally two magnifications were used: an image of the entire sizing tray, as shown in Figure 3.2, and four images of roughly four quadrants of the tray using roughly twice $(2 \mathrm{x})$ the base magnification. For example, Figure 3.3 shows the lower-right quadrant of Figure 3.2. The chess pawn-like object is a 4-inch-high marker with 1/4-inch steps on its base inserted to assist with estimating sizes of objects on the sizing tray. Note the length of the shadow from this marker, indicating the angle of primary illumination.

One image of part of one quadrant was recorded at roughly four times the magnification covering the entire tray. By comparing images at the $2 \mathrm{x}$ and $4 \mathrm{x}$ magnifications, we determined that the smallest pieces

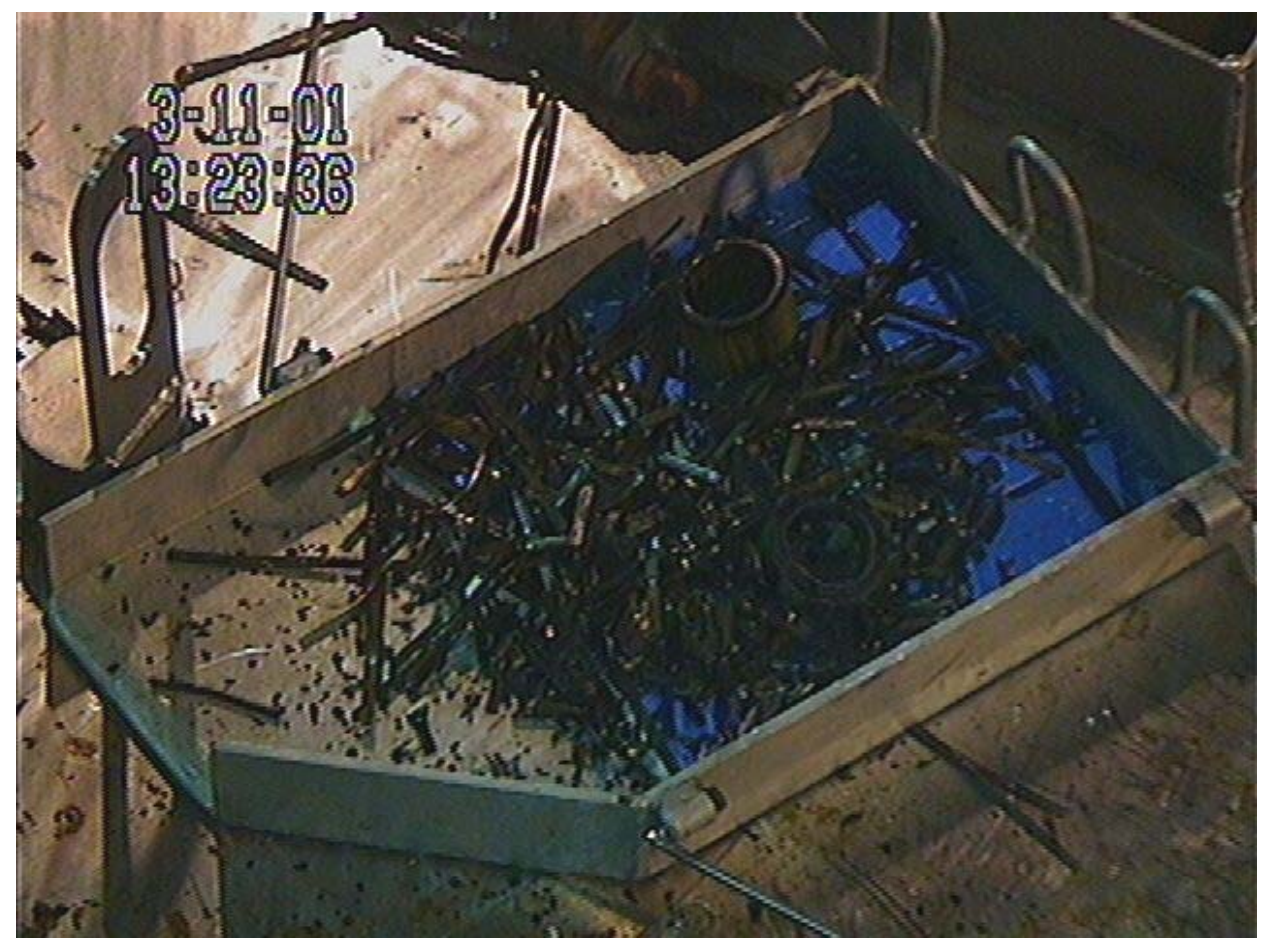

Figure 3.1. Scrap on the Sorting Tray 


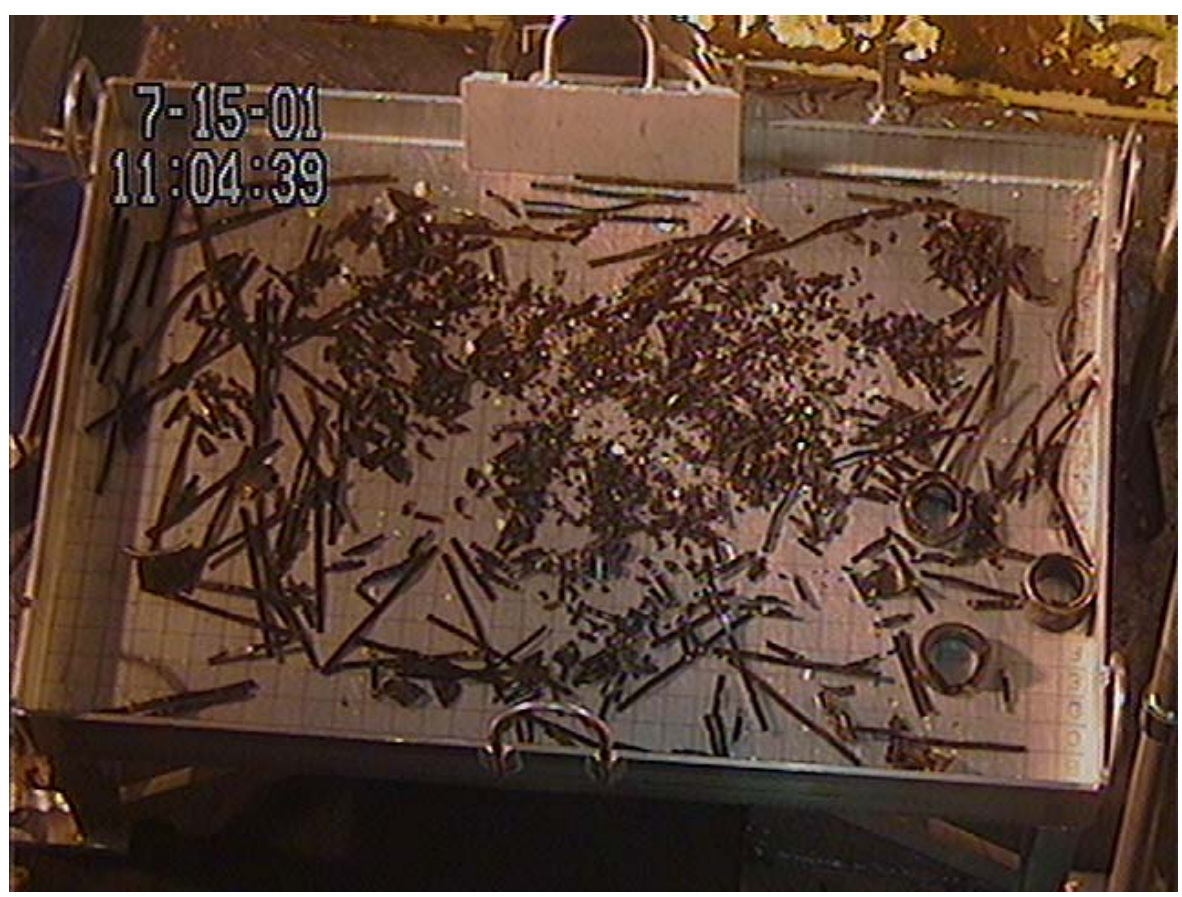

Figure 3.2. Portion of Scrap on the Sizing Tray

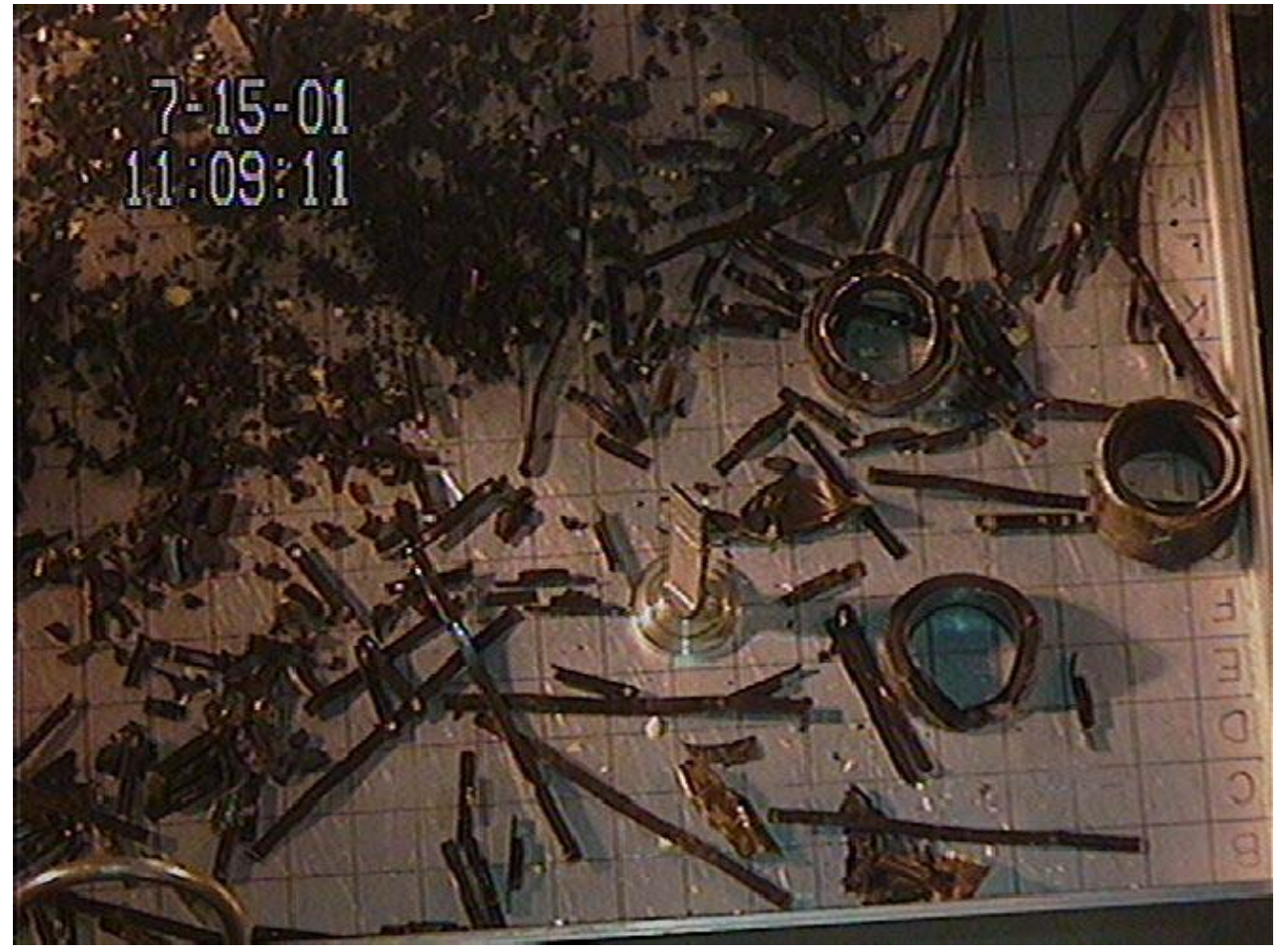

Figure 3.3. Lower Right Quadrant of Sizing Tray Shown in Figure 3.2 
visible at $4 \mathrm{x}$ magnification that were also visible at the $2 \mathrm{x}$ magnification measured $1 / 16 \mathrm{inch}$. Thus, we took this to be the limit of visibility of small particles at the $2 \mathrm{x}$ magnification used to document all four quadrants of each sizing tray-full of scrap.

\subsection{Characterization from Photographs}

Using the photographs, we estimated the mass, area, and size of scrap pieces.

\subsubsection{Estimating the Masses of Scrap Pieces}

We estimated the masses of inert material and the masses and areas of uranium pieces in the scrap. The mass of scrap collected in a canister was determined by weighing the canister and subtracting the known weight of the canister. The masses of the scrap components (Zircaloy ${ }^{\mathrm{TM}}$ and big and small pieces of uranium) were determined as follows.

- Zircaloy ${ }^{\mathrm{TM}}$. The Zircaloy ${ }^{\mathrm{TM}}$ pieces appeared to retain their as-designed configuration: 5.7 -inches $\mathrm{x}$ 1/4-inch x 1/8-inch for W-springs and 0.8-inch x 0.25 -inch x 0.25 -inch for spacers. Hence, we estimated their collective volume by counting the number of spacers and springs. The resolution of the video images was sufficient to do this. The counting was done by "eye" from the video images taken at the $2 \mathrm{x}$ magnification.

- Big pieces of uranium. Some of the uranium scraps are relatively large portions of cylinders ( 1-inch to 3-inch lengths). The apparent geometries included entire rings, incomplete arcs of cylinders, or trapezoidal-like fragments. We located these pieces and cataloged them by "eye" by examining the $2 \mathrm{x}$ magnification images. Depending on the apparent geometry of the piece, we estimated three pertinent dimensions ( 3 lengths or 2 lengths and an angle) for each piece. From these dimensions, we computed the volume and hence the mass of each piece, and similarly computed the geometric reactive surface area, which is the unclad (broken) surfaces of these pieces.

- Small pieces of uranium. The panel estimated the mass of the numerous small pieces of uranium by subtracting our estimate of the mass of the large pieces and of the mass of Zircaloy ${ }^{\mathrm{TM}}$ from the measured mass of the scrap. This introduces substantial relative uncertainty because typically the mass of small pieces is substantially less than the mass of both Zircaloy ${ }^{\mathrm{TM}}$ and large pieces of uranium. That is, the mass of small uranium scrap pieces tends to be a small difference between larger masses.

\subsubsection{Estimating the Area of Large Uranium Pieces}

We estimated the area of the large pieces of uranium from the same dimensions estimated from the images and used to estimate their volume and thence their mass. We derived the area of the small pieces by estimating a size distribution to determine the effective area-to-mass ratio and then multiplying by the mass estimated as noted above. 


\subsubsection{Sizing the Small Pieces of Uranium}

The scrap poured onto the sizing tray was spread around using long-handled squeegee tools. This resulted in a combination of 1) particles lying distinctly separate from other particles and hence separately countable, and 2) particles residing in piles or too densely packed to be counted separately. For example, Figure 3.3 shows some small pieces lying in piles or otherwise too close together to distinguish and count. In the case of Figure 3.4, most of the countable pieces measure less than 1/4-inch.

We assume that the distribution of sizes of particles happening to lie separately from other particles is the same as all of the small particles. We counted the number of these separate particles falling in four size ranges bounded by five boundaries $-1 / 16 \mathrm{inch}, 1 / 4 \mathrm{inch}, 3 / 8 \mathrm{inch}, 1 / 2 \mathrm{inch}$, and $5 / 8 \mathrm{inch}$. The lower boundary of $1 / 16$ inch is the visibility limit, as noted above. The upper boundary of $5 / 8$ inch was taken to be the lower limit of "big pieces" that were cataloged and counted separately. Such pieces are large enough to be visible whether or not they reside next to other particles. The procedure for analyzing the photos is described in Appendix C.

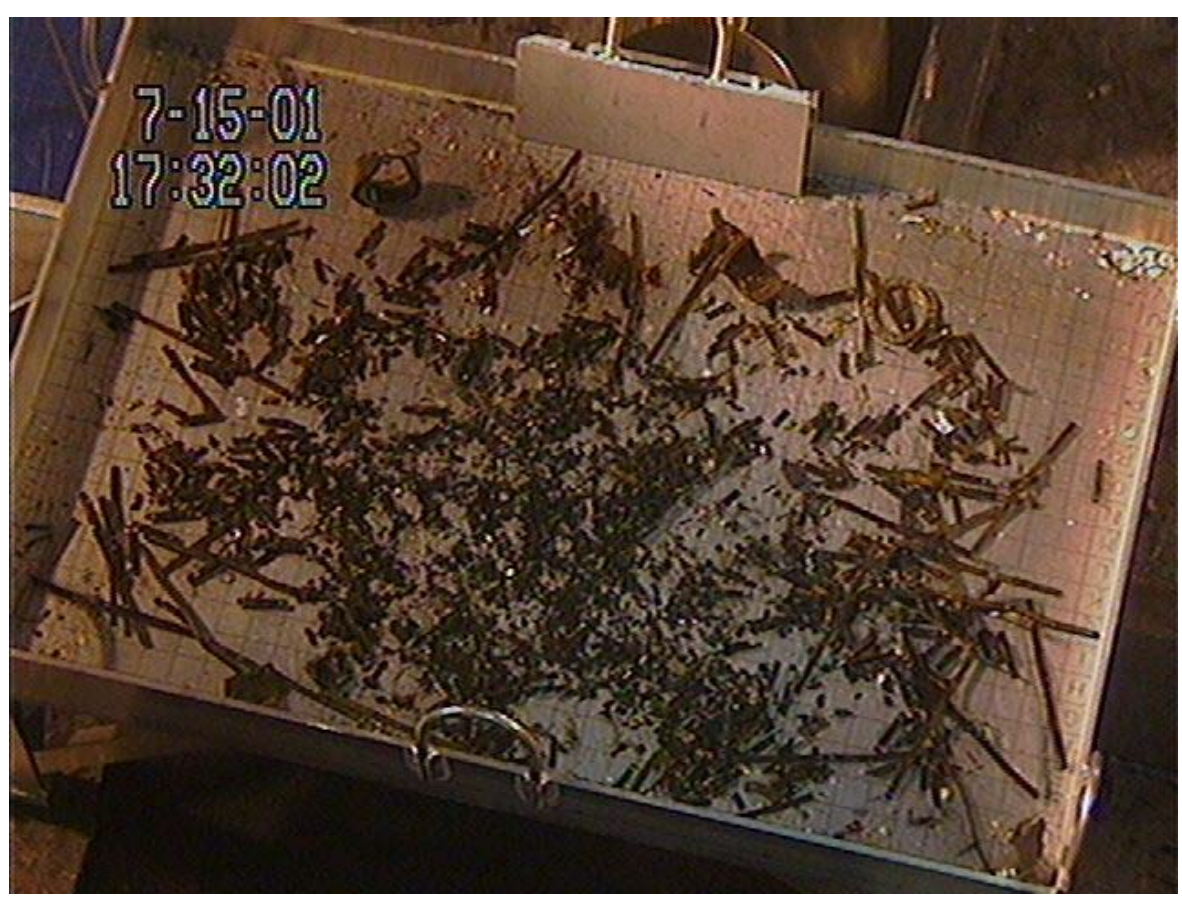

Figure 3.4. Sorting Tray with Small Pieces too Close

Together to Distinguish and Count Separately. 


\subsection{Results}

The measured weights of the scrap collected and the counts of Zircaloy ${ }^{\mathrm{TM}}$ pieces, cataloging of large pieces of uranium, and "binning" by size of percentages of small pieces of uranium provide the data from which in this section we estimate the geometric reactive surface area of the uranium and compare this to the requirements of the baseline project.

\subsection{Quantitative Results from Weighing Scrap and Examining Images}

Table 4.1 shows the results from weighing the scrap and examining the images. The first two columns display the results for replicate examinations of canister 5459, denoted 5459-1 and 5459-2, which we show to illustrate the order of uncertainty of our observations. A priori, the results for these replicates should be the same, so the differences between them provide an estimate of the collective uncertainty in our measurements.

Table 4.1. Summary of Characterization of SNF Scrap

\begin{tabular}{|c|c|c|c|c|c|c|c|c|}
\hline Scrap Canister & 5459-1 & $5459-2$ & 5456 & 5461 & 5460 & 5459-ave & 2344 & Sum \\
\hline Key date & 13686 & 13686 & 10259 & 11449 & 13650 & 13686 & 13859 & \\
\hline No. of fuel cans & 78 & 78 & 4 & 25 & 75 & 78 & 135 & 317.0 \\
\hline Scrap, lb & 55.0 & 55.0 & 8.6 & 43.8 & 68.3 & 55.0 & 15.0 & 190.7 \\
\hline Scrap/can, lb & 0.7 & 0.7 & 2.2 & 1.8 & 0.9 & 0.7 & 0.1 & 0.6 \\
\hline No. of $\mathrm{Zr}$ springs & 509 & 550 & 11 & 111 & 691 & 530 & 176 & 1519 \\
\hline No. of $\mathrm{Zr}$ spacers & 278 & 420 & 41 & 198 & 538 & 349 & 102 & 1228 \\
\hline Big $U$, in $^{3}$ & 64.3 & 53.7 & 18.5 & 61.2 & 60.6 & 59.0 & 6.1 & 205.3 \\
\hline $\operatorname{Big} U$, in $^{2}$ & 47.6 & 52.8 & 23.6 & 43.7 & 50.1 & 50.2 & 10.2 & 177.8 \\
\hline \multicolumn{9}{|c|}{ Underwater Weights } \\
\hline Scrap, kg & 25.0 & 25.0 & 3.9 & 19.9 & 31.0 & 25.0 & 6.8 & 86.6 \\
\hline $\mathrm{Zr}, \mathrm{kg}$ & 9.5 & 10.8 & 0.4 & 2.7 & 13.6 & 10.1 & 3.3 & 30.1 \\
\hline Big U, kg & 17.5 & 14.6 & 5.0 & 16.6 & 16.5 & 16.0 & 1.6 & 55.8 \\
\hline Small U, kg & -2.0 & -0.4 & -1.5 & 0.6 & 0.9 & -1.2 & 1.9 & 0.7 \\
\hline \multicolumn{9}{|l|}{ Masses } \\
\hline $\mathrm{Zr}, \mathrm{kg}$ & 11.2 & 12.7 & 0.4 & 3.2 & 16.0 & 9.6 & 3.9 & 33.2 \\
\hline $\mathrm{U}, \mathrm{kg}$ & 16.4 & 15.0 & 3.8 & 18.2 & 18.5 & 18.4 & 3.7 & 62.5 \\
\hline Big U, kg & & & 5.3 & 17.6 & 17.5 & 17.6 & 1.8 & 59.7 \\
\hline Small U, kg & & & -1.6 & 0.6 & 1.0 & 0.8 & 2.0 & 2.8 \\
\hline \multicolumn{9}{|c|}{ Volume $\%$ of metal } \\
\hline $\mathrm{U}$ & $35 \%$ & $30 \%$ & $76 \%$ & $68 \%$ & $30 \%$ & $33 \%$ & $26 \%$ & $39 \%$ \\
\hline Small U, kg & -2.1 & -0.4 & -1.6 & 0.6 & 1.0 & -1.3 & 2.0 & 0.7 \\
\hline \multicolumn{9}{|c|}{ Small U Characteristics - Fraction of Particles Appearing in Four Size Ranges } \\
\hline$<1 / 4$ in. & $44 \%$ & $47 \%$ & $87 \%$ & $52 \%$ & $69 \%$ & $46 \%$ & $85 \%$ & $69 \%$ \\
\hline$>1 / 4$ in. $<3 / 8$ in. & $22 \%$ & $37 \%$ & $5 \%$ & $27 \%$ & $21 \%$ & $31 \%$ & $8 \%$ & $17 \%$ \\
\hline$>3 / 8$ in. $<1 / 2$ in. & $25 \%$ & $8 \%$ & $6 \%$ & $16 \%$ & $10 \%$ & $15 \%$ & $3 \%$ & $10 \%$ \\
\hline$>1 / 2$ in. $<5 / 8$ in. & $8 \%$ & $8 \%$ & $2 \%$ & $5 \%$ & $1 \%$ & $8 \%$ & $4 \%$ & $4 \%$ \\
\hline
\end{tabular}


The other columns in Table 4.1 are sorted left to right by the age of the fuel, described by the key date. The smaller key dates denote older fuel. The last column is the sum of the five columns to the left; i.e., excluding those showing the replicate results for 5459 .

Because the scrap was weighed under water, we calculated the weights of Zircaloy ${ }^{\mathrm{TM}}$ and large pieces of uranium considering the buoyancy of water in order to determine by difference the weight of small uranium pieces under water. We then corrected each of these calculations for the buoyancy to determine the masses.

The uncertainty in these measurements needs to be analyzed before the results can be interpreted. Our procedure for analyzing the uncertainty is presented in Appendix D and the results are included in the following sections.

\subsection{Zircaloy ${ }^{\mathrm{TM}}$ Mass and Volume for Each Scrap Canister}

The count of the numerous pieces of Zircaloy ${ }^{\mathrm{TM}}$ is shown in Table 4.1. Because we know the dimensions of both W-springs and spacers, we can calculate the corresponding volumes, weights underwater, and masses. It appears from the images that the vast majority of the springs are intact; i.e., they are 5.7 inches long. Therefore, we simply counted the springs and assumed that every spring exists in its original dimensions, from which we computed the total volume and thence the total mass of the springs. Similarly, it appears that the vast majority of the spacers are intact, so again we simply counted the spacers and computed their volume from their original dimensions and thence their total mass.

Comparing the replicate results for 5459-1 and 5459-2, we find a relative standard deviation of $9 \%$ for canister 5459 and a standard deviation of the sum over canisters of $1.7 \mathrm{~kg}$.

\subsection{Big Uranium Pieces Mass, Volume, and Area for Each Scrap Canister}

The results of estimating the characteristic dimensions of the large pieces of uranium and from these the volume and area, assuming for the area that they are all clad on "front and back" surfaces, are shown in Table 4.1 as "big U, in3" (volume) and "big U, in2" (area). From the volumes, we calculated the weights underwater and the masses. Detailed information appears in tables in Appendix E.

Comparing the replicate results for the mass of big pieces for canister 5450, we found a relative standard deviation of $13 \%$. The predicted standard deviation for the mass summed over the canisters (the last column in Table 4.1) is then $3.59 \mathrm{~kg}$. Similarly, we found the relative standard deviations for area and volume to be $7 \%$ and $13 \%$, respectively, from which the predicted standard deviations for the area and volume summed over the canisters are $5.9 \mathrm{in}^{2}$ and $12 \mathrm{in}^{3}$, respectively.

\subsection{Small Uranium Pieces Mass and Counting}

The results for estimated masses and counting of the small pieces of uranium are as follows: 
- Estimated masses. The sum of the masses estimated for the small uranium debris is only a small fraction of the sum of the masses of the scrap; however, the variance of those estimates is large because it is a small difference between large, uncertain values. The variance of the sum or differences of masses is the sum of the variances of the individual masses. Since we estimate the mass of the small pieces of uranium as the mass of the scrap minus the mass of the Zircaloy ${ }^{\mathrm{TM}}$ minus the mass of the big pieces of uranium, then

$$
\sigma_{\text {small }, \text { sum }}=\sqrt{\sigma_{\text {small } U, \text { sum }}^{2}}=\sqrt{\sigma_{\text {scrap }, \text { sum }}^{2}+\sigma_{Z r, \text { sum }}^{2}+\sigma_{\text {big } U, \text { sum }}^{2}}
$$

Thus, using weights as measured underwater, $\sigma_{\text {small } \mathrm{U}}=\left(0.32^{2}+1.72^{2}+3.59^{2}\right)^{1 / 2}=4.0 \mathrm{~kg}$. The sum, as shown in Table 4.1 , is $0.7 \mathrm{~kg}$. Thus, to two standard deviations, we have

$$
\Sigma_{\text {small U }} \approx 0.7 \pm 8 \mathrm{~kg} \text {. }
$$

That is, the variability is large compared to the mean. Because the physical value must be positive, this suggests that the variability seen in the estimates of the mass of small uranium for individual canisters is the result of measurement uncertainty, as one would surmise from the existence of physically impossible negative values among the estimates for individual canisters.

- Counting results. The results of counting distinct particles by size according to the counting scheme described above are shown in Table 4.1 under "small U characteristics" as the percentage of pieces appearing in the four size ranges. Tables in Appendix E contain detailed counting information. The fraction of uranium particles with sizes less than $1 / 4$ inch ranges from $46 \%$ to $87 \%$. The PCM strainer basket is perforated with 1/4-inch holes, based upon which designers expected the size of particles in scrap collected in this basket not to fall much below 1/4 inch. Apparently, scrap caught in the basket filters out debris smaller than $1 / 4$ inch. The characteristic size of the particles actually caught probably scales with the size of the interstices in the packed bed formed by caught scrap in the basket. This size depends on the scrap actually generated during washing and how it happens to pack in the basket, and would be difficult to predict for future washing operations. Therefore, it would be difficult to predict the fraction of particles in scrap caught in future washing operations that are less than $1 / 4$ inch in size.

\subsection{Size Distribution}

As noted in Section 2.5, we are especially interested in the particles with the smallest size because they have the largest surface area per volume. Even if their collective volume is small, if their size is small enough their area will still be large. However, because the available resolution of our images limits our ability to distinguish among sizes smaller than $1 / 4$ inch, to infer information about the "tail" we need to assume something about the nature of the size distribution.

Assemblages of particles caused by complex processes, such as in geologic media, from grinding, etc., often follow a "lognormal" distribution, where the probability of finding a given size is Gaussian in shape when plotted against the logarithm of the size of the particles instead of the size of the particles. We 
assumed this kind of distribution as a default. The pertinent attributes of this distribution and our application of it are described in Appendix F.

The results of fitting the truncated lognormal distribution to the counting data for the scrap from the five canisters are shown in Table 4.2. (The fit of the data to the lognormal distribution is sufficient to not invalidate the use of the distribution as our default.)

Table 4.2. Results of Fitting a Truncated Lognormal Distribution to the Counting Data

\begin{tabular}{|c|c|c|c|c|}
\hline Size range, inches & $<0.625,>0.5$ & $<0.5,>0.375$ & $<0.375,>0.25$ & $<0.25,>.0625$ \\
\hline \multicolumn{5}{|l|}{ Canister 5459-1 } \\
\hline Counts (measured) & 17 & 51 & 45 & 88 \\
\hline$\%$ (measured) & $8 \%$ & $25 \%$ & $22 \%$ & $44 \%$ \\
\hline$\%$ (predicted) & $14 \%$ & $18 \%$ & $25 \%$ & $44 \%$ \\
\hline \multicolumn{5}{|l|}{ Canister 5459-2 } \\
\hline Counts (measured) & 24 & 25 & 118 & 150 \\
\hline$\%$ (measured) & $8 \%$ & $8 \%$ & $37 \%$ & $47 \%$ \\
\hline$\%$ (predicted) & $3 \%$ & $11 \%$ & $37 \%$ & $48 \%$ \\
\hline \multicolumn{5}{|c|}{ Canister 5459-average } \\
\hline Counts (measured) & 20.5 & 38 & 81.5 & 119 \\
\hline$\%$ (measured) & $8 \%$ & $15 \%$ & $31 \%$ & $46 \%$ \\
\hline$\%$ (predicted) & $8 \%$ & $15 \%$ & $31 \%$ & $46 \%$ \\
\hline \multicolumn{5}{|l|}{ Canister 2344} \\
\hline Counts (measured) & 12 & 11 & 24 & 268 \\
\hline$\%$ (measured) & $4 \%$ & $3 \%$ & $8 \%$ & $85 \%$ \\
\hline$\%$ (predicted) & $4 \%$ & $5 \%$ & $7 \%$ & $85 \%$ \\
\hline \multicolumn{5}{|l|}{\begin{tabular}{|l|} 
Canister 5456 \\
\end{tabular}} \\
\hline Counts (measured) & 17 & 51 & 45 & 744 \\
\hline$\%$ (measured) & $2 \%$ & $6 \%$ & $5 \%$ & $87 \%$ \\
\hline$\%$ (predicted) & $3 \%$ & $4 \%$ & $6 \%$ & $87 \%$ \\
\hline \multicolumn{5}{|l|}{ Canister 5460} \\
\hline Counts (measured) & 4 & 49 & 102 & 341 \\
\hline$\%$ (measured) & $1 \%$ & $10 \%$ & $21 \%$ & $69 \%$ \\
\hline$\%$ (predicted) & $3 \%$ & $8 \%$ & $21 \%$ & $69 \%$ \\
\hline \multicolumn{5}{|l|}{ Canister 5461} \\
\hline Counts (measured) & 42 & 128 & 211 & 409 \\
\hline$\%$ (measured) & $5 \%$ & $16 \%$ & $27 \%$ & $52 \%$ \\
\hline$\%$ (predicted) & $7 \%$ & $14 \%$ & $27 \%$ & $52 \%$ \\
\hline \multicolumn{5}{|c|}{ Canister Sum of 5459, 2344, 5456, 5460, and 5461} \\
\hline Counts (measured) & 95.5 & 277 & 463.5 & 1881 \\
\hline$\%$ (measured) & $4 \%$ & $10 \%$ & $17 \%$ & $69 \%$ \\
\hline$\%$ (predicted) & $5 \%$ & $9 \%$ & $17 \%$ & $69 \%$ \\
\hline
\end{tabular}


The three kinds of information appearing in Table 4.2 are defined as:

$$
\begin{aligned}
& \text { counts }_{\text {measured }}=\left.N\left(z_{i}, z_{i-1}\right)\right|_{\text {measured }} \\
& \%_{\text {measured }}=\left.\frac{N\left(z_{i}, z_{i-1}\right)}{N\left(z_{2}, z_{1}\right)}\right|_{\text {measured }} \\
& \%_{\text {predicted }}=\left.\frac{N\left(z_{i}, z_{i-1}\right)}{N\left(z_{2}, z_{1}\right)}\right|_{\text {calculated }}
\end{aligned}
$$

which are explained in Appendix F.

The distribution is described by two parameters, $\mu$ and $\sigma$, as described in Appendix F. The fitted values of $\mu$ and $\sigma$ for all the cases are shown in Table 4.3. For two cases, the value of $\mu$ is approximately zero and $\sigma$ is correspondingly large. In these cases, the significance of either $\mu$ or $\sigma$ is probably only that the uncertainty in the data, and the predominance of counts in a single bin at the lower bound of the measurements, prevents determining meaningful values of $\mu$ and $\sigma$ from the fit.

The value of the effective particle size, $\mathrm{x}_{\mathrm{eff}}$, is also shown. This is the size of a particle that would have the same area-to-volume ratio as the ratio of the total area to the total volume of all the particles in a lognormal distribution described by the fitted parameters and for a maximum particle size of $5 / 8$ inch, the upper limit of the sizes to which we attempted to fit a distribution. That is, we consider all particles from size 0 to 5/8 inch. As shown in Appendix F, the effective particle size is

$$
x_{\text {eff }}=\mu e^{\frac{5}{4} \sigma^{2}} \frac{\operatorname{erfc}\left(\frac{3}{2} \sigma-z_{2}\right)}{\operatorname{erfc}\left(\sigma-z_{2}\right)}
$$

where $\mathrm{d}_{\mathrm{HI}}$ is $5 / 8$ inch, the upper limit of the sizes in the distribution.

In spite of the difficulty in fitting some of the data, it is encouraging that the value of the effective particle size, $\mathrm{x}_{\text {eff }}$, resulting from the fit varies very little -0.28 to $0.39 \mathrm{inch}$. For two canisters -2344 and

Table 4.3. Fitted Parameters of the Lognormal Distribution

\begin{tabular}{|l|c|l|c|}
\hline Canister & $\mu$, inch & $\sigma$ & $\mathbf{x}_{\text {eff }}$, inch \\
\hline 5459 (ave) & 0.27 & 0.74 & 0.39 \\
\hline 2344 & $\sim 0$ & 4.7 & 0.30 \\
\hline 5456 & $\sim 0$ & 4.4 & 0.28 \\
\hline 5460 & 0.19 & 0.82 & 0.34 \\
\hline 5461 & 0.26 & 0.86 & 0.39 \\
\hline Sum & 0.16 & 1.3 & 0.37 \\
\hline
\end{tabular}


5456-the least squares fit is a wide distribution centered at $\mu \sim 0$. We presume that the value of $\mu$ is not physically meaningful, yet the simultaneous fit of $\sigma$ required to fit the data results in a physically reasonable prediction of $\mathrm{x}_{\mathrm{eff}}$.

As noted previously, the ratio of reactive uranium area per scrap volume due to particles, which determines the thermal stability of the scrap, can be expressed in terms of $\mathrm{x}_{\mathrm{eff}}$ :

$$
\frac{\text { Area }}{\text { Volume }}=\frac{6(1-\phi) \kappa_{f}}{d_{\text {eff }}}
$$




\subsection{Significance of the Results}

The technical review enhanced our understanding of the mass, surface area, and the challenges introduced by the particle size of the scrap.

\subsection{Mass of Scrap}

The mass of scrap collected from the canisters averaged $0.6 \mathrm{lb} /$ fuel can, which is less than expected. The mass fraction of the small uranium debris, i.e., pieces small than $5 / 8$ inch as we defined it, is very small: less than $15 \%$, even when using conservative (two standard deviations) estimates of the masses. The scrap was obtained from fuel with key dates ranging from 10259 to 13686, a range of dates that includes much of the SNF.

\subsection{Surface Area}

As shown in Section 2.5, the reactive-surface-area-to-scrap-volume ratio determines the thermal stability of the scrap, quantified by the ignition parameter. The volume will be essentially the same as the volume of an MCO; therefore, the principal technical issue is the reactive area of scrap that would fill an MCO, which will expect be about $100 \mathrm{~kg}$. Other factors affecting the ignition parameter will not vary significantly among baskets of scrap unless intentionally varied, such as by homogeneously adding a high thermal conductivity inert material to the scrap. Homogeneously adding inert material to the scrap will increase the scrap volume without increasing the reactive surface area, and hence will decrease the reactive-surface-area-to-scrap-volume ratio.

We consider the scrap to be composed of the following:

- fine particles too numerous to characterize individually and which must be characterized in terms of a representative distribution of particles

- coarse particles that were sparse enough to characterize individually and large enough to be able to distinguish geometric features from which we estimated the area and volume

- non-fuel material, viz. Zircaloy ${ }^{\mathrm{TM}}$ spacers and W-springs.

Limiting the height of fill in a scrap basket can affect the conduction distance. In round numbers, the scrap basket is about 2 feet high, and the conduction distance in the coarse section is about 6 inches. Therefore, conduction length remains effectively constant for any basket fill height between 6 inches and the full 24 inches.. In other words, conduction length stays the same unless basket loading is less than $25 \%$ full. For a less full basket, the effective conduction length is the depth of the material, and conduction occurs primarily to the basket bottom plate.

Considering the coarse and fine parts of the reactive area, then the reactive area, $\mathrm{A}_{\mathrm{rx}}$, is 


$$
A_{r x}=A_{r x, \text { fine }}+A_{r x, \text { coarse }}=\frac{6(1-\phi) \kappa_{f} M_{s}(1-c)}{\rho_{f} d_{e f f, f}}+\frac{6(1-\phi) \kappa_{f} M_{s} c}{\rho_{f} d_{e f f, c}}
$$

where:

$$
\begin{aligned}
& \phi=\text { the volume fraction of fuel in the scrap, } \kappa_{\mathrm{f}} \text { is the mass fraction of fuel in the scrap } \\
& \mathrm{M}_{\mathrm{s}}=\text { the mass of the scrap, } \mathrm{c} \text { is the mass fraction of large pieces of uranium in the fuel } \\
& \rho_{\mathrm{f}}=\text { the average density of the clad fuel } \\
& \mathrm{x}_{\mathrm{eff}, \mathrm{f}}=\text { the effective size of the fine pieces of fuel (uranium debris) } \\
& \mathrm{x}_{\mathrm{eff}, \mathrm{c}}=\text { the effective diameter of the coarse pieces of fuel. }
\end{aligned}
$$

The present estimate of less than $100 \mathrm{~kg}$ of scrap will fit into a single scrap basket coarse section (6 outer sectors) whose volume is about $150 \mathrm{~L}$, because the scrap density is greater than $1 \mathrm{~kg} / \mathrm{L}$. Hence, we assume that

$$
\mathrm{M}_{\mathrm{s}}=100 \mathrm{~kg}
$$

From Table 3.2, using values for the sum of the scrap examined, we estimate conservatively that

$$
\begin{aligned}
& \left.\mathrm{M}_{\text {coarse }}=52 \mathrm{~kg} \text { (lower } 2 \sigma \text { value }\right) \\
& \left.\mathrm{M}_{\text {fine }}=8.8 \mathrm{~kg} \text { (upper } 2 \sigma \text { value }\right) \\
& \left.\mathrm{M}_{\mathrm{Zr}}=32.1 \mathrm{~kg} \text { (lower } 2 \sigma \text { value }\right)
\end{aligned}
$$

Then

$$
\begin{array}{lll}
\kappa_{\mathrm{f}} & =52 /(52+32.1)=65.4 \% \\
\mathrm{c} & =52 /(5+8.8)=85.6 \% \\
\mathrm{X}_{\mathrm{eff}, \mathrm{f}} \sim 0.36 \text { inches } & =0.0091 \mathrm{~m} . \\
\phi & =40 \% \text { (assumed, typical of packed beds) }
\end{array}
$$

Using the volume and area of the big uranium pieces and their variances, we take the effective diameter of the large pieces to be

$\mathrm{x}_{\mathrm{eff}, \mathrm{c}}=0.16 \mathrm{~m}$ (lower $2 \sigma$ value $)$

All of these are rough estimates based on values summed over the canisters we examined. The average density of the clad fuel is

$$
\rho_{\mathrm{f}}=16,900 \mathrm{~kg} / \mathrm{m}^{3}
$$

Substitution gives a conservatively estimated reactive area:

$$
\mathrm{A}_{\mathrm{rx}}=\mathrm{A}_{\mathrm{rx}, \text { fine }}+\mathrm{A}_{\mathrm{rx}, \text { coarse }}=0.22 \mathrm{~m}^{2}+0.07 \mathrm{~m}^{2}=0.3 \mathrm{~m}^{2}
$$


This compares to the baseline requirement of $4.5 \mathrm{~m}^{2}$. That is, based on these estimates, the reactive surface area per $100 \mathrm{~kg}$ of scrap would be an order of magnitude less (better) than that required by the baseline.

However, during our review we did not gain an understanding of the physical process that generates the uranium debris, unintentional filtration by scrap caught in the PCM strainer basket, and hence we cannot predict the size or mass of uranium particles collected during future operations. Therefore, for the existing washing process we cannot ensure that in future operations the mass and the effective size of particles in uranium debris together will be acceptable. Also, the uncertainty analysis is based on the assumption that the variances estimated by comparing the replicate analyses of the scrap in canister 5459 are representative of all of the scrap in the canisters examined here.

We have not attempted to determine the uncertainty in the estimate of the effective fine particle size, 0.36 inch, because we cannot a priori defend the use of a lognormal distribution and because we do not know what fraction of the particles we were able to count for each of the canisters. However, we can determine the value of the effective size that would have resulted in estimating an area of $4.5 \mathrm{~m}^{2}$, the value currently assumed for the baseline. This value is $0.02 \mathrm{inch}$, an order of magnitude smaller than the estimate obtained by fitting a lognormal distribution to the sum over canisters of the counts of the particles in each bin, and about a third the size of the smallest particles we judged we could see in examining the images.

\subsection{Effect of Removing Very Small Particles}

One potential improvement to the washing process that might alleviate problems with the size of the uranium debris would be to assure that particles below a certain size are not collected in, or subsequently are removed from, the scrap. The predicted effect this can have on the effective particle size of the resulting scrap depends on the parameters $\mu$ and $\sigma$ that describe the distribution from which one would remove small particles.

We can modify the previous expression for $\mathrm{x}_{\mathrm{eff}}$ as a function of $\mu$ and $\sigma$ to include the effect of a finite lower bound on the particle size in the distribution, as shown in Appendix F. Given the values of $\mu$ and $\sigma$ in Table 3.2, which describe the distributions fit to the data for the particular canisters of scrap, and given the upper bound, $d_{2}$, of $5 / 8$ inches for particles in the distribution, then the predicted effect on $\mathrm{x}_{\text {eff }}$ of removing from the distribution particles smaller than $\mathrm{x}_{\text {removed }}$ is given by

$$
\begin{aligned}
& d_{\text {eff }}\left(d^{*}, \sigma ; d_{2}, d_{\text {removed }}\right)=d^{*} e^{\frac{5}{4} \sigma^{2}} \frac{\operatorname{erf}\left(x_{2}-\frac{3}{2} \sigma\right)-\operatorname{erf}\left(x_{\text {removed }}-\frac{3}{2} \sigma\right)}{\operatorname{erf}\left(x_{2}-\sigma\right)-\operatorname{erf}\left(x_{\text {removed }}-\sigma\right)} \\
& x_{2} \equiv \frac{\ln \left(d_{2} / d^{*}\right)}{\sigma}, \quad x_{\text {removed }} \equiv \frac{\ln \left(d_{\text {removed }} / d^{*}\right)}{\sigma}
\end{aligned}
$$

We show the result in Figure 5.1. For the cases of canisters 2344 and 5456, for which the best fit was for very small values of $\mu$ and a wide distribution (large $\sigma$ ), there is an effect for any particle size removed. However, the variation in the resulting effective particle size is not substantial, ranging from 0.28 to 


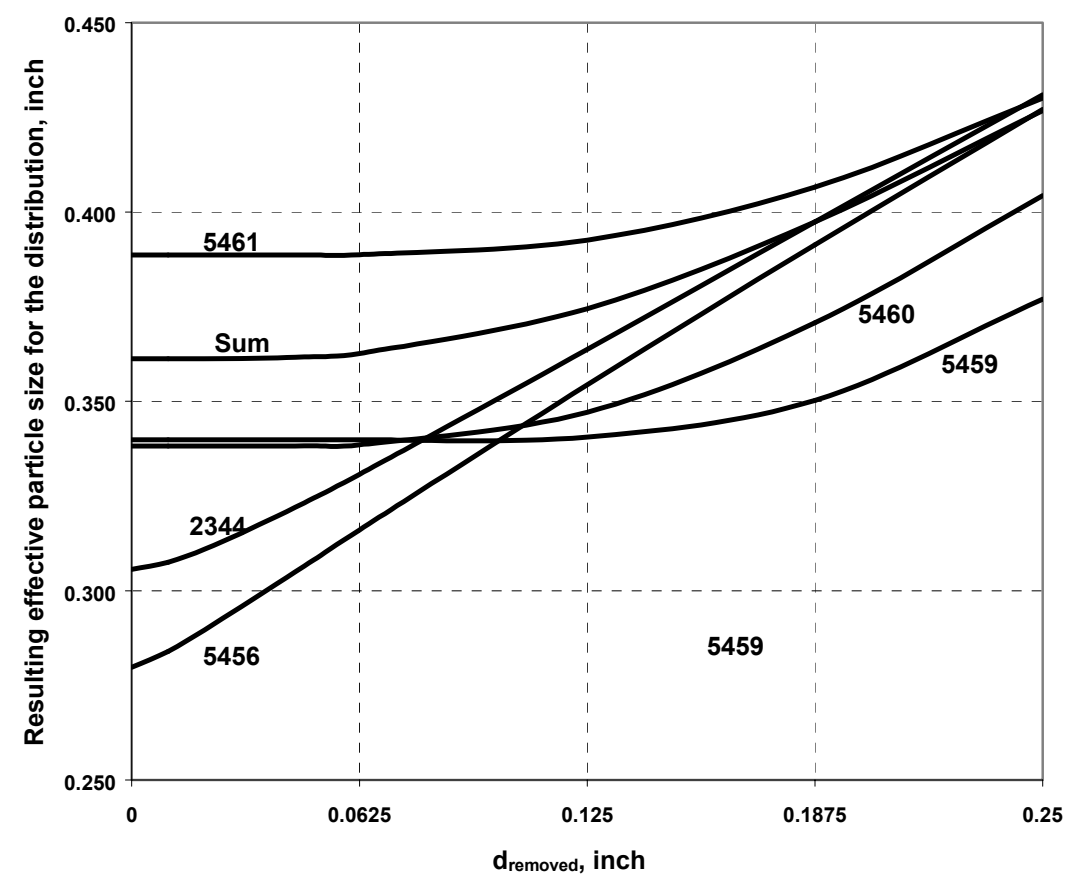

Figure 5.1. Effect of Removing Particles Below Size $x_{\text {removed }}$ on the Effective Particle Size of the Fitted Lognormal Distributions for the Various Canisters

0.42 inches. As found above, the effective particle size for the distribution describing the counts of particles summed over all the canisters, where we found $\mu=0.16$ inches and $\sigma=1.3$, is 0.37 inches. The fact that the mass of small uranium particles summed over the canisters is so small results in a predicted reactive surface area of only $0.3 \mathrm{~m}^{2}$ per $100 \mathrm{~kg}$ of scrap loaded into a basket. Therefore, whenever the mass of small particles of uranium is this small, there is little incentive to modify the washing process to reduce the effective particle size to less than 0.37 inches. As shown in Figure 5.1, removing particles down to $1 / 8$ inches in size accomplishes this even for canisters 2344 and 5456, based on a best fit of the lognormal distribution. 


\subsection{Conclusions and Recommendations}

Based on the results and interpretation presented in Section 5.0, the review panel concludes and recommends the following for each of the three review objectives.

Objective 1: "Based on the physical characteristics that are important to ensuring that scrap can be safely dried and stored, provide a technically defensible position that all scrap that will be generated is qualified for loading into canisters for cold vacuum drying by qualifying the existing washing equipment and process."

Conclusions:

- The technical review panel did not learn enough from the available information about the physical processes that generated and caught the scrap to be able to predict either the mass of uranium debris or its effective particle size.

- The panel believes the results are very encouraging because the quantity of scrap generated was very small. However, the size and mass of the scrap depend both on processes degrading the fuel while in the basin and processes catching debris in the PCM basket during washing, the latter including essentially unintentional filtration by the bed of debris that accumulates in the basket. This is not a sufficiently strong technical position from which to extrapolate the results from the examined scrap to all future scrap generated by the existing process.

- Based on fitting lognormal particle size distributions to the scrap we examined, modifying the washing process to assure that particles smaller than $1 / 8$ in. are not retained as scrap may result in effective particle sizes in future scrap that result in acceptable reactive surface areas.

- Relatively simple modifications to the process, such as sorting (e.g., sieving) the scrap and additional washing to remove particles below some selected size, would likely allow the resulting process to be qualified as producing scrap acceptable for loading into MCOs. This could be true even if the scrap as washed from fuel assemblies varies substantially in the particle size distribution and mass of small particles.

Recommendation: Consider modifying the washing process to assure an acceptable minimum particle size in the uranium debris in the scrap.

Objective 2: "Based on these same physical characteristics, qualify the SNF scrap we examined for loading into canisters for drying."

Conclusion: For the scrap we examined, the mass of uranium debris less than 5/8 inch in size is so small, and the composite effective particle size is sufficiently large, that the corresponding reactive surface area 
per $100 \mathrm{~kg}$ of scrap, $0.3 \mathrm{~m}^{2}$, is more than an order of magnitude smaller than that required to meet existing assumptions for the baseline project, $4.5 \mathrm{~m}^{2}$.

Recommendation: The estimated geometric reactive surface area of the scrap examined and characterized as part of this review appears to meet criteria set by the SNFP. The project should revisit the criteria for loading scrap into an MCO for cold vacuum drying, specifically the criteria based on geometric reactive surface area of scrap that may be loaded into a scrap basket, and consider if scrap examined as part of this review can be loaded without further processing. The review panel did not review the origin of the criterion for maximum allowable reactive surface area, and so it cannot itself conclude that the existing scrap is suitable to be loaded into an MCO.

Objective 3: "Recommend potential improvements that could improve or accommodate the characteristics of scrap if either future scrap generated by the existing process, or the scrap we examined, cannot be qualified for loading canisters for drying."

Conclusion: Apparently, the packed bed of scrap that accumulates in the scrap-collection basket acts as an unintended particle filter that can collect small particles, e.g., resulting in some cases of $85 \%$ of the observed particles being smaller than $1 / 4$ inch. The panel proposes that the SNFP could modify the washing process to prevent this. We discussed two possible modifications:

- Wash the collected scrap. SNF scrap could be loaded into a canister designed to subject its contents to washing similar to the washing of the fuel assemblies that generate the scrap. This would subject the scrap to substantial hydraulic forces in varying directions that could simultaneously agitate the scrap, as opposed to modest hydraulic forces acting only downward through a packed bed. We expect this would expel particles significantly smaller than openings in the walls of this scrapwashing canister.

- Develop an alternate scrap-collection design. Rather than collect scrap in a static basket, the basket could be something like a rotating, perforated drum into which debris from fuel washing is routed hydraulically and within which the scrap is simultaneously agitated and washed to prevent inadvertent filtration by preventing the formation of a static packed bed.

Recommendation: Consider making the above possible modifications, or equivalent modifications, to the washing process. Generate and examine scrap using a modified process and confirm that the modification truncates the particle size distribution on the small end at the intended minimum particle size. 


\subsection{References}

Duncan, D.R., and M.G. Plys. 1998. Simulation of Normal and Off-Normal Multi-Canister Overpack Behavior. HNF-2256, Rev. 2, DE\&S Hanford, Inc., Richland, Washington.

Ball, D.E., and D.R. Duncan. 1998. Fuel Surface Area. HNF-SD-CN-017, Rev 3, DE\&S Hanford, Inc., Richland, Washington.

Plys M.G., and D.R. Duncan. 2000. Uranium Pyrophoricity Phenomena and Prediction (FAI/00-39). SNF-6781, Fluor Hanford, Inc., Richland, Washington.

Pajunen, A.L. 2000. Spent Nuclear Fuel Project Product Specification. HNF-SD-SNF-OCD-001, Rev. 5, Fluor Hanford, Inc., Richland, Washington. 


\section{Appendix A}

\section{Details of the Spent Nuclear Fuel, Scrap, and}

Processing Done by the Spent Nuclear Fuel Project 


\section{Appendix A}

\section{Details of the Spent Nuclear Fuel, Scrap, and Processing Done by the Spent Nuclear Fuel Project}

This appendix describes the spent nuclear fuel (SNF) from which the scrap originates and the relationship of the fuel that has been washed to the fuel remaining to be washed. This is pertinent to the representativeness of the scrap we have examined to scrap that will be generated in the future.

\section{A.1 Spent Nuclear Fuel}

Under the Spent Nuclear Fuel Project (SNFP), spent fuel consists of the irradiated fuel assemblies currently in canisters stored in the K East (KE) and K West (KW) Basins. Each canister stores up to 14 fuel assemblies. Regardless of fuel type, each fuel assembly has a concentric tube-in-tube configuration of an inner element and an outer element. The diameter, length, and fuel enrichment varies between the fuel types. Each element is made of uranium metal and is clad with Zircaloy-2 ${ }^{\mathrm{TM}}$. Table A.1 summarizes the variation in the basic characteristics of $\mathrm{N}$ Reactor fuel (Packer 1999). The table describes two types of fuel, Mark IV and Mark IA, but, as can be seen in the table, they are practically identical and we treated them as such during our review.

A significant part of the scrap is Zircaloy ${ }^{\top \mathrm{M}}$, which originates with certain structural items in the fuel assemblies. Six Zircaloy ${ }^{\mathrm{TM}}$ spacers were welded to the outside of the inner element to ensure proper alignment inside the outer element when the two elements were assembled together. Eight Zircaloy- $2^{\text {TM }}$ support clips were welded to the outside of the outer element to ensure proper alignment of the element when inserted into tubes in the N Reactor core. Low-carbon steel "shoes" were crimped onto these Zircaloy-2 $2^{\mathrm{TM}}$ clips to minimize the tendency for galling to occur between assemblies and the reactor elements during fuel insertion and removal.

The fuel was irradiated in the N Reactor. Since its discharge from the reactor, the fuel has been stored under water in the K-Basins. The physical condition of the fuel varies from heavily corroded fuel elements, in which substantial cladding splitting and "mushrooming" of the uranium fuel has occurred due to corrosion, to intact elements in "like new" condition.

\section{A.2 Relationship of Examined Fuel to K Basin Fuel Population}

The fuel processed during the period for which these data were collected represents $16 \%$ of the KE- and KW-Basin total inventory. Of the fuel processed, $91 \%$ had been in storage for nearly 20 years, $8 \%$ for roughly 25 years, and $1 \%$ for 29 years. All of the fuel processed was from sealed KW-Basin canisters. The older fuel appears to have larger scrap weights per fuel canister than the younger fuel. However, due 
Table A.1. Details of the Characteristics of Spent Nuclear Fuel Stored in the K-Basins that Are Pertinent to this Study

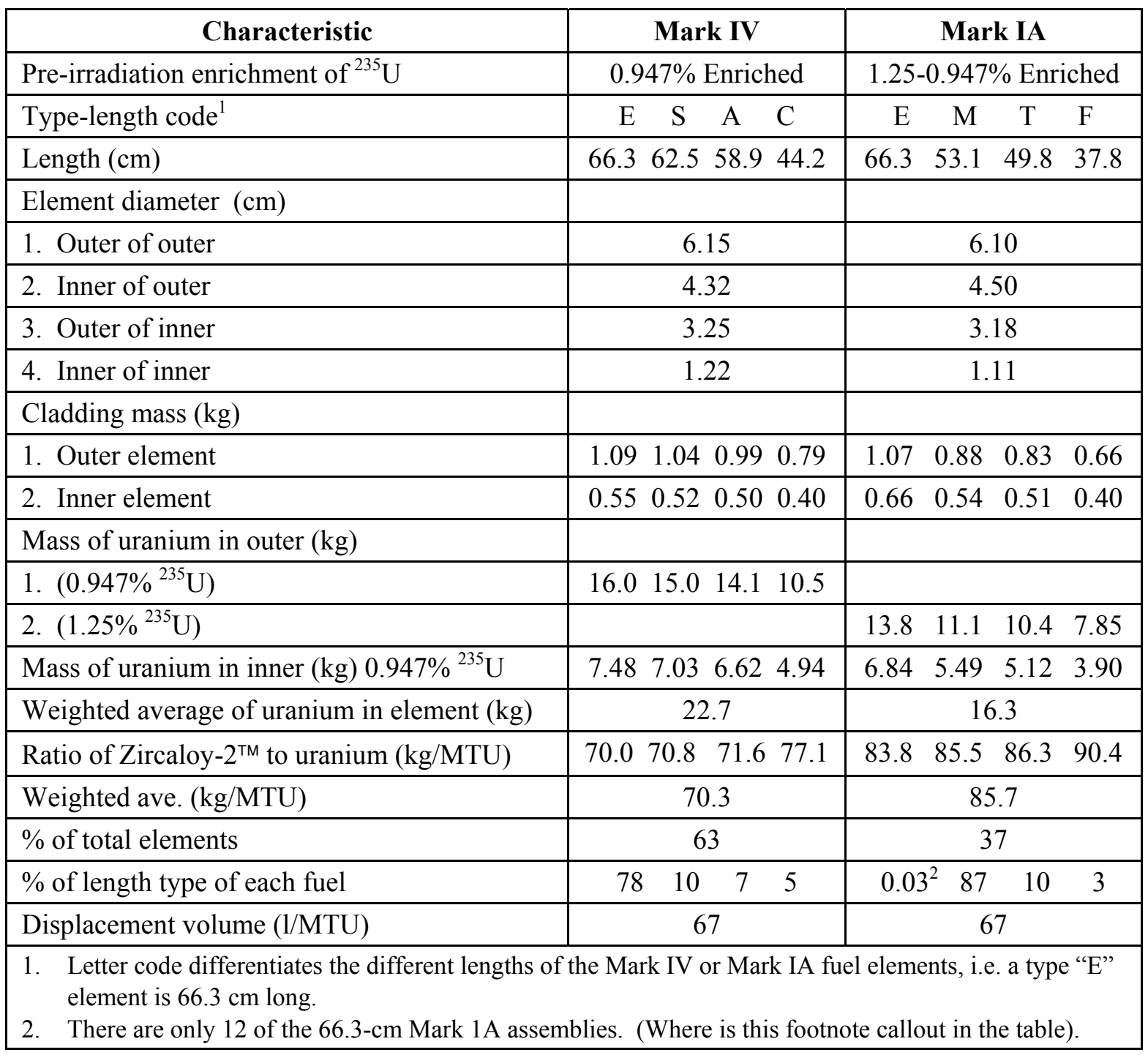

to limited population and variability in the younger fuel, it is difficult to extrapolate and apply the data to the entire KW fuel population. The KW data cannot be extrapolated to the KE-Basin fuel, which has been stored in open canisters in the Basin.

\section{A.3 SNF Scrap}

Scrap is defined in the SNF Project Product Specification (Pajunen 2000) as "all fuel bearing material that is not allowed to be loaded in a fuel basket." The pieces can measure from a maximum of $1 / 4$ inch across in size to an entire fuel element that cannot be fit into a fuel basket. Scrap is derived from corroding fuel and material removed during the washing process. Sometimes a portion of the fuel has 
corroded and broken into pieces. A primary cleaning machine removes these pieces of scrap fuel, which range in size from small annular lengths of the outer (typically) fuel assembly to rubble with maximum dimensions on the order of $1 / 4$ inch or smaller. The scrap also includes zircalloy "W-springs," originally positioned between the outer fuel assembly and the fuel element, and zircalloy spacers, originally positioned between the inner and outer fuel assemblies. Some of these pieces are also released from the fuel assemblies during washing and become part of the scrap. Thus, the scrap is a mixture of uranium metal, zircalloy spacers, and W-springs.

\section{A.4 SNFP Process}

The SNFP's SNF safety and environmental cleanup mission involves the following functions conducted primarily in three facilities:

- preparing and loading SNF into multi-canister overpacks (MCOs) in the K-Basins

- transporting wet MCOs from the K-Basins to the Cold Vacuum Drying Facility

- (CVDF)

- draining free water from the MCOs and drying them in the CVDF

- transporting loaded MCOs from the CVDF to the Canister Storage Building (CSB)

- storing loaded MCOs on an interim basis in the CSB facility, pending ultimate

- disposal in a suitable repository.

The MCO is a stainless steel canister approximately 24 inches in diameter and almost 14 feet long (with its cover assembly installed). Figure A.1 shows the overall process.

In the K-Basins, the fuel-handling process begins with the de-capping station, which opens the canisters inside a box designed to capture radioactive gasses and sludge. A larger box adjacent to the de-capper box contains a primary cleaning station, where the fuel canisters are rotated in a primary cleaning machine (PCM) and flushed with a water stream to remove corrosion products. The fuel canisters are unloaded onto a series of underwater process tables where the fuel assemblies undergo inspection, sorting, and removal of any foreign objects or debris still clinging to them. Fuel is then loaded into steel baskets, with intact fuel segregated in separate baskets from fuel pieces that have broken into scrap. Three streams of material result: washed fuel to be loaded as cylinders in MCOs for drying; scrap to be loaded in baskets in MCOs for drying; and sludge to be accumulated in the basins and treated later.

In the CVDF, water is removed from the MCO using pressurized helium to force the water out through an installed dip tube. Additional free water is removed by cold vacuum drying performed at less than 0.1 pounds per square inch, absolute, and at $50^{\circ}$ centigrade for a minimum processing time of 50 hours. After cold vacuum drying, no more than 0.5 pounds of free water is expected to remain in the MCO. 


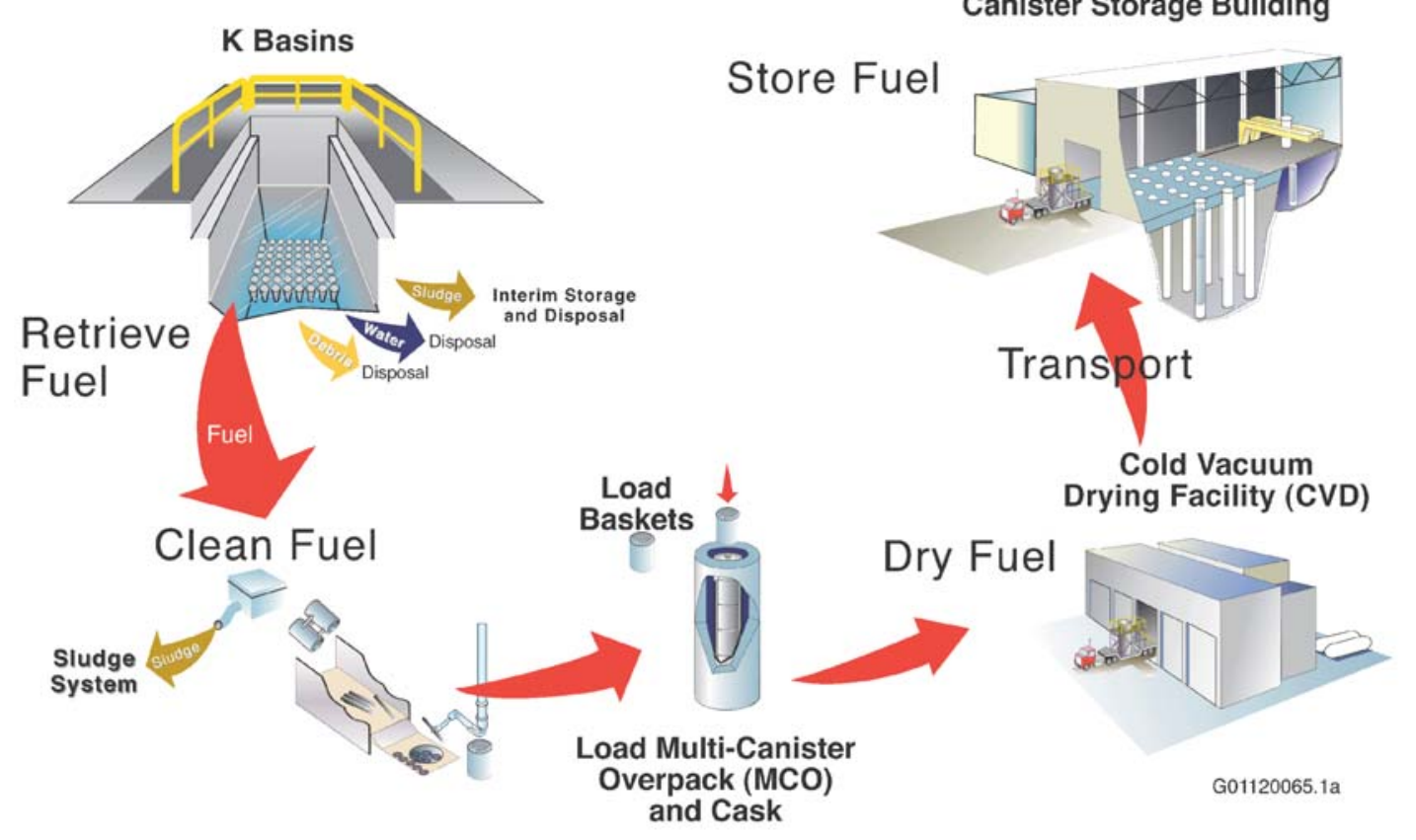

Figure A.1. Spent Nuclear Fuel Project Process

Pajunen, A.L. 2000. SNF Project Product Specification. HNF-SD-SNF-OCD-001, Rev. 5, Fluor Hanford, Inc., Richland, Washington.

Packer, M.J. 1999. 105-K Basin Material Design Basis Feed Description for Spent Nuclear Fuel Project Facilities, Volume 1, Fuel. HNF-SD-SNF-T1-009, Vol. 1, Rev. 3, Numatec Hanford, Inc., Richland, Washington. 


\section{Appendix B}

Physical Handling of Scrap Canister During the Process Test 


\section{Appendix B}

\section{Physical Handling of Scrap Canister During the Process Test}

Each scrap canister was retrieved from basin storage and weighed before dumping the scrap on the process table. The empty canister was then weighed to establish the weight of the canister contents, and the canister was placed into the canister well on the process table. The grid table was positioned so that the discharge chute on the table fed into one of the canister barrels.

The scrap pieces (including the $\mathrm{W}$-springs) were then swept into a 12-inch by 12 -inch dustpan using longhandled squeegee tools. Only a limited amount of scrap material was loaded into the dustpan each time for transfer to the grid table to avoid overloading the table and restricting the view. The number of dustpans required to complete the transfer ranged from one to seven per canister, depending on the contents of each canister.

After dumping the scrap from the dustpan onto the 2-foot by 3-foot grid table, the scrap was spread out on the table using the long-handled squeegee tools. Once the scrap was adequately distributed in this manner, electronic photographs were taken of the scrap on the grid table. This included an overall view of the scrap on the table, followed by individual close-ups of each quadrant of the table. The grid table was lined with 1-inch squares, and a height standard was positioned on the table for each quadrant photograph. The height standard consisted of three layered vertical cylinders each 0.25 -inch high.

After each set of photographs was completed, a gate was removed from the side of the grid table and the scrap pieces were swept down the chute into the canister barrel using the long-handled squeegee tools. The gate was then replaced and another dustpan load was processed. This procedure was repeated until all the scrap dumped from the canister had been processed. The canister was reweighed after the final scrap loading, and the canister was returned to basin storage. The next canister was then processed in a similar manner.

Table B.1 summarizes the scrap canisters examined, the associated MCOs (the number in the table indicates the order in the processing sequence) and number of fuel canisters processed, and weight of the scrap in each canister that was examined. Note that MCO numbers $1,3,4,5$, and 6 had no scrap generated during their processing. The scrap canister from Location W5459 was processed twice to check for repeatability of test results. 
Table B.1. Scrap Canister Data

\begin{tabular}{|l|c|c|c|c|}
\hline $\begin{array}{c}\text { Canister } \\
\text { Location }\end{array}$ & Key Date & $\begin{array}{c}\text { Associated } \\
\text { MCOs }\end{array}$ & $\begin{array}{c}\text { No. of Fuel Canisters } \\
\text { Processed }\end{array}$ & $\begin{array}{c}\text { Scrap Weight } \\
\text { (lb) }\end{array}$ \\
\hline W5456 & 10259 & 2 & 5 & 8.6 \\
\hline W2344 & 13859 & 7,8 & 135 & 15 \\
\hline W5459 & 13686 & $9,10,11$ & 78 & 55 \\
\hline W5460 & 13650 & $12,13,14,15$ & 75 & 68.3 \\
\hline W5461 & 11449 & 15,16 & 25 & 43.8 \\
\hline
\end{tabular}




\section{Appendix C}

\section{Procedure for Analyzing Photographs of K-Basin Spent Fuel Scrap Material}




\section{PNNL Technical Procedure}

Title: Analyzing Photographs of K-Basin Spent Fuel Scrap Material

\begin{tabular}{|c|c|}
\hline Work Location: General & Page $\underline{1}$ of $\underline{8}$ \\
\hline Author: John Abrefah & \multirow{2}{*}{$\begin{array}{l}\text { Effective Date: August 8, } 2001 \\
\text { Supersedes Date: New }\end{array}$} \\
\hline Use Category Identification: ANALYSIS & \\
\hline $\begin{array}{l}\text { Identified Hazards: } \\
-\quad \text { Radiological } \\
-\quad \text { Hazardous Materials } \\
-\quad \text { Physical Hazards } \\
-\quad \text { Hazardous Environment } \\
\text { - }\end{array}$ & $\begin{array}{l}\text { Required Reviewers: } \\
\underline{X} \text { Technical Reviewer } \\
\underline{X} \text { Quality Engineer } \\
\text { _ Building Manager }\end{array}$ \\
\hline
\end{tabular}

Are One-time Modifications Allowed to this Document?

- Yes or $\underline{\mathrm{X}}$ No

NOTE: If Yes, then modifications are not anticipated to impact safety. For documentation requirements of a modification see SBMS or the controlling Project QA Plan as appropriate.

On-The Job Training Required? __ Yes or $\mathrm{X}$ No

\section{FOR REVISIONS:}

Is retraining to this document required? _ Yes or $\mathrm{X}$ No

Does the OJT package associated with this document require revision to reflect document changes? _ _ Yes _ _ No _ X N/A

\section{Signatures:}

Author

John Abrefah -- Technical Team Member

Technical Reviewer

James C. Wiborg -- Technical Team Member

(Date)

\section{Approval:}

Project Manager 


\begin{tabular}{|c|l|}
\hline PNNL Technical Procedure & $\begin{array}{l}\text { Document No.: SNF-SCRAP-001 } \\
\text { Rev. No.: } 0\end{array}$ \\
\hline Title: Analyzing Photographs of K-Basin Spent Fuel Scrap Material \\
\hline
\end{tabular}




\section{PURPOSE/SCOPE}

The purpose of this procedure is to provide the guidance to analyze the photographs of K-Basin scrap materials for:

- Weight and/or volume fraction of non-fuel (i.e., inert) materials in the scrap

- Number and total weight of the larger fuel pieces

- Size distribution and weight fraction of the spent fuel particulates in the scrap.

\section{APPLICABILITY}

This procedure applies to the photographs of the K-Basin scrap material. This procedure establishes the process for inventorying the metallic fuel particulates in the K-Basin fuel scrap that were photographed. The photos were taken of scrap material associated with 5 canisters (i.e., 2344, 5459, 5460 and 5461). This procedure is applicable to all the photos but the initial effort will be to analyze those of the 5459 canister.

\section{DEFINITIONS}

Note: Definitions below are applicable to this procedure only.

Non-fuel material (Inert Materials): The non-fuel materials are the W-springs and the spacers in the scrap. The white/yellowish paint chips are excluded in the material balance and will not be accounted.

Large Fuel Pieces: These spent fuel pieces that have major dimensions greater than 0.625 inches and may have cladding attached to the fuel meat. Most of these are broken pieces of a thick fuel tube, and a subsection of cylindrical piece (i.e., half-cylinder or a curved piece of cylindrical element).

\section{PREREQUISITE}

To ensure complete and accurate generation of data, all Staff involved in the analysis shall be trained to this procedure. The analysis will be done using hard copies of the photographs originating from the same printer.

\section{ROLES AND RESPONSIBILITIES}

\section{Technical Review Team:}

Analytical Staff: Staff that are responsible for performing the analysis to generate the particle size distribution using hard copy photographs of the K-Basin scrap material.

\section{C.3}




\section{WORK INSTRUCTIONS}

\subsection{Count the Number of Zircaloy ${ }^{\mathrm{TM}} \mathrm{W}$-Springs and Spacers}

Hard copies of the photographs for the particular canister (e.g., 5459) will be provided to the analytical team. Each photograph is given an identification number such as:

$$
\text { 5459-1-1-A }
$$

where the first number refers to the canister; the second digit refers to the sequence; the third refers to the pan/tray number and the letter refers to the area on the tray that was photographed as indicated below

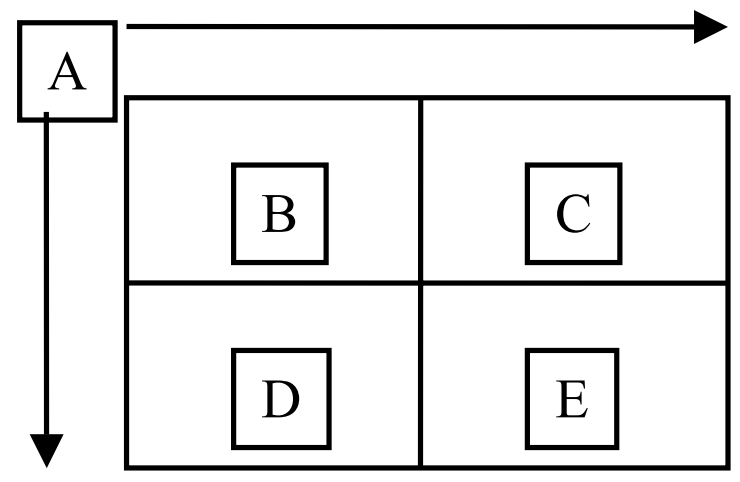

Thus, for each pan/tray there will be 5 photographs and you need to analyze the 4 quadrants (i.e., B, C, D, and $\mathrm{E}$ ) photographs and use the A photograph for verification to see whether the entire tray was photographed when $\mathrm{B}, \mathrm{C}, \mathrm{D}$ and $\mathrm{E}$ are put together and also to verify overlapping images.

Note: The quarter of the tray should have 36x24 grids. Even though a photo of the quadrant may consist of more grids, only the images in the $36 \times 24$ grids zone should be analyzed. Check for overlapping images to minimize double counting.

1.1 Mark the W-springs on each photograph with identification signs (e.g., filled circles) using powerpoint or other image processing software.

1.2 Repeat step 1.1 for the spacers in each photograph using different markings (e.g., filled triangles).

1.3 Print hard copies of the photographs for counting the $\mathrm{W}$-springs and the spacers.

1.4 Count the number of W-Springs appearing in each photograph and record the number in the attached Tables 1 and 2. The criteria should be W-Springs with lengths $\geq 4$ "'.

\section{Note: Dimensions of W-Spring: 5.7" long x 0.25" wide x.0.125" thick.}


1.5 Count the number of Spacer Clips appearing in each photograph and record the number in the attached Tables 1 and 2. The criteria should be a thick object that is about the grid size long with a square cross-section.

Note: Dimensions of Spacer: 0.8 " to 1.25 " long x 0.25 " wide x.0.25" thick.

\subsection{Counting the Number of Large Fuel Pieces}

2.1 Count the large spent fuel pieces that appear in the photographs and record the number in Tables 1 and 2.

2.2 Determine and list the characteristics sizes of each fuel piece. For a broken cylindrical piece, estimate the axial length using the depth scale provided by height standard. For a case where the large piece has very odd shape and presents difficulty in estimating the dimensions make a note of the image with sketches and location for further evaluations

NOTE: The height standard consists of three concentric rings each $1 / 4$-inch high, with a 4 -inch long handle on top. The bottom ring is $13 / 4$ inch diameter, the second is $1 \frac{1}{4}$ inch diameter, and the third ring is $3 / 4$ inch diameter. Also the lighting provides significant shadow that could be used to estimate the height of the fuel pieces that is in direct view of the camera.

2.2.1 Estimate the weight of the large fuel pieces that are in the photographs and record the weights in Tables 1 and 2. If the geometrical shape presents difficulty in estimating the weight, make a note of the image by recording the ID of the photograph for further evaluation.

\subsection{Counting the Size Spread of the Fuel Particulates}

3.1 Divide the photograph of each quadrant (e.g., photo: $5469-1-1-B$ ) into either $5 \times 5$ or 6 x 6 grid zones for the analysis.

\section{NOTE: The grid size is 1 inch square and a quadrant should consist of 36.x 24 grids}

3.2 Count the fuel particulates that happen to be separated from a pile of debris in each zone and record the number in Tables 3 and 4 . Enter the zone number in the $2^{\text {nd }}$ row as indicated in Tables $3 \mathrm{a}$ and $4 \mathrm{a}$ for the other tables generated given the number of zones in each photograph.

\section{NOTE: Tables 3 and 4 can be duplicated to cover all the zones.}

3.3 For the particulates identified in step 3.2, estimate the characteristic major dimensions, $\mu$, and distribute them in the size bins of (a) 0.5 " $<\mu<0.625$ ", (b) $0.375^{\prime \prime}<\mu<0.5$ ", (c) 0.25 " $<\mu<$ 0.375 ", and (d) $\mu<0.25$ ". Record the results in Tables 3 and 4 . 


\section{Appendix D}

Analysis of Uncertainty in Measurements of Scrap Characteristics 


\section{Appendix D}

\section{Analysis of Uncertainty in Measurements of Scrap Characteristics}

In interpreting the results of the measurements of the scrap characteristics, we can use the relative standard deviations found for the replicate characterization of canister 5459 as a rough estimate of the relative standard deviation of the corresponding measurements for the other canisters. From this we can estimate the standard deviation of the sum over the canisters as follows.

First, the variance of the sum is given by

$$
\sigma_{\Sigma}^{2}=\sum_{i=5459} \sigma_{i}^{2}+\sum_{i=n o t} \sigma_{i}^{2}
$$

where we assume there is no significant covariance among the measurements and " $i$ " denotes a canister and we distinguish between canister 5459 and the others, because the results for 5459 are the average of two replicate measurements. Next, we assume that the relative standard deviation for all measurements, including the individual replicate measurements for 5459, are the same, denoted $\sigma^{\prime}$, which we estimate from the standard deviation for the replicate measurements for 5459:

$$
\sigma^{\prime} \approx \frac{\sigma_{5459}}{\bar{x}_{5459}}
$$

The corresponding standard deviation for each canister is then

$$
\sigma_{i} \approx\left\{\begin{array}{l}
=\frac{\sigma^{\prime}}{\sqrt{2}} \bar{x}_{i}, i=5459 \\
=\sigma^{\prime} \bar{x}_{i}, \text { i not } 5459
\end{array}\right.
$$

where for canister 5459 this results from the mean being found from two measurements. Thus, the standard deviation for the sum over canister measurements, including the averaged value for 5459 , is

$$
\sigma_{\Sigma} \approx \frac{\sigma_{5459}}{\bar{x}_{5459}} \sqrt{\frac{\bar{x}_{5459, \text { ave }}^{2}}{2}+\sum_{i=n o t 5459} \bar{x}_{i}^{2}}
$$


For example, for the underwater weight (proportional to mass) of scrap we have $\sigma_{\text {scrap }, 5459}=0.42 \mathrm{~kg}$, $\mathrm{x}_{\text {scrap }, 5459}=24.9 \mathrm{~kg}$, therefore $\sigma_{\text {scrap }, 5459}^{\prime}=0.8 \%$. Completing the rest of the calculation, we find that $\sigma_{\text {scrap, sum }}=0.32 \mathrm{~kg}$. 


\section{Appendix E}

Scrap Mass, Volume, and Area Details 


\section{Appendix E}

\section{Scrap Mass, Volume, and Area Details}

Table E.1. Particulate Size Measurement for Canister 5459-1

\begin{tabular}{|c|c|c|c|c|c|c|c|c|c|c|c|c|c|}
\hline \multicolumn{14}{|c|}{ Number and Size Distribution of Particulates } \\
\hline \multirow[t]{2}{*}{ Photo ID } & \multicolumn{4}{|c|}{ Zone: 1; \# of Particulates } & \multicolumn{4}{|c|}{ Zone: 2; \# of Particulates } & \multicolumn{4}{|c|}{ Zone: 3; \# of Particulates } & \multirow{2}{*}{ Comments } \\
\hline & $\begin{array}{l}<0.625 \\
>0.5\end{array}$ & $\begin{array}{l}<0.5, \\
>0.3755\end{array}$ & $\begin{array}{l}<0.375 \\
>0.25\end{array}$ & $<0.25$ & $\begin{array}{l}<0.625 \\
>0.5\end{array}$ & $\begin{array}{l}<0.5 \\
>0.3755\end{array}$ & $\begin{array}{l}<0.375 \\
>0.25\end{array}$ & $<0.25$ & $\begin{array}{l}<0.625 \\
>0.5\end{array}$ & $\begin{array}{l}<0.5 \\
>0.3755\end{array}$ & $\begin{array}{l}<0.375 \\
>0.25\end{array}$ & $<0.25$ & \\
\hline \multicolumn{14}{|l|}{$5459-1-1-B$} \\
\hline $5459-1-1-\mathrm{C}$ & & & & & & & & & & & & 3 & \\
\hline \multicolumn{14}{|l|}{ 5459-1-1-D } \\
\hline \multicolumn{14}{|l|}{$5459-1-1-\mathrm{E}$} \\
\hline $5459-1-2-B$ & & & & & & & & & & 1 & 1 & 1 & \\
\hline $5459-1-2-\mathrm{C}$ & & & & & & 2 & & & & & 1 & 2 & \\
\hline $5459-1-2-\mathrm{D}$ & & 3 & 1 & 1 & 1 & & & & & & & & \\
\hline $5459-1-2-\mathrm{E}$ & & & 3 & 5 & 5 & & 1 & 1 & & & & & \\
\hline \multicolumn{14}{|l|}{$5459-1-3-B$} \\
\hline $5459-1-3-\mathrm{C}$ & & & & & 1 & & 1 & & & & 3 & 1 & \\
\hline \multicolumn{14}{|l|}{ 5459-1-3-D } \\
\hline $5459-1-3-\mathrm{E}$ & & 1 & 1 & & & & & & & & & & \\
\hline \multicolumn{14}{|l|}{ 5459-1-4-B } \\
\hline \multicolumn{14}{|l|}{$5459-1-4-\mathrm{C}$} \\
\hline \multicolumn{14}{|l|}{ 5459-1-4-D } \\
\hline 5459-1-4-E & & 1 & 4 & & & & & 1 & & & & & \\
\hline \multicolumn{14}{|l|}{ 5459-1-5-B } \\
\hline $5459-1-5-\mathrm{C}$ & & & & 4 & 4 & 1 & 4 & 2 & & & 1 & 2 & \\
\hline \multicolumn{14}{|l|}{ 5459-1-5-D } \\
\hline $5459-1-5-\mathrm{E}$ & & & 4 & 6 & 6 & & 1 & 10 & & & & & \\
\hline Bin Totals & 0 & 5 & 13 & 16 & 1 & 3 & 7 & 14 & 0 & 1 & 6 & 8 & \\
\hline Zone Totals & 1 & 9 & 26 & 38 & & & & & & & & & \\
\hline
\end{tabular}

E.1 
Table E.1. (contd)

\begin{tabular}{|c|c|c|c|c|c|c|c|c|c|c|c|c|c|}
\hline \multicolumn{14}{|c|}{ Number and Size Distribution of Particulates } \\
\hline \multirow[t]{2}{*}{ Photo ID } & \multicolumn{4}{|c|}{ Zone: 4; \# of Particulates } & \multicolumn{4}{|c|}{ Zone: 5; \# of Particulates } & \multicolumn{4}{|c|}{ Zone: 6; \# of Particulates } & \multirow[t]{2}{*}{ Comments } \\
\hline & $\begin{array}{l}<0.625 \\
>0.5\end{array}$ & $\begin{array}{l}<0.5 \\
>0.3755\end{array}$ & $\begin{array}{l}<0.375 \\
>0.25\end{array}$ & $<0.25$ & $\begin{array}{l}<0.625 \\
>0.5\end{array}$ & $\begin{array}{l}<0.5 \\
>0.3755\end{array}$ & $\begin{array}{l}<0.375 \\
>0.25\end{array}$ & $<0.25$ & $\begin{array}{l}<0.625, \\
>0.5\end{array}$ & $\begin{array}{l}<0.5 \\
>0.3755\end{array}$ & $\begin{aligned} & <0.375 \\
5 & >0.25\end{aligned}$ & $<0.25$ & \\
\hline \multicolumn{14}{|l|}{$5459-1-1-B$} \\
\hline \multicolumn{14}{|l|}{$5459-1-1-\mathrm{C}$} \\
\hline \multicolumn{14}{|l|}{$5459-1-1-\mathrm{D}$} \\
\hline \multicolumn{14}{|l|}{$5459-1-1-\mathrm{E}$} \\
\hline & & & & & & & & & & & & & \\
\hline $5459-1-2-B$ & & & & & & 2 & 2 & & 1 & 1 & 3 & 3 & 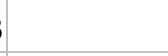 \\
\hline $5459-1-2-\mathrm{C}$ & & & & & & & & & & & & 1 & 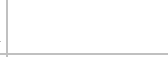 \\
\hline $5459-1-2-\mathrm{D}$ & & & 4 & 5 & 5 & & 6 & 6 & & & & & \\
\hline $5459-1-2-\mathrm{E}$ & & & 2 & 2 & & & 5 & 5 & & & & & \\
\hline & & & & & & & & & & & & & \\
\hline \multicolumn{14}{|l|}{ 5459-1-3-B } \\
\hline $5459-1-3-\mathrm{C}$ & & & 2 & 2 & 1 & 1 & 1 & & & & & 1 & \\
\hline \multicolumn{14}{|l|}{ 5459-1-3-D } \\
\hline $5459-1-3-\mathrm{E}$ & & 2 & : & & & & & & & & & & \\
\hline & & & & & & & & & & & & & \\
\hline 5459-1-4-B & & & & & & & & & & 1 & 1 & & \\
\hline $5459-1-4-\mathrm{C}$ & & & & 1 & 1 & & & & & & & & \\
\hline \multicolumn{14}{|l|}{ 5459-1-4-D } \\
\hline \multicolumn{14}{|l|}{ 5459-1-4-E } \\
\hline & & & & & & & & & & & & & \\
\hline 5459-1-5-B & & & & & & & 2 & ? & & & 1 & 1 & \\
\hline $5459-1-5-C$ & & & & & & & & & & & 2 & 2 & \\
\hline \multicolumn{14}{|l|}{ 5459-1-5-D } \\
\hline 5459-1-5-E & & & 4 & 25 & & & 2 & 8 & 8 & & & & \\
\hline Bin Totals & 0 & 2 & 12 & 31 & 1 & 3 & 15 & 8 & 1 & 2 & 6 & 6 & 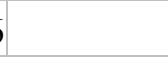 \\
\hline Zone Totals & 2 & 7 & 33 & 45 & & & & & & & & & \\
\hline
\end{tabular}


Table E.1. (contd)

\begin{tabular}{|c|c|c|c|c|c|c|c|c|c|c|c|c|c|}
\hline \multicolumn{14}{|c|}{ Number and Size Distribution of Particulates } \\
\hline \multirow{3}{*}{\begin{tabular}{|r} 
Photo ID \\
$5459-1-1-B$ \\
\end{tabular}} & \multicolumn{4}{|c|}{ Zone: 7; \# of Particulates } & \multicolumn{4}{|c|}{ Zone: 8; \# of Particulates } & \multicolumn{4}{|c|}{ Zone: 9; \# of Particulates } & \multirow[t]{2}{*}{ Comments } \\
\hline & \multirow[t]{2}{*}{$\begin{array}{l}<0.625 \\
>0.5\end{array}$} & \multirow[t]{2}{*}{$\begin{array}{l}<0.5 \\
>0.3755\end{array}$} & \multirow[t]{2}{*}{$\begin{array}{l}<0.375 \\
>0.25\end{array}$} & \multicolumn{2}{|c|}{$\begin{aligned} & <0.625 \\
<0.25 & >0.5\end{aligned}$} & \multirow{2}{*}{$\begin{aligned} \mathbf{5}, & <\mathbf{0 . 5}, \\
& >\mathbf{0 . 3 7 5 5} \\
& 2\end{aligned}$} & \multirow{2}{*}{$\begin{array}{l}<0.375 \\
>0.25\end{array}$} & \multirow{2}{*}{$<0.25$} & \multirow[t]{2}{*}{$\begin{array}{l}<0.625 \\
>0.5\end{array}$} & \multicolumn{2}{|c|}{$\begin{array}{l}<0.5, \quad<0.375 \\
>0.3755>0.25\end{array}$} & $<0.25$ & \\
\hline & & & & & & & & & & & 2 & & \\
\hline \multicolumn{14}{|l|}{$5459-1-1-\mathrm{C}$} \\
\hline $5459-1-1-\mathrm{D}$ & & 1 & 1 & & & 1 & & & & & & & \\
\hline \multicolumn{14}{|l|}{$5459-1-1-\mathrm{E}$} \\
\hline & & & & & & & & & & & & & \\
\hline $5459-1-1-B$ & & & & & & & 2 & 1 & & & 10 & & \\
\hline \multicolumn{14}{|l|}{$5459-1-2-C$} \\
\hline $5459-1-2-\mathrm{D}$ & & & 4 & & & & 2 & 2 & & & & & \\
\hline \multicolumn{14}{|l|}{ 5459-1-2-E } \\
\hline & & & & & & & & & & & & & \\
\hline \multicolumn{14}{|l|}{$5459-1-3-B$} \\
\hline \multicolumn{14}{|l|}{$5459-1-3-\mathrm{C}$} \\
\hline 5459-1-3-D & 1 & 1 & & 1 & & & 1 & 1 & & & & & \\
\hline \multicolumn{14}{|l|}{$5459-1-3-\mathrm{E}$} \\
\hline \multicolumn{14}{|l|}{ 5459-1-4-B } \\
\hline $5459-1-4-\mathrm{C}$ & & & & & & & & 1 & & & & & \\
\hline $5459-1-4-\mathrm{D}$ & & & 2 & & & & & & & & & & \\
\hline \multicolumn{14}{|l|}{ 5459-1-4-E } \\
\hline & & & & & & & & & & & & & \\
\hline $5459-1-5-B$ & & & & & & & & 1 & & & & & \\
\hline $5459-1-5-\mathrm{C}$ & & & & & & & & & & & 2 & & \\
\hline $5459-1-5-\mathrm{D}$ & & & 1 & & & & & 1 & & & & & \\
\hline $5459-1-5-\mathrm{E}$ & & & 3 & & & & & & & & & & \\
\hline Bin Totals & 1 & 1 & 10 & 1 & 0 & 3 & 5 & 4 & 0 & 4 & 10 & 0 & 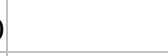 \\
\hline Zone Totals & 1 & 8 & 25 & 5 & & & & & & & & & \\
\hline
\end{tabular}


Table E.2. Particulate Size Measurement for Canister 5459-2

\begin{tabular}{|c|c|c|c|c|c|c|c|c|c|c|c|c|c|}
\hline \multicolumn{14}{|c|}{ Number and Size Distribution of Particulates } \\
\hline \multirow{3}{*}{$\begin{array}{r}\text { Photo ID } \\
5459-2-1-B\end{array}$} & \multicolumn{4}{|c|}{ Zone: 1; \# of Particulates } & \multicolumn{4}{|c|}{ Zone: 2; \# of Particulates } & \multicolumn{4}{|c|}{ Zone: 3; \# of Particulates } & \multirow[t]{2}{*}{ Comments } \\
\hline & \multirow{2}{*}{$\begin{array}{l}<0.625 \\
>0.5 \\
2\end{array}$} & $\begin{array}{l}<0.5 \\
>0.3755\end{array}$ & \multirow[t]{2}{*}{$\begin{array}{l}<0.375 \\
>0.25\end{array}$} & \multirow{2}{*}{$<0.25$} & \multirow{2}{*}{$\begin{array}{l}<0.625 \\
>0.5\end{array}$} & \multirow{2}{*}{$\begin{array}{l}<0.5 \\
>0.3755\end{array}$} & \multirow{2}{*}{$\begin{array}{l}<0.375 \\
>0.25\end{array}$} & \multirow[t]{2}{*}{$<0.25$} & \multicolumn{3}{|c|}{$\begin{array}{lll}<0.625, & <0.5, & <0.375 \\
>0.5 & >0.3755 & >0.25\end{array}$} & \multirow[t]{2}{*}{$<0.25$} & \\
\hline & & & & & & & & & & & & & \\
\hline $5459-2-1-\mathrm{C}$ & & & & & & & & 1 & & & & & \\
\hline 5459-2-1-D & & 1 & & & & & & & & & 1 & & \\
\hline \multicolumn{14}{|l|}{$5459-2-1-\mathrm{E}$} \\
\hline & & & & & & & & & & & & & \\
\hline $5459-2-2-B$ & & 1 & & & & & & & & & & & \\
\hline $5459-2-2-\mathrm{C}$ & & & & 1 & 1 & & & 4 & & & 1 & 4 & \\
\hline \multicolumn{14}{|l|}{ 5459-2-2-D } \\
\hline $5459-2-2-\mathrm{E}$ & & & & 4 & 4 & & 1 & & & & & 4 & \\
\hline & & & & & & & & & & & & & \\
\hline $5459-2-3-B$ & & & & & & & 1 & & & & & & \\
\hline $5459-2-3-\mathrm{C}$ & & & 1 & & & & & & & & & & \\
\hline \multicolumn{14}{|l|}{ 5459-2-3-D } \\
\hline \multicolumn{14}{|l|}{$5459-2-3-E$} \\
\hline & & & & & & & & & & & & & \\
\hline 5459-2-4-B & & & & & & & 1 & & & & & & \\
\hline $5459-2-4-\mathrm{C}$ & & 1 & & & 1 & 1 & 1 & 4 & & & 1 & 3 & \\
\hline \multicolumn{14}{|l|}{ 5459-2-4-D } \\
\hline $5459-2-4-\mathrm{E}$ & & & & 1 & 1 & & & & & & & & \\
\hline & & & & & & & & & & & & & \\
\hline 5459-2-5-B & & 3 & & & & & & & & & & & \\
\hline $5459-2-5-C$ & & & & & & & & & & & & 1 & \\
\hline 5459-2-5-D & 1 & & & & & & & & & & & & \\
\hline \multicolumn{14}{|l|}{ 5459-2-5-E } \\
\hline & & & & & & & & & & & & & \\
\hline 5459-2-6-B & & & & & & & & & & & 1 & & \\
\hline 5459-2-6-C & & 1 & & & & & 3 & 1 & & & 7 & 9 & \\
\hline 5459-2-6-D & & & & 2 & 2 & & & & & & & & \\
\hline 5459-2-6-E & & 1 & 4 & 4 & 4 & 1 & 1 & & & & & & \\
\hline & & & & & & & & & & & & & \\
\hline 5459-2-7-B & 1 & & & & & & & & & & & & \\
\hline 5459-2-7-C & & & & 2 & 2 & & 2 & 3 & & & 2 & 5 & \\
\hline 5459-2-7-D & & & & & & & 1 & & & & & & \\
\hline 5459-2-7-E & & 1 & & 3 & 3 & & & 5 & & & & & \\
\hline Bin Totals & 4 & 9 & 5 & 17 & 1 & 2 & 11 & 18 & 0 & 0 & 13 & 26 & \\
\hline Zone Totals & 5 & 11 & 29 & 61 & & & & & & & & & \\
\hline
\end{tabular}


Table E.2. (contd)

\begin{tabular}{|c|c|c|c|c|c|c|c|c|c|c|c|c|c|}
\hline \multicolumn{14}{|c|}{ Number and Size Distribution of Particulates } \\
\hline \multirow[t]{2}{*}{ Photo ID } & \multicolumn{4}{|c|}{ Zone: 4; \# of Particulates } & \multicolumn{4}{|c|}{ Zone: 5; \# of Particulates } & \multicolumn{4}{|c|}{ Zone: 6; \# of Particulates } & \multirow{2}{*}{ Comments } \\
\hline & $\begin{array}{l}<0.625, \\
>0.5\end{array}$ & $\begin{array}{l}<0.5, \\
>0.3755\end{array}$ & $\begin{array}{l}<0.375 \\
>0.25\end{array}$ & $<0.25>$ & $\begin{array}{l}<0.625 \\
>0.5\end{array}$ & $\begin{array}{l}<0.5 \\
>0.3755\end{array}$ & $\begin{array}{l}<0.375 \\
>0.25\end{array}$ & $<0.25$ & $\begin{array}{l}<0.625, \\
>0.5\end{array}$ & $\begin{array}{l}<0.5 \\
>0.3755\end{array}$ & $\begin{array}{c}<0.375 \\
5>0.25\end{array}$ & $<0.25$ & \\
\hline $5459-2-1-B$ & 1 & & & & & & & & & & 1 & 1 & \\
\hline $5459-2-1-\mathrm{C}$ & 1 & & & & & & & & & & & & \\
\hline 5459-2-1-D & & & & 1 & & & & & & & & & \\
\hline \multicolumn{14}{|l|}{$5459-2-1-\mathrm{E}$} \\
\hline & & & & & & & & & & & & & \\
\hline $5459-2-2-B$ & & & 1 & & & & 1 & & & & 1 & 1 & \\
\hline $5459-2-2-\mathrm{C}$ & & & & & & & & & & & 4 & 4 & \\
\hline $5459-2-2-\mathrm{D}$ & & & 4 & 10 & & & 1 & & 1 & & 1 & 6 & \\
\hline \multicolumn{14}{|l|}{ 5459-2-2-E } \\
\hline & & & & & & & & & & & & & \\
\hline $5459-2-3-\mathrm{B}$ & & & & & & & 1 & 4 & & & & & \\
\hline $5459-2-3-\mathrm{C}$ & & & 1 & & & & & & & 1 & 2 & 2 & \\
\hline 5459-2-3-D & 1 & 1 & 5 & & & 1 & & 2 & & & & & \\
\hline \multicolumn{14}{|l|}{ 5459-2-3-E } \\
\hline & & & & & & & & & & & & & \\
\hline $5459-2-4-B$ & & & & 2 & & & 2 & & 1 & & 1 & 1 & \\
\hline $5459-2-4-\mathrm{C}$ & & & & & & & 9 & & & & & & \\
\hline $5459-2-4-\mathrm{D}$ & & & & 2 & & & & & & & & & \\
\hline \multicolumn{14}{|l|}{$5459-2-4-\mathrm{E}$} \\
\hline & & & & & & & & & & & & & \\
\hline $5459-2-5-B$ & & & & & 3 & 3 & & & & & & & \\
\hline $5459-2-5-\mathrm{C}$ & & & & & & & 1 & & & & 1 & 1 & \\
\hline \multicolumn{14}{|l|}{$5459-2-5-\mathrm{D}$} \\
\hline $5459-2-5-\mathrm{E}$ & & & & & & 1 & & & & & & & \\
\hline & & & & & & & & & & & & & \\
\hline $5459-2-6-B$ & & & & & & & & & & 1 & 3 & 4 & \\
\hline $5459-2-6-\mathrm{C}$ & & & 1 & & & & 5 & & & 1 & 1 & 4 & \\
\hline 5459-2-6-D & & & & 4 & & & 1 & & & & & & \\
\hline 5459-2-6-E & & & 1 & & & & & & & & & & \\
\hline & & & & & & & & & & & & & \\
\hline $5459-2-7-B$ & & & & & & & 1 & 6 & 1 & 1 & 1 & & \\
\hline $5459-2-7-\mathrm{C}$ & & 1 & 1 & & & & 1 & 6 & & & & & \\
\hline 5459-2-7-D & 1 & & & & & & & & & & & & \\
\hline $5459-2-7-\mathrm{E}$ & 1 & & & & & & & & & & & & \\
\hline Bin Totals & 5 & 2 & 13 & 19 & 3 & 2 & 23 & 18 & 3 & 4 & 14 & 17 & \\
\hline Zone Totals & 11 & 8 & 50 & 54 & & & & & & & & & \\
\hline
\end{tabular}


Table E.2. (contd)

\begin{tabular}{|c|c|c|c|c|c|c|c|c|c|c|c|c|c|}
\hline \multicolumn{14}{|c|}{ Number and Size Distribution of Particulates } \\
\hline \multirow{3}{*}{\begin{tabular}{|r} 
Photo ID \\
$5459-2-1-B$ \\
\end{tabular}} & \multicolumn{4}{|c|}{ Zone: 7; \# of Particulates } & \multicolumn{4}{|c|}{ Zone: 8; \# of Particulates } & \multicolumn{4}{|c|}{ Zone: 9; \# of Particulates } & \multirow{2}{*}{ Comments } \\
\hline & $\begin{array}{l}<0.625, \\
>0.5\end{array}$ & $\begin{array}{l}<0.5, \\
>0.3755\end{array}$ & $\begin{array}{l}<0.375 \\
>0.25\end{array}$ & $<0.25$ & $\begin{array}{l}<0.625, \\
>0.5\end{array}$ & $\begin{array}{l}<0.5, \\
>0.3755\end{array}$ & $\begin{array}{l}<0.375 \\
>0.25\end{array}$ & $<0.25$ & $\begin{array}{l}<0.625 \\
>0.5\end{array}$ & $\begin{array}{l}<0.5 \\
>0.3755\end{array}$ & $\begin{array}{c}<0.375 \\
5>0.25\end{array}$ & $<0.25$ & \\
\hline & & & & & & & 1 & & & & & & \\
\hline \multicolumn{14}{|l|}{$5459-2-1-\mathrm{C}$} \\
\hline \multicolumn{14}{|l|}{ 5459-2-1-D } \\
\hline \multicolumn{14}{|l|}{ 5459-2-1-E } \\
\hline & & & & & & & & & & & & & \\
\hline $5459-2-2-B$ & & & & & & & & & & & 2 & 2 & \\
\hline $5459-2-2-\mathrm{C}$ & & & & & & & 1 & & & & & & \\
\hline \multicolumn{14}{|l|}{ 5459-2-2-D } \\
\hline \multirow{2}{*}{\multicolumn{14}{|c|}{ 5459-2-2-E }} \\
\hline & & & & & & & & & & & & & \\
\hline $5459-2-3-B$ & & & 2 & & & & 1 & & & 2 & 2 & & \\
\hline \multicolumn{14}{|l|}{$5459-2-3-\mathrm{C}$} \\
\hline 5459-2-3-D & 2 & & 1 & 2 & & & & & & & & & \\
\hline \multicolumn{14}{|l|}{ 5459-2-3-E } \\
\hline & & & & & & & & & & & & & \\
\hline $5459-2-4-B$ & & 1 & 1 & & & & 1 & & & & & & \\
\hline $5459-2-4-\mathrm{C}$ & 1 & & 1 & & & 1 & & & & & & & \\
\hline \multicolumn{14}{|l|}{$5459-2-4-\mathrm{D}$} \\
\hline \multicolumn{14}{|l|}{$5459-2-4-\mathrm{E}$} \\
\hline & & & & & & & & & & & & & \\
\hline $5459-2-5-B$ & & & & & & & 1 & & 1 & & & & \\
\hline $5459-2-5-\mathrm{C}$ & & & & & 1 & & & & & & & & \\
\hline 5459-2-5-D & & & & & & 1 & & & & & & & \\
\hline \multicolumn{14}{|l|}{$5459-2-5-\mathrm{E}$} \\
\hline & & & & & & & & & & & & & \\
\hline $5459-2-6-B$ & & & & & & 1 & 2 & & & & 15 & & \\
\hline $5459-2-6-\mathrm{C}$ & & & & 2 & & & & & & & & & \\
\hline 5459-2-6-D & & & 2 & 1 & & & & & & & & & \\
\hline \multicolumn{14}{|l|}{ 5459-2-6-E } \\
\hline & & & & & & & & & & & & & \\
\hline $5459-2-7-B$ & & & & 5 & & & 5 & 10 & & & 3 & 10 & \\
\hline $5459-2-7-\mathrm{C}$ & & & & & & & & 3 & & & & 1 & \\
\hline $5459-2-7-\mathrm{D}$ & 1 & & & & 1 & & & & & & & & \\
\hline \multicolumn{14}{|l|}{$5459-2-7-\mathrm{E}$} \\
\hline Bin Totals & 5 & 1 & 7 & 11 & 2 & 3 & 12 & 13 & 1 & 2 & 20 & 11 & \\
\hline Zone Totals & 8 & 6 & 3 & 35 & & & & & & & & & \\
\hline
\end{tabular}


Table E.3. Particulate Size Measurement for Canister 5456

\begin{tabular}{|c|c|c|c|c|c|c|c|c|c|c|c|c|c|}
\hline \multirow{3}{*}{ Photo ID } & \multicolumn{12}{|c|}{ Number and Size Distribution of Particulates } & \multirow{3}{*}{ Comments } \\
\hline & \multicolumn{4}{|c|}{ Zone: 1; \# of Particulates } & \multicolumn{4}{|c|}{ Zone: 2; \# of Particulates } & \multicolumn{4}{|c|}{ Zone: 3; \# of Particulates } & \\
\hline & $\begin{array}{l}<0.625 \\
>0.5\end{array}$ & $\begin{array}{l}<0.5 \\
>0.3755\end{array}$ & $\begin{array}{l}<0.375 \\
>0.25\end{array}$ & $<0.25$ & $\begin{array}{l}<0.625 \\
>0.5\end{array}$ & $\begin{array}{l}<0.5, \\
>0.3755\end{array}$ & $\begin{array}{l}<0.375 \\
>0.25\end{array}$ & $<0.25$ & $\begin{array}{l}<0.625 \\
>0.5\end{array}$ & $\begin{array}{l}<0.5 \\
>0.3755\end{array}$ & $\begin{array}{l}<0.375 \\
>0.25\end{array}$ & $<0.25$ & \\
\hline $5456-1-1-B$ & & & & 4 & + & & & 34 & & & 1 & 29 & \\
\hline $5456-1-1-\mathrm{C}$ & & & 1 & 14 & 1 & 3 & 2 & 26 & & 8 & 11 & 11 & \\
\hline 5456-1-1-D & & & & 6 & 5 & & & 1 & & & 1 & 16 & \\
\hline $5456-1-1-\mathrm{E}$ & & 4 & 1 & 24 & & 4 & 1 & 40 & & & 2 & 65 & \\
\hline Bin Totals & 0 & 4 & 2 & 48 & 1 & 7 & 3 & 101 & 0 & 8 & 15 & 121 & \\
\hline \multirow[t]{2}{*}{ Zone Totals } & 1 & 19 & 20 & 270 & & & & & & & & & \\
\hline & \multicolumn{12}{|c|}{ Number and Size Distribution of Particulates } & \\
\hline \multirow[t]{2}{*}{ Photo ID } & \multicolumn{4}{|c|}{ Zone: 4; \# of Particulates } & \multicolumn{4}{|c|}{ Zone: 5; \# of Particulates } & \multicolumn{4}{|c|}{ Zone: 6; \# of Particulates } & Comments \\
\hline & $\begin{array}{l}<0.625 \\
>0.5\end{array}$ & $\begin{array}{l}<0.5 \\
>0.3755\end{array}$ & $\begin{array}{l}<0.375 \\
>0.25\end{array}$ & $<0.25$ & $\begin{array}{l}<0.625 \\
>0.5\end{array}$ & $\begin{array}{l}<0.5 \\
>0.3755\end{array}$ & $\begin{array}{l}<0.375 \\
>0.25\end{array}$ & $<0.25$ & $\begin{array}{l}<0.625 \\
>0.5\end{array}$ & $\begin{array}{l}<0.5 \\
>0.3755\end{array}$ & $\begin{array}{l}<0.375 \\
>0.25\end{array}$ & $<0.25$ & \\
\hline 5461-1-1-B & & & & 30 & & & & 60 & 2 & 2 & 2 & 30 & \\
\hline $5461-1-1-\mathrm{C}$ & 2 & & & 33 & 1 & 7 & 7 & 12 & 1 & 7 & 5 & 28 & \\
\hline 5461-1-1-D & 1 & 2 & 2 & 40 & 1 & 1 & & 12 & 1 & 1 & 4 & 15 & \\
\hline $5461-1-1-\mathrm{E}$ & & 1 & 2 & 10 & & 1 & 1 & 4 & & & 2 & 22 & \\
\hline Bin Totals & 3 & 3 & 2 & 113 & 2 & 8 & 0 & 88 & 4 & 10 & 13 & 95 & \\
\hline \multirow[t]{2}{*}{ Zone Totals } & 9 & 21 & 15 & 296 & & & & & & & & & \\
\hline & \multicolumn{12}{|c|}{ Number and Size Distribution of Particulates } & \\
\hline \multirow[t]{2}{*}{ Photo ID } & \multicolumn{4}{|c|}{ Zone: 7; \# of Particulates } & \multicolumn{4}{|c|}{ Zone: 8; \# of Particulates } & \multicolumn{4}{|c|}{ Zone: 9; \# of Particulates } & Comments \\
\hline & $\begin{array}{l}<0.625 \\
>0.5\end{array}$ & $\begin{array}{l}<0.5 \\
>0.3755\end{array}$ & $\begin{array}{l}<0.375 \\
>0.25\end{array}$ & $<0.25$ & $\begin{array}{l}<0.625 \\
>0.5\end{array}$ & $\begin{array}{l}<0.5 \\
>0.3755\end{array}$ & $\begin{array}{l}<0.375 \\
>0.25\end{array}$ & $<0.25$ & $\begin{array}{l}<0.625, \\
>0.5\end{array}$ & $\begin{array}{l}<0.5 \\
>0.3755\end{array}$ & $\begin{array}{l}<0.375 \\
>0.25\end{array}$ & $<0.25$ & \\
\hline $5461-1-1-B$ & & & & 15 & 1 & 1 & & 33 & 6 & 5 & 4 & 35 & \\
\hline $5461-1-1-\mathrm{C}$ & & & & 9 & 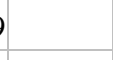 & & & 9 & & 5 & 5 & 2 & \\
\hline 5461-1-1-D & & & & 27 & & 5 & 5 & 31 & & & & 9 & \\
\hline 5461-1-1-E & & & & 5 & 5 & & 1 & 3 & & & & & \\
\hline Bin Totals & 0 & 0 & 0 & 56 & 1 & 5 & 6 & 76 & 6 & 6 & 4 & 46 & \\
\hline Zone Totals & 7 & 11 & 10 & 178 & & & & & & & & & \\
\hline
\end{tabular}


Table E.4. Large Particulate Size Calculations for Canister 2344

\begin{tabular}{|c|c|c|c|c|c|c|c|c|c|c|c|c|c|c|c|c|c|c|c|c|c|c|c|c|c|}
\hline \multirow{3}{*}{\multicolumn{3}{|c|}{ Image ID }} & \multirow[b]{3}{*}{ Loc } & \multirow{2}{*}{\multicolumn{3}{|c|}{\begin{tabular}{|c|} 
Inches \\
$\begin{array}{c}\text { - Fraction of } \\
\text { Circle }\end{array}$
\end{tabular}}} & \multicolumn{9}{|c|}{ Inches } & \multirow{2}{*}{\multicolumn{5}{|c|}{ Volume, in ${ }^{3}$}} & \multirow{2}{*}{\multicolumn{5}{|c|}{ Area, in ${ }^{2}$}} \\
\hline & & & & & & & \multicolumn{3}{|c|}{$\begin{array}{l}2 \text { - Cylinder } \\
\text { with Gap }\end{array}$} & \multicolumn{3}{|c|}{$\begin{array}{l}3 \text { - Chord of } \\
\text { Cylinder }\end{array}$} & \multicolumn{3}{|c|}{4 - Trapezoid } & & & & & & & & & & \\
\hline & & & & \multirow[t]{2}{*}{ 堷 } & \multirow[t]{2}{*}{ 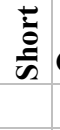 } & \multirow[t]{2}{*}{$\begin{array}{c}\% \\
\text { Circle }\end{array}$} & \multirow[t]{2}{*}{ 泀 } & \multirow[t]{2}{*}{$\frac{5}{\tilde{D}}$} & \multirow[t]{2}{*}{ Gap } & \multirow[t]{2}{*}{$\begin{array}{l}0.00 \\
\bar{\Xi} \\
\end{array}$} & \multirow[t]{2}{*}{$\frac{\bar{b}}{\bar{n}}$} & \multirow[t]{2}{*}{ Chord } & \multirow[t]{2}{*}{ 占 } & \multirow[t]{2}{*}{ 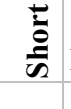 } & Height & \multirow[t]{2}{*}{1} & 2 & 3 & 4 & All & 1 & 2 & 3 & 4 & All \\
\hline 2344 & & & & & & & & & & & & & & & & & & & & 6.1 & & & & & 10.2 \\
\hline 2344 & 2 & $1 \mathrm{~A}$ & & & & & & & & & & & & & & & & & & & & & & & \\
\hline & & & $2 \mathrm{~K} 9$ & & & & & & & & & & 0.8 & 0.4 & 0.9 & & & & 0.2 & 0.2 & & & & 1.0 & 1.0 \\
\hline 2344 & 2 & $1 \mathrm{C}$ & & & & & & & & & & & & & & & & & & & & & & & \\
\hline & & & 3 D21 & & & & & & & & & & 1.3 & 0.4 & 1.4 & & & & & 0.4 & & & & 1.6 & 1.6 \\
\hline 2344 & 2 & $1 \mathrm{D}$ & & & & & & & & & & & & & & & & & & & & & & & \\
\hline & & & $4 \mathrm{Q} 7$ & & & & & & & 1.2 & 0.6 & 1.8 & & & & & & 0.3 & & 0.3 & & & 0.5 & & 0.5 \\
\hline 2344 & 2 & $2 \mathrm{~A}$ & & & & & & & & & & & & & & & & & & & & & & & \\
\hline & & & $1 \mathrm{I} 3$ & & & & & & & & & & 0.4 & 0.4 & 1.0 & & & & 0.1 & 0.1 & & & & 1.0 & 1.0 \\
\hline & & & $2 \mathrm{M} 10$ & & & & & & & & & & 0.3 & 0.3 & 0.9 & & & & 0.1 & 0.1 & & & & 0.9 & 0.9 \\
\hline 2344 & 2 & $2 \mathrm{~B}$ & & & & & & & & & & & & & & & & & & & & & & & \\
\hline & & & $3 \mathrm{C} 23$ & & & & & & & 1.0 & 0.5 & 1.1 & & & & & & 0.2 & & 0.2 & & & 0.4 & & 0.4 \\
\hline & & & $4 \mathrm{~B} 25$ & & & & & & & 1.8 & 1.7 & 1.3 & & & & & & 0.4 & & 0.4 & & & 0.9 & & 0.9 \\
\hline 2344 & 2 & $2 \mathrm{C}$ & & & & & & & & & & & & & & & & & & & & & & & \\
\hline 2344 & 2 & $2 \mathrm{D}$ & & & & & & & & & & & & & & & & & & & & & & & \\
\hline & & & $5 \mathrm{~T} 13$ & & & & & & & & & & 1.3 & 1.1 & 2.6 & & & & 1.1 & 1.1 & & & & 2.7 & 2.7 \\
\hline 2344 & 2 & $2 \mathrm{E}$ & & & & & & & & & & & & & & & & & & & & & & & \\
\hline
\end{tabular}


Table E.5. Large Particulate Size Calculations for Canister 5456

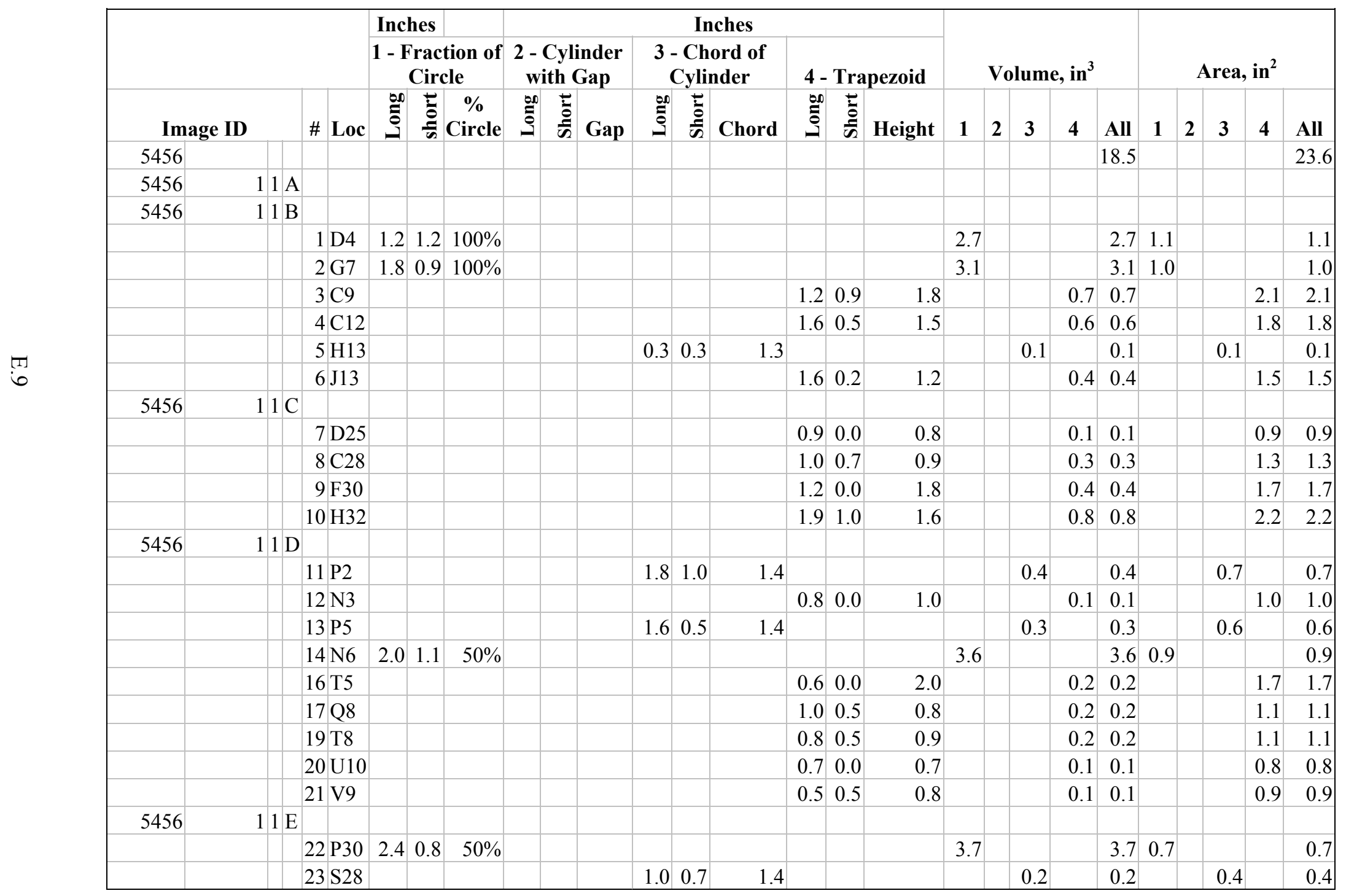


Table E.6. Large Particulate Size Calculations for Canister 5459-1

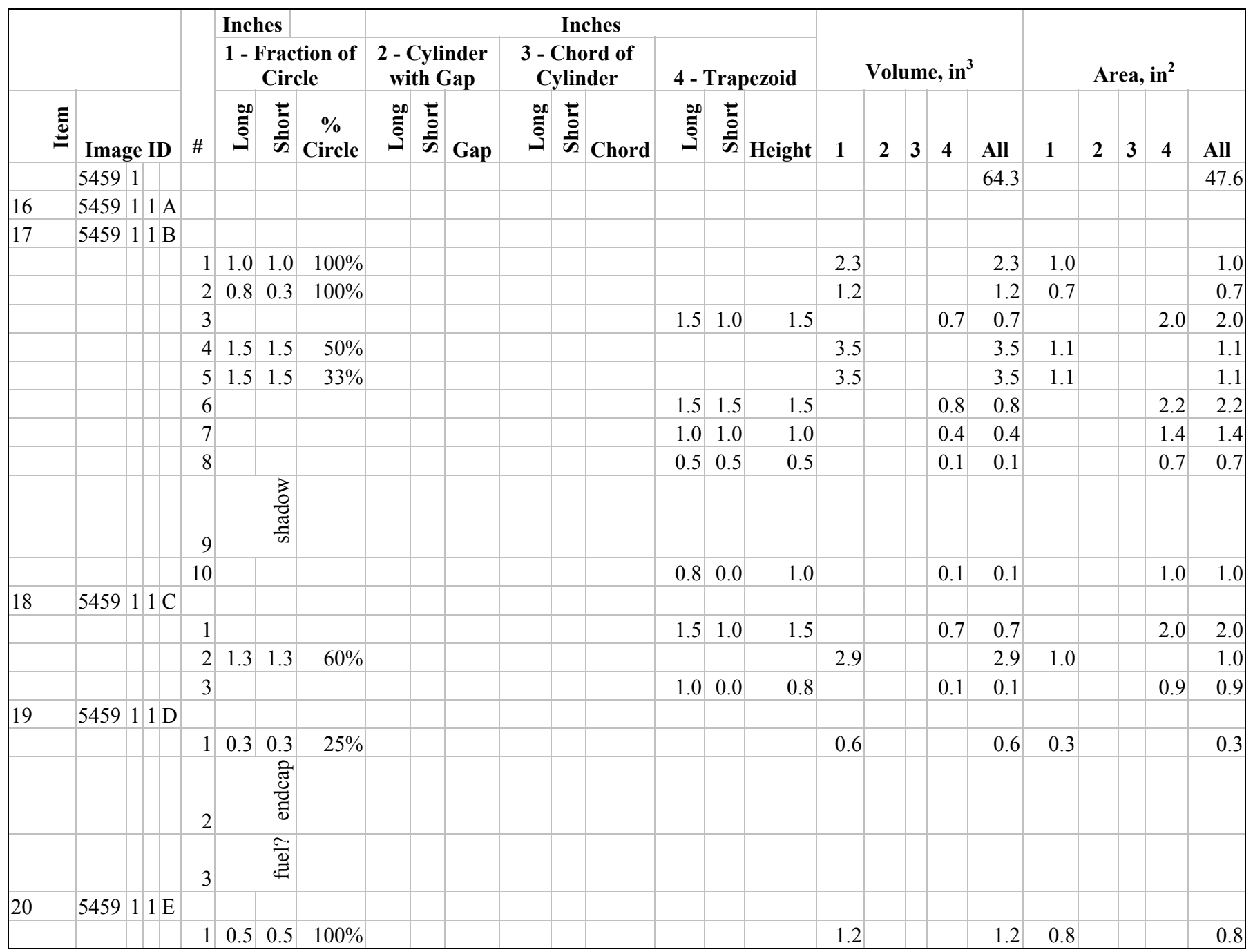


Table E.6. (contd)

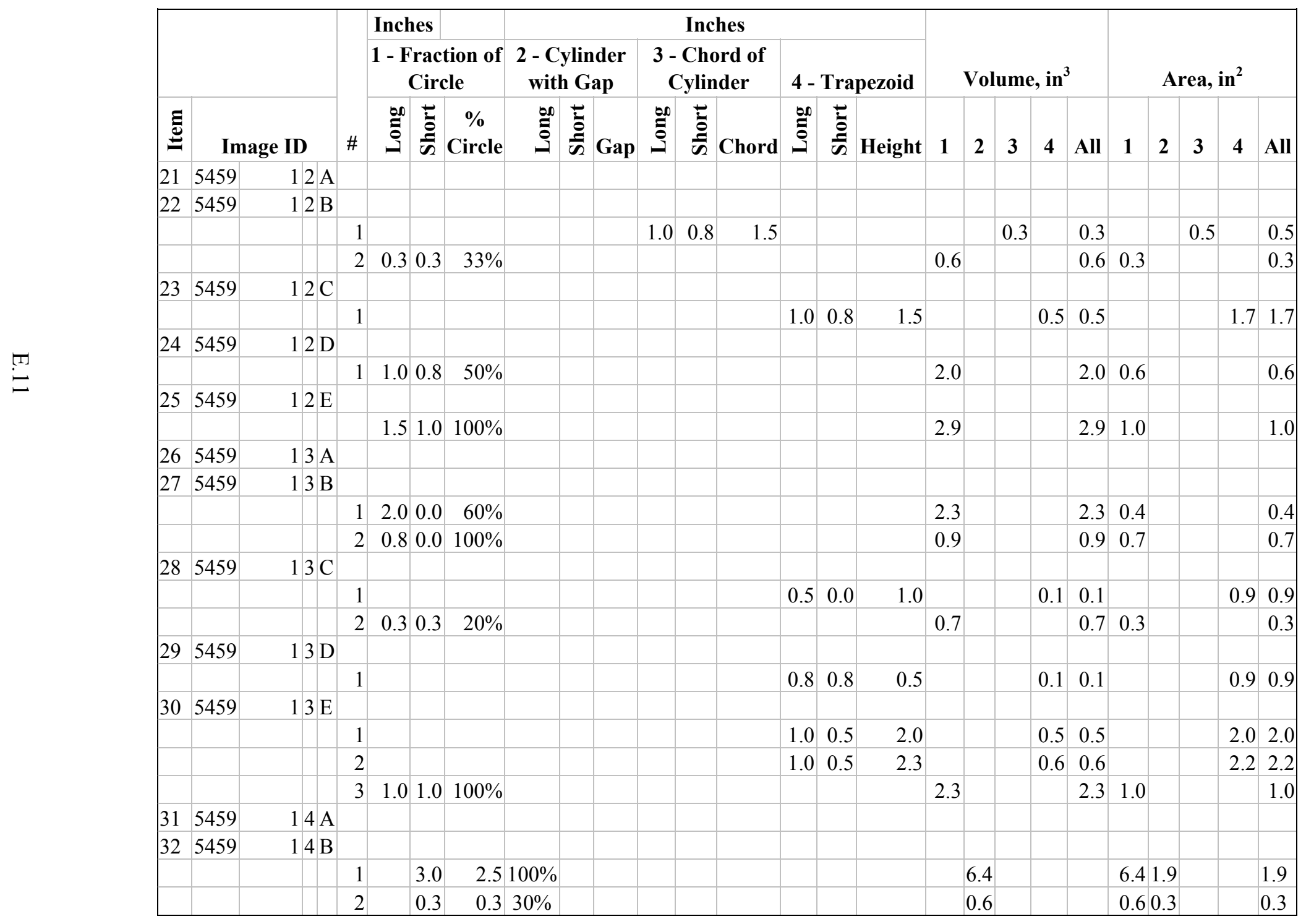


Table E.6. (contd)

\begin{tabular}{|c|c|c|c|c|c|c|c|c|c|c|c|c|c|c|c|c|c|c|c|c|c|c|c|c|c|}
\hline & & & & Inch & & & & & & & Inch & hes & & & & & & & & & & & & & \\
\hline & & & & $1-F$ & $\begin{array}{l}\text { racti } \\
\text { Circl }\end{array}$ & $\begin{array}{l}\text { tion of } \\
\text { le }\end{array}$ & & $\begin{array}{l}\text { Cyli } \\
\text { th }\end{array}$ & $\begin{array}{l}\text { inder } \\
\text { Gap }\end{array}$ & $\begin{array}{r}3-( \\
C\end{array}$ & $\begin{array}{l}\text { Chor } \\
\text { ylind }\end{array}$ & $\begin{array}{l}\text { rd of } \\
\text { der }\end{array}$ & $4-T$ & Trap & pezoid & & Volt & Ime, & in $^{3}$ & & & & ea, in & & \\
\hline$\Xi$ & Imag & ge ID & \# Loc & 悉 & 竞 & $\begin{array}{c}\% \\
\text { Circle }\end{array}$ & 电 & 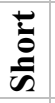 & Gap & 然 & क्ष & Chord & 些 & 言 & Height & 1 & 2 & 3 & 4 & All & 1 & 2 & 3 & 4 & All \\
\hline 33 & 5459 & $14 \mathrm{C}$ & & & & & & & & & & & & & & & & & & & & & & & \\
\hline & & & 1 & & & & & & & & & & 3.0 & 1.5 & 1.3 & & & & 1.0 & 1.0 & & & & 2.5 & 2.5 \\
\hline 34 & 5459 & $14 \mathrm{D}$ & & & & & & & & & & & & & & & & & & & & & & & \\
\hline 35 & 5459 & $14 \mathrm{E}$ & & & & & & & & & & & & & & & & & & & & & & & \\
\hline & & & 1 & 1.0 & 0.3 & $100 \%$ & & & & & & & & & & 1.6 & & & & 1.6 & 0.8 & & & & 0.8 \\
\hline & & & 2 & 2.0 & 2.0 & $50 \%$ & & & & & & & & & & 4.7 & & & & 4.7 & 1.5 & & & & 1.5 \\
\hline 36 & 5459 & $15 \mathrm{~A}$ & & & & & & & & & & & & & & & & & & & & & & & \\
\hline 37 & 5459 & $15 \mathrm{~B}$ & & & & & & & & & & & & & & & & & & & & & & & \\
\hline $\bar{N}$ & & & 1 & end $c$ & & & & & & & & & & & & & & & & & & & & & \\
\hline & & & 2 & & & & & & & 1.4 & 0.8 & 1.9 & & & & & & 0.5 & & 0.5 & & & 0.6 & & 0.6 \\
\hline 38 & 5459 & $15 \mathrm{C}$ & & & & & & & & & & & & & & & & & & & & & & & \\
\hline & & & 1 & & & & & & & & & & 1.01 & 1.0 & 1.5 & & & & 0.5 & 0.5 & & & & 1.8 & 1.8 \\
\hline & & & 2 & & & & & & & 1.5 & 1.0 & 2.0 & & & & & & 0.6 & & 0.6 & & & 0.6 & & 0.6 \\
\hline & & & 3 & end $\mathrm{c}$ & & & & & & & & & & & & & & & & & & & & & \\
\hline & & & 4 & & & & & & & & & & 1.01 & 1.0 & 1.0 & & & & 0.4 & 0.4 & & & & 1.4 & 1.4 \\
\hline & & & 5 & & & & & & & 1.1 & 0.0 & 1.8 & & & & & & 0.2 & & 0.2 & & & 0.4 & & 0.4 \\
\hline & & & E32 & & & & & & & 1.0 & 0.5 & 1.5 & & & & & & 0.2 & & 0.2 & & & 0.4 & & 0.4 \\
\hline 39 & 5459 & $15 \mathrm{D}$ & & & & & & & & & & & & & & & & & & & & & & & \\
\hline & & & 1 & 1.2 & 0.3 & $25 \%$ & & & & & & & & & & 1.7 & & & & 1.7 & 0.3 & & & & 0.3 \\
\hline & & & 2 & 1.1 & 0.8 & $20 \%$ & & & & & & & & & & 2.2 & & & & 2.2 & 0.6 & & & & 0.6 \\
\hline 40 & 5459 & $15 \mathrm{E}$ & & & & & & & & & & & & & & & & & & & & & & & \\
\hline & & & 1 & & & & & & & & & & 1.0 & 1.0 & 1.0 & & & & 0.4 & 0.4 & & & & 1.4 & 1.4 \\
\hline & & & 2 & & & & & & & 1.0 & 0.0 & 1.6 & & & & & & 0.2 & & 0.2 & & & 0.4 & & 0.4 \\
\hline & & & $\mathrm{T} 31$ & 2.0 & 0.5 & $50 \%$ & & & & & & & & & & 2.9 & & & & 2.9 & 0.5 & & & & 0.5 \\
\hline & & & V33 & & & & & & & 1.0 & 1.0 & 1.0 & & & & & & 0.2 & & 0.2 & & & 0.5 & & 0.5 \\
\hline
\end{tabular}


Table E.7. Large Particulate Size Calculations for Canister 5459-2

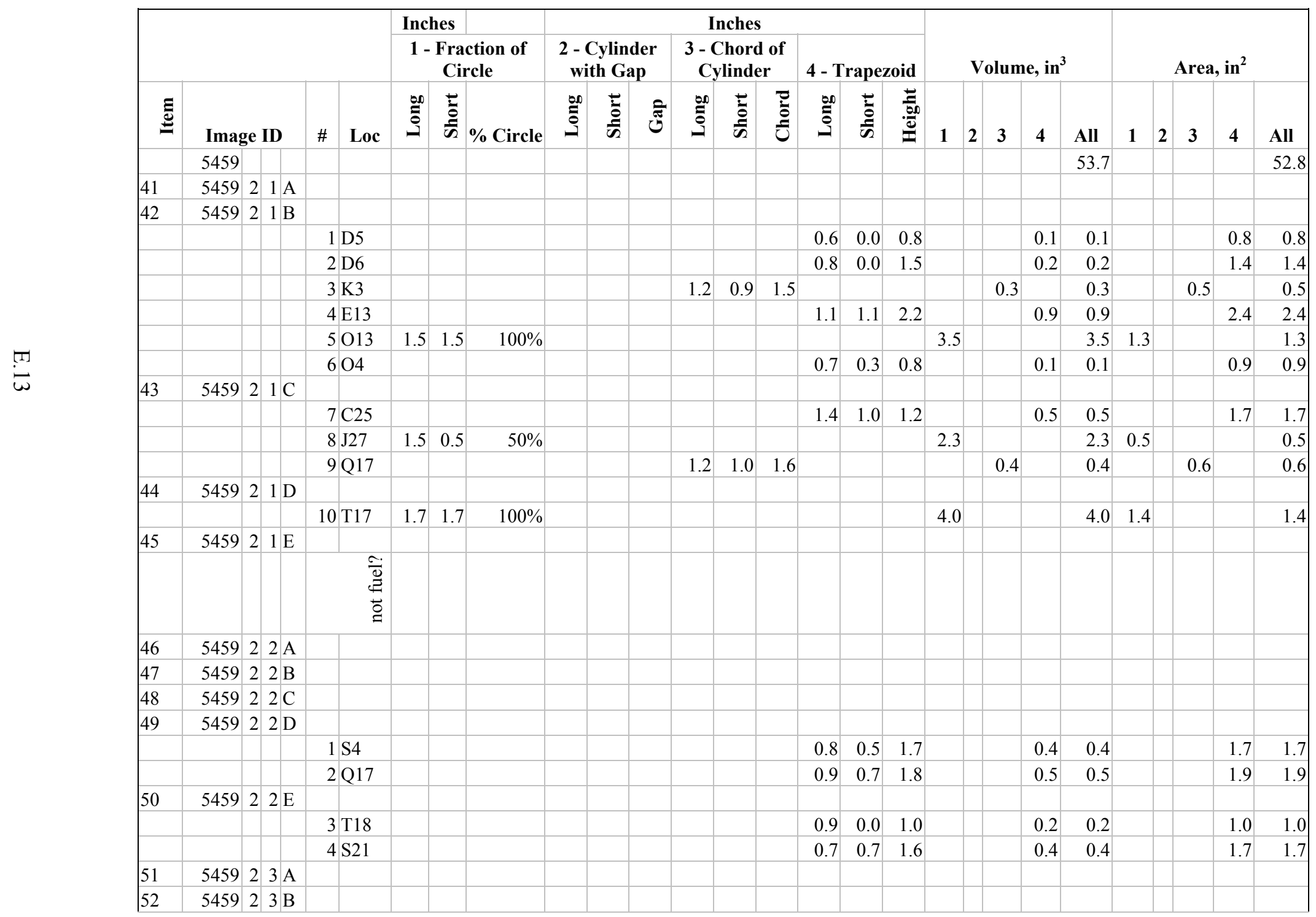


Table E.7. (contd)

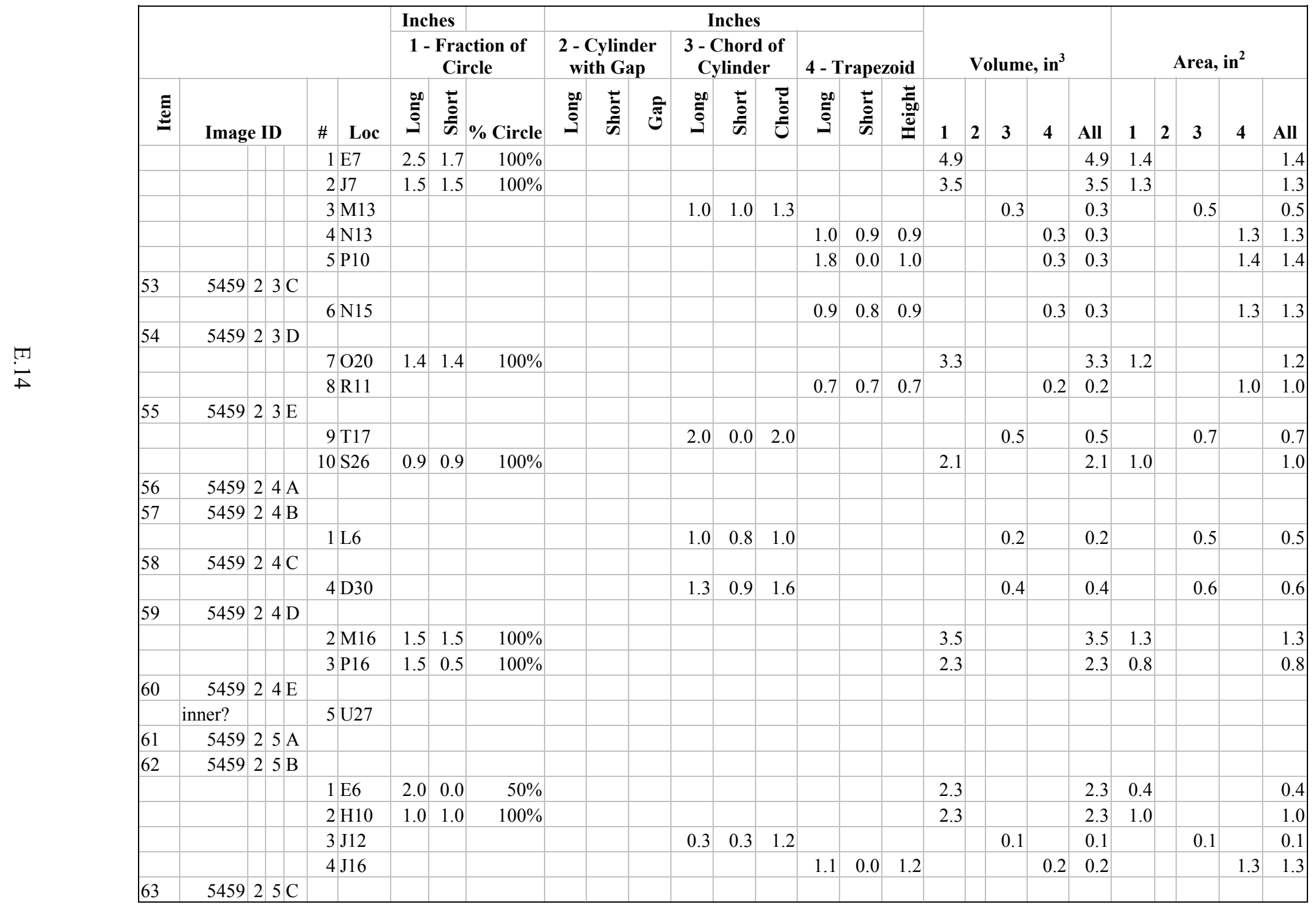


Table E.7. (contd)

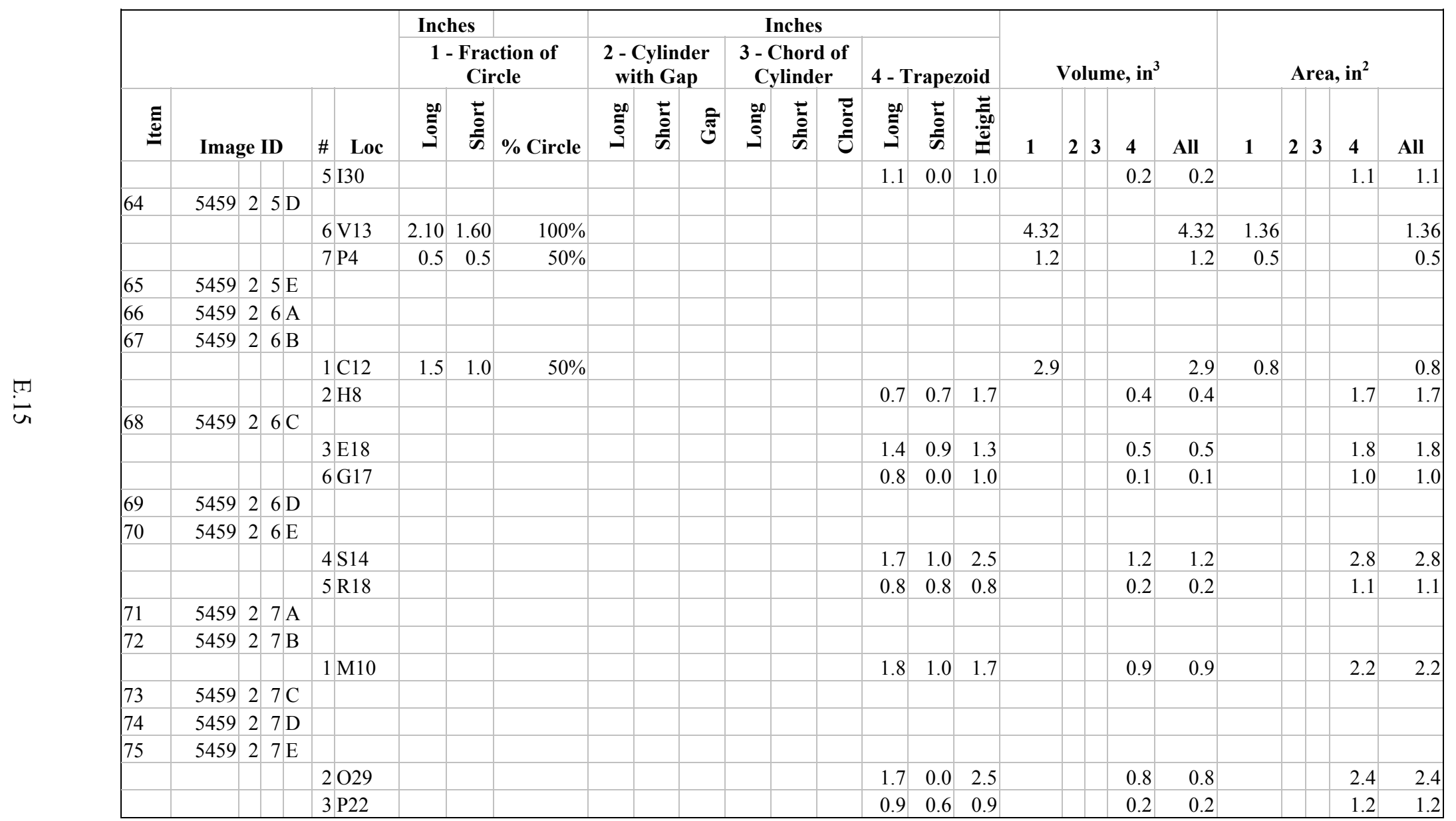


Table E.8. Large Particulate Size Calculations for Canister 5460

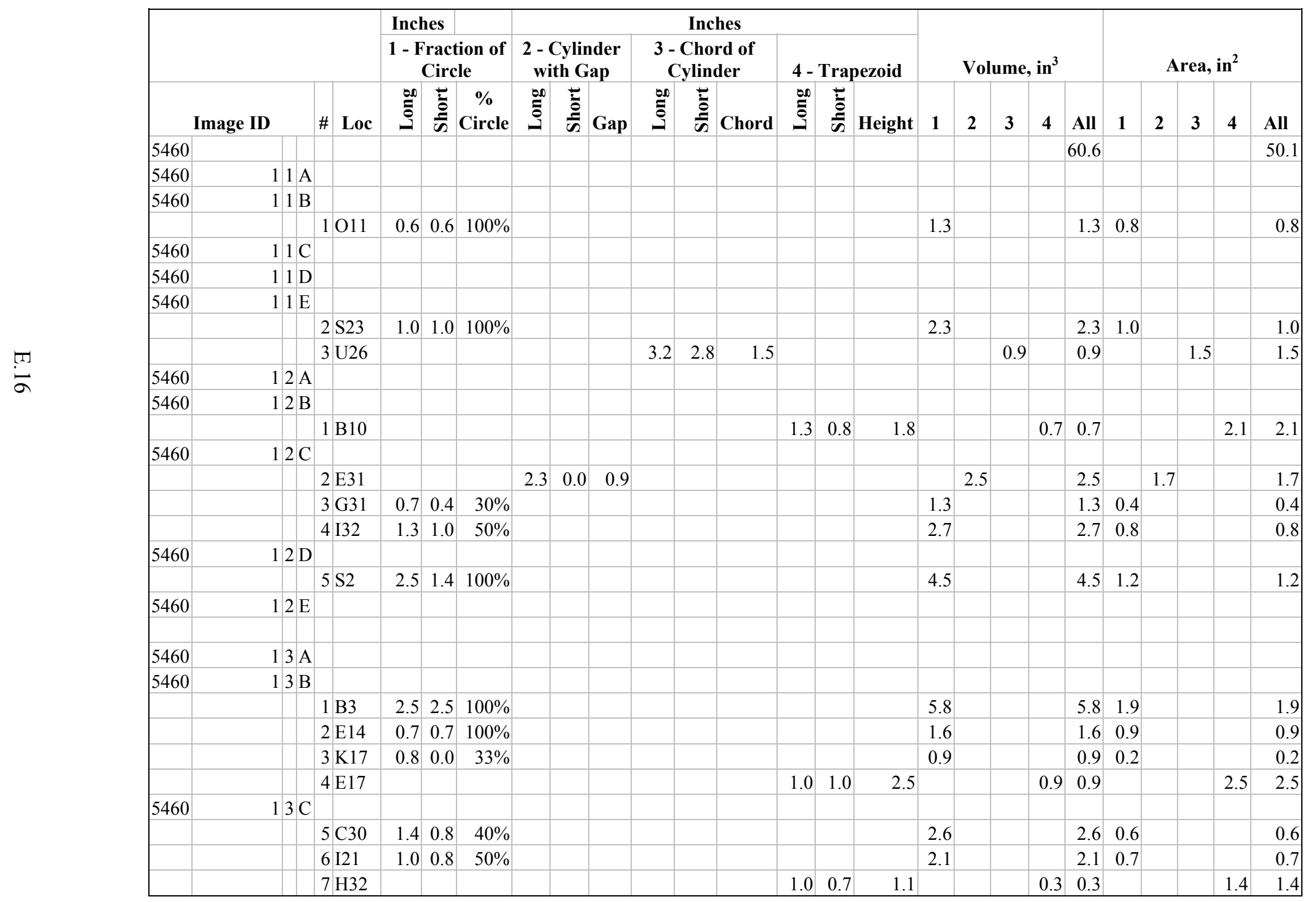


Table E.8. (contd)

\begin{tabular}{|c|c|c|c|c|c|c|c|c|c|c|c|c|c|c|c|c|c|c|c|c|c|c|c|c|c|}
\hline & & & & Inche & & & & & & & Inch & & & & & & & & & & & & & & \\
\hline & & & & $1-\mathrm{Fr}$ & $\begin{array}{l}\text { ractio } \\
\text { Circle }\end{array}$ & ion of & $\begin{array}{r}2-C \\
\text { wit }\end{array}$ & $\begin{array}{l}\text { ylinc } \\
\text { th Ga }\end{array}$ & $\begin{array}{l}\text { Ider } \\
\text { app }\end{array}$ & & $\begin{array}{l}\text { Chor } \\
\text { ylind }\end{array}$ & $\begin{array}{l}\text { rd of } \\
\text { der }\end{array}$ & & Trap & pezoid & & Volu & Ime, & & & & & rea, & & \\
\hline & Imag & ge ID & \# Loc & $\begin{array}{l}200 \\
\bar{\Xi} \\
\end{array}$ & $\stackrel{ \pm}{\bar{\Xi}} \mathbf{C}$ & $\begin{array}{c}\% \\
\text { Circle }\end{array}$ & 电 & $\frac{\grave{E}}{\omega}$ & Gap & 些 & $\frac{ \pm}{\bar{D}}$ & Chord & 象 & $\frac{E}{\omega}$ & Height & 1 & 2 & 3 & 4 & All & 1 & 2 & 3 & 4 & All \\
\hline 5460 & 1 & $3 \mathrm{D}$ & & & & & & & & & & & & & & & & & & & & & & & \\
\hline 5460 & 1 & $3 \mathrm{E}$ & & & & & & & & & & & & & & & & & & & & & & & \\
\hline & & & $8 \mathrm{P} 20$ & $1.1 \mathrm{C}$ & 0.3 & $40 \%$ & & & & & & & & & & 1.6 & & & & 1.6 & 0.4 & & & & 0.4 \\
\hline & & & & & & & & & & & & & & & & & & & & & & & & & \\
\hline 5460 & 1 & $4 \mathrm{~A}$ & & & & & & & & & & & & & & & & & & & & & & & \\
\hline 5460 & 1 & 4B & & & & & & & & & & & & & & & & & & & & & & & \\
\hline & & & $1 \mathrm{H} 15$ & & & & & & & & & & 1.0 & 1.0 & 1.0 & & & & & 0.4 & & & & 1.4 & 1.4 \\
\hline & & & 2 M5 & & & & 1.0 & 1.0 & 1.4 & & & & & & & & 2.1 & & & 2.1 & & 1.0 & & & 1.0 \\
\hline (T) & & & $3 \mathrm{M} 7$ & $1.2 \mathrm{C}$ & 0.3 & $50 \%$ & & & & & & & & & & 1.7 & & & & 1.7 & 0.4 & & & & 0.4 \\
\hline 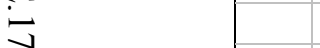 & & & $4 \mathrm{~N} 8$ & $1.0 \mathrm{C}$ & 0.3 & $40 \%$ & & & & & & & & & & 1.5 & & & & 1.5 & 0.4 & & & & 0.4 \\
\hline & & & $5 \mathrm{O} 6$ & & & & & & & & & & 0.8 & 0.5 & 1.1 & & & & & 0.3 & & & & 1.3 & 1.3 \\
\hline 5460 & 1 & $4 \mathrm{C}$ & & & & & & & & & & & & & & & & & & & & & & & \\
\hline & & & $6 \mathrm{I} 25$ & & & & & & & & & & 0.8 & 0.5 & 0.9 & & & & & 0.2 & & & & 1.1 & 1.1 \\
\hline & & & 7 P22 & $1.6 \mathrm{C}$ & 0.5 & $33 \%$ & & & & & & & & & & 2.4 & & & & 2.4 & 0.4 & & & & 0.4 \\
\hline 5460 & 1 & $4 \mathrm{D}$ & & & & & & & & & & & & & & & & & & & & & & & \\
\hline & & & $8 \mathrm{U} 1$ & 0.80 & \begin{tabular}{l|l}
$0.4 \quad 1$ \\
\end{tabular} & $100 \%$ & & & & & & & & & & 1.3 & & & & 1.3 & 0.8 & & & & 0.8 \\
\hline & & & 9S11 & & & & & & & & & & 1.1 & 0.8 & 1.0 & & & & & 0.3 & & & & 1.4 & 1.4 \\
\hline & & & $10 \mathrm{M} 13$ & & & & & & & & & & 0.8 & 0.5 & 0.4 & & & & & 0.1 & & & & 0.8 & 0.8 \\
\hline 5460 & 1 & $4 \mathrm{E}$ & & & & & & & & & & & & & & & & & & & & & & & \\
\hline & & & $11 \mathrm{R} 26$ & & & & & & & & & & 1.2 & 0.8 & 1.2 & & & & & 0.4 & & & & 1.6 & 1.6 \\
\hline & & & $12 \mathrm{~T} 27$ & & & & & & & & & & 1.1 & 0.6 & 1.7 & & & & & 50.5 & & & & 1.8 & 1.8 \\
\hline & & & & & & & & & & & & & & & & & & & & & & & & & \\
\hline 5460 & 1 & $5 \mathrm{~A}$ & & & & & & & & & & & & & & & & & & & & & & & \\
\hline 5460 & 1 & $5 \mathrm{~B}$ & & & & & & & & & & & & & & & & & & & & & & & \\
\hline & & & $1 \mathrm{~K} 2$ & 1.20 & 0.0 & $40 \%$ & & & & & & & & & & 1.4 & & & & 1.4 & 0.3 & & & & 0.3 \\
\hline & & & $2 \mathrm{E} 4$ & & & & & & & & & & 0.7 & 0.7 & 0.7 & & & & & 0.2 & & & & 1.0 & 1.0 \\
\hline & & & $3 \mathrm{C} 14$ & 0.90 & 0.5 & $40 \%$ & & & & & & & & & & 1.6 & & & & 1.6 & 0.5 & & & & 0.5 \\
\hline 5460 & 1 & $5 \mathrm{C}$ & & & & & & & & & & & & & & & & & & & & & & & \\
\hline 5460 & 1 & $5 \mathrm{D}$ & & & & & & & & & & & & & & & & & & & & & & & \\
\hline 5460 & $\begin{array}{ll}0 & 1 \\
\end{array}$ & $5 \mathrm{E}$ & & & & & & & & & & & & & & & & & & & & & & & \\
\hline
\end{tabular}


Table E.8. (contd)

\begin{tabular}{|c|c|c|c|c|c|c|c|c|c|c|c|c|c|c|c|c|c|c|c|c|c|c|c|c|}
\hline & & & Inch & & & & & & & Inch & hes & & & & & & & & & & & & & \\
\hline & & & 1 - F & $\begin{array}{l}\text { Fract } \\
\text { Circl }\end{array}$ & $\begin{array}{l}\text { tion of } \\
\text { cle }\end{array}$ & $2-$ & $\begin{array}{l}\text { Cylin } \\
\text { th G }\end{array}$ & $\begin{array}{l}\text { nder } \\
\text { Sap }\end{array}$ & & $\begin{array}{l}\text { Chor } \\
\text { ylind }\end{array}$ & $\begin{array}{l}\text { rd of } \\
\text { der }\end{array}$ & $4-7$ & Trap & pezoid & & Vol & Ime, & in $^{3}$ & & & & rea, & & \\
\hline & Image ID & Loc & 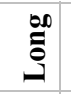 & $\stackrel{ \pm}{\bar{\Xi}}$ & $\begin{array}{c}\% \\
\text { Circle }\end{array}$ & $\stackrel{00}{\Xi}$ & 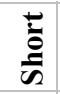 & Gap & 望 & $\frac{ \pm}{\bar{E}}$ & Chord & 我 & $\frac{ \pm}{\mathscr{D}}$ & Height & 1 & 2 & 3 & 4 & All & 1 & 2 & 3 & 4 & All \\
\hline & & $4 \mathrm{~S} 30$ & & & & & & & & & & 1.0 & 0.9 & 1.6 & & & & & 0.5 & & & & 1.8 & 1.8 \\
\hline & & & & & & & & & & & & & & & & & & & & & & & & \\
\hline & $546016 \mathrm{~A}$ & & & & & & & & & & & & & & & & & & & & & & & \\
\hline & $546016 \mathrm{~B}$ & & & & & & & & & & & & & & & & & & & & & & & \\
\hline & & $1 \mathrm{E} 4$ & 0.5 & 0.5 & $75 \%$ & & & & & & & & & & 1.2 & & & & 1.2 & 0.6 & & & & 0.6 \\
\hline & & $2 \mathrm{H} 1$ & 1.8 & 1.8 & $100 \%$ & & & & & & & & & & 4.1 & & & & 4.1 & 1.5 & & & & 1.5 \\
\hline & & $3 \mathrm{~K} 5$ & 1.0 & 1.0 & $100 \%$ & & & & & & & & & & 2.3 & & & & 2.3 & 1.0 & & & & 1.0 \\
\hline & & $4 \mathrm{~B} 5$ & & & & & & & & & & 2.0 & 1.1 & 1.2 & & & & & 70.7 & & & & 2.0 & 2.0 \\
\hline & & $5 \mathrm{C} 8$ & & & & & & & & & & 0.4 & 0.4 & 1.8 & & & & & 0.3 & & & & 1.6 & 1.6 \\
\hline & $546016 \mathrm{C}$ & & & & & & & & & & & & & & & & & & & & & & & \\
\hline & & $6 \mathrm{C} 21$ & & & & & & & 1.1 & 0.0 & 1.0 & & & & & & 0.1 & & 0.1 & & & 0.4 & & 0.4 \\
\hline & & $7 \mathrm{C} 22$ & & & & & & & & & & 0.9 & 0.5 & 1.1 & & & & & 0.3 & & & & 1.3 & 1.3 \\
\hline & & $8 \mathrm{G} 31$ & & & & & & & & & & 2.0 & 1.4 & 1.2 & & & & & 0.7 & & & & 2.1 & 2.1 \\
\hline & & $9 \mathrm{~K} 23$ & & & & & & & & & & 0.8 & 0.4 & 0.8 & & & & & 0.2 & & & & 1.0 & 1.0 \\
\hline & & \begin{tabular}{|l|l|}
10 & $\mathrm{~J} 28$ \\
\end{tabular} & & & & & & & & & & 0.6 & 0.3 & 1.2 & & & & & 0.2 & & & & 1.2 & 1.2 \\
\hline & $546016 \mathrm{D}$ & & & & & & & & & & & & & & & & & & & & & & & \\
\hline & & $11 \mathrm{~T} 2$ & 0.5 & 0.5 & $25 \%$ & & & & & & & & & & 1.2 & & & & 1.2 & 0.4 & & & & 0.4 \\
\hline & $546016 \mathrm{E}$ & & & & & & & & & & & & & & & & & & & & & & & \\
\hline & & $12 \mathrm{~K} 32$ & & & & & & & & & & 1.3 & 0.0 & 0.7 & & & & & 0.2 & & & & 1.0 & 1.0 \\
\hline & & 13 P31 & & & & & & & & & & 1.0 & 0.0 & 0.4 & & & & & 0.1 & & & & 0.6 & 0.6 \\
\hline & & $14 \mathrm{U} 23$ & & & & & & & 0.9 & 0.0 & 1.0 & & & & & & 0.1 & & 0.1 & & & 0.3 & & 0.3 \\
\hline & & & & & & & & & & & & & & & & & & & & & & & & \\
\hline & $546017 \mathrm{~A}$ & & & & & & & & & & & & & & & & & & & & & & & \\
\hline & $546017 \mathrm{~B}$ & & & & & & & & & & & & & & & & & & & & & & & \\
\hline & $546017 \mathrm{C}$ & & & & & & & & & & & & & & & & & & & & & & & \\
\hline & & $1 \mathrm{G} 30$ & 0.8 & 0.8 & $40 \%$ & & & & & & & & & & 1.7 & & & & 1.7 & 0.6 & & & & 0.6 \\
\hline & $546017 \mathrm{D}$ & & & & & & & & & & & & & & & & & & & & & & & \\
\hline & & $2 \mathrm{R} 1$ & & & & & & & 1.0 & 0.0 & 1.9 & & & & & & 0.2 & & 0.2 & & & 0.4 & & 0.4 \\
\hline & $546017 \mathrm{E}$ & & & & & & & & & & & & & & & & & & & & & & & \\
\hline
\end{tabular}


Table E.9. Large Particulate Size Calculations for Canister 5461

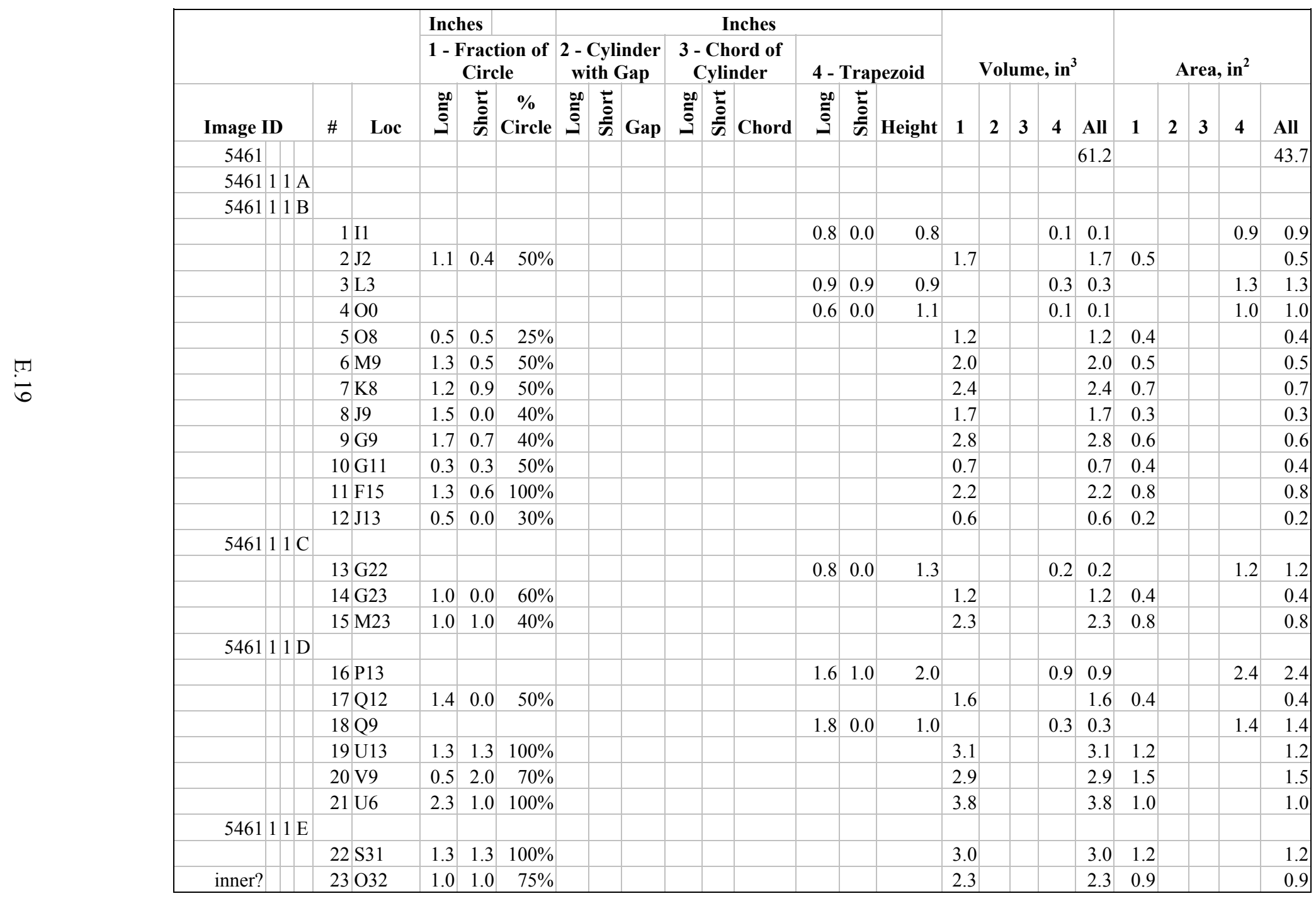


Table E.9. (contd)

\begin{tabular}{|c|c|c|c|c|c|c|c|c|c|c|c|c|c|c|c|c|c|c|c|c|c|c|c|c|}
\hline \multirow{3}{*}{\multicolumn{2}{|c|}{\begin{tabular}{|l|} 
Image ID \\
\end{tabular}}} & \multirow[b]{3}{*}{ Loc } & \multirow{2}{*}{\multicolumn{3}{|c|}{\begin{tabular}{|l|} 
Inches \\
$\begin{array}{c}1 \text { - Fraction of } \\
\text { Circle }\end{array}$ \\
\end{tabular}}} & \multicolumn{9}{|c|}{ Inches } & \multirow{2}{*}{\multicolumn{5}{|c|}{ Volume, in ${ }^{3}$}} & \multirow{2}{*}{\multicolumn{5}{|c|}{ Area, in ${ }^{2}$}} \\
\hline & & & & & & \multicolumn{3}{|c|}{$\begin{array}{c}2 \text { - Cylinder } \\
\text { with Gap }\end{array}$} & \multicolumn{3}{|c|}{$\begin{array}{l}3 \text { - Chord of } \\
\text { Cylinder }\end{array}$} & \multicolumn{3}{|c|}{4 - Trapezoid } & & & & & & & & & & \\
\hline & & & $\stackrel{00}{\Xi}$ & $\underset{\frac{a}{a}}{\tilde{a}}$ & $\begin{array}{c}\% \\
\text { Circle }\end{array}$ & 电 & 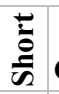 & Gap & $\stackrel{000}{\Xi}$ & $\frac{1}{\mathscr{D}}$ & Chord & $\stackrel{\infty 00}{\Xi}$ & $\frac{ \pm}{\bar{E}}$ & Height & 1 & 2 & 3 & $4 A$ & All & 1 & 2 & 3 & 4 & All \\
\hline & & \multicolumn{2}{|l|}{24 M26 } & & & & & & & & & 0.5 & 0.8 & 1.3 & & & & 0.30 & 0.3 & & & & 1.4 & 1.4 \\
\hline & & & & & & & & & & & & & & & & & & & & & & & & \\
\hline 5461 & $12 \mathrm{~A}$ & & & & & & & & & & & & & & & & & & & & & & & \\
\hline \multirow[t]{3}{*}{5461} & $12 \mathrm{~B}$ & & & & & & & & & & & & & & & & & & & & & & & \\
\hline & & $1 \mathrm{~B} 7$ & & & & & & & & & & 1.2 & 0.9 & 0.9 & & & & 0.30 & 0.3 & & & & 1.4 & 1.4 \\
\hline & & $2 \mathrm{C} 16$ & 0.8 & 0.6 & $33 \%$ & & & & & & & & & & 1.6 & & & & 1.6 & 0.5 & & & & 0.5 \\
\hline \multirow[t]{4}{*}{5461} & $12 \mathrm{C}$ & & & & & & & & & & & & & & & & & & & & & & & \\
\hline & & $3 \mathrm{C} 24$ & 1.0 & 0.5 & $33 \%$ & & & & & & & & & & 1.7 & & & & 1.7 & 0.4 & & & & 0.4 \\
\hline & & \begin{tabular}{l|l}
$4 \mathrm{~F} 28$ \\
\end{tabular} & & & & & & & & & & 0.8 & 0.0 & 1.1 & & & & 0.20 & 0.2 & & & & 1.1 & 1.1 \\
\hline & & $6 \mathrm{~J} 21$ & & & & & & & & & & 1.6 & 0.0 & 1.4 & & & & & 0.4 & & & & 1.6 & 1.6 \\
\hline 5461 & $12 \mathrm{D}$ & & & & & & & & & & & & & & & & & & & & & & & \\
\hline & & $7 \mathrm{O} 10$ & 1.6 & 0.0 & $40 \%$ & & & & & & & & & & 1.9 & & & & 1.9 & 0.3 & & & & 0.3 \\
\hline & & 8 P8 & & & & & & & & & & 2.8 & 0.0 & 1.8 & & & & 0.90 & 0.9 & & & & 2.3 & 2.3 \\
\hline & & 9 Q6 & & & & & & & & & & 2.4 & 0.0 & 2.0 & & & & 0.90 & 0.9 & & & & 2.3 & 2.3 \\
\hline & & $10 \mathrm{U} 8$ & & & & 1.5 & 0.7 & 0.8 & & & & & & & & 2.4 & & & 2.4 & & 1.2 & & & 1.2 \\
\hline & & $11 \mathrm{U} 9$ & & & & & & & & & & 2.0 & 0.0 & 2.2 & & & & 0.80 & 0.8 & & & & 2.3 & 2.3 \\
\hline & & $12 \mathrm{~V} 12$ & 0.5 & 0.5 & $100 \%$ & & & & & & & & & & 1.2 & & & & 1.2 & 0.8 & & & & 0.8 \\
\hline & & 13 U14 & 0.7 & 0.7 & $50 \%$ & & & & & & & & & & 1.6 & & & & 1.6 & 0.6 & & & & 0.6 \\
\hline & & 14 U17 & 0.8 & 0.8 & $100 \%$ & & & & & & & & & & 1.7 & & & & 1.7 & 0.9 & & & & 0.9 \\
\hline 5461 & $12 \mathrm{E}$ & & & & & & & & & & & & & & & & & & & & & & & \\
\hline & & $15 \mathrm{U} 21$ & 1.9 & 1.9 & $100 \%$ & & & & & & & & & & 4.4 & & & & 4.4 & 1.5 & & & & 1.5 \\
\hline & & $16 \mathrm{~S} 32$ & 0.9 & 0.9 & $100 \%$ & & & & & & & & & & 2.0 & & & & 2.0 & 1.0 & & & & 1.0 \\
\hline & & & & & & & & & & & & & & & & & & & & & & & & \\
\hline 5461 & $13 \mathrm{~A}$ & & & & & & & & & & & & & & & & & & & & & & & \\
\hline 5461 & $13 \mathrm{~B}$ & & & & & & & & & & & & & & & & & & & & & & & \\
\hline 5461 & $13 \mathrm{C}$ & & & & & & & & & & & & & & & & & & & & & & & \\
\hline & & $1 \mathrm{I} 31$ & & & & & & & & & & 1.8 & 0.8 & 1.4 & & & & & 0.7 & & & & 1.9 & 1.9 \\
\hline & & $2 \mathrm{~N} 29$ & & & & & & & & & & 0.7 & 0.7 & 0.7 & & & & & 0.2 & & & & 1.0 & 1.0 \\
\hline 5461 & $13 \mathrm{D}$ & & & & & & & & & & & & & & & & & & & & & & & \\
\hline & & 3 T12 & & & & & & & & & & 0.9 & 0.6 & 0.8 & & & & 0.20 & 0.2 & & & & 1.1 & 1.1 \\
\hline 5461 & $13 \mathrm{E}$ & & & & & & & & & & & & & & & & & & & & & & & \\
\hline
\end{tabular}




\section{Appendix F}

Application of the Lognormal Distribution 


\section{Appendix F}

\section{Application of the Lognormal Distribution}

An untruncated lognormal distribution, $\mathrm{F}_{\infty}$, expressed as the cumulative probability distribution of finding particles smaller than a certain size, $\mathrm{x}$, is

$$
\begin{aligned}
& F_{\infty}(x, 0)=\frac{1}{\sqrt{\pi}} \int_{-\infty}^{\ln (x / \mu) / \sigma} e^{-w^{2}} d w \\
& \text { or } \\
& F_{\infty}(z,-\infty)=\frac{1}{\sqrt{\pi}} \int_{-\infty}^{z} e^{-w^{2}} d z, \quad z \equiv \frac{1}{\sigma} \ln \left(\frac{x}{\mu}\right)
\end{aligned}
$$

where the probability can be expressed either in terms of the size, $x$, or a normalized logarithm of size, $z$, as defined above. The cumulative distribution describes the fraction of the number of particles smaller than $\mathrm{x}$ compared to the total number of particles; i.e.,

$$
\begin{aligned}
& F_{\infty}(x, 0)=\frac{N(x, 0)}{N(\infty, 0)} \text { or } \\
& F_{\infty}(z,-\infty)=\frac{N(z,-\infty)}{N(\infty,-\infty)}
\end{aligned}
$$

where $\mathrm{N}\left(\mathrm{x}_{\mathrm{b}}, \mathrm{x}_{\mathrm{a}}\right)$ is the number of particles with sizes between $\mathrm{x}_{\mathrm{a}}$ and $\mathrm{x}_{\mathrm{b}}>\mathrm{x}_{\mathrm{a}}$ or equivalently $\mathrm{N}\left(\mathrm{z}_{\mathrm{b}}, \mathrm{z}_{\mathrm{a}}\right)$ is the number with normalized logarithmic sizes between $z_{a}$ and $z_{b}$

The untruncated probability distribution function in terms of normalized logarithmic size $\mathrm{z}$ is

$$
\frac{d F_{\infty}}{d z}=\frac{1}{\sqrt{\pi}} e^{-z^{2}}
$$

However, our distribution is truncated at least on the upper end in that we counted no particles greater than $\mathrm{x}=5 / 8$ inch, and we need to be able to consider the effect of truncating the distribution at the lower end, such as by physically removing from the distribution particles less than a certain size. Therefore, we must be able to evaluate the consequences of a truncated lognormal distribution, with a domain from $\mathrm{x}_{1}$ to $\mathrm{x}_{2}$, corresponding to the normalized logarithmic size domain from $\mathrm{z}_{1}$ to $\mathrm{z}_{2}$. 
For an untruncated lognormal distribution, $\mu$ is the mode of the distribution and the mean of the logarithm of the size and $\sigma^{2} / 2$ is the variance of the logarithm of the size. For our truncated distribution, $\mu$ is still the mode but no longer the mean; both the mean and variance depend on $\mu$ and $\sigma$ and the truncation of the distribution. Therefore, $\mu$ and $\sigma$ are best just thought of as parameters describing the distribution along with the upper and lower truncation limits.

To consider the effect of very small particles that we could not count directly, we assume that the shape of the probability distribution function, $\mathrm{dF} / \mathrm{dz}$, over the truncated domain is the same as that for an untruncated lognormal distribution:

$$
\frac{d F}{d z}=\frac{1}{K} e^{-z^{2}}
$$

where $\mathrm{K}$ depends on the upper and lower limits of a truncated distribution. The number of particles in a differential size domain $\mathrm{dx}$, or equivalently $\mathrm{dz}$, is then

$$
d N=N_{0} d F=\frac{d F}{d z} d z=\frac{N_{0}}{K} e^{-z^{2}} d z
$$

where $\mathrm{N}_{0}$ is the total number of particles in the truncated distribution.

To fit the parameters $\mu$ an $\sigma$ to a distribution, we calculate the number of particles predicted to be in a size bin, defined by the bin's bounding sizes, say $\mathrm{x}_{\mathrm{a}}$ and $\mathrm{x}_{\mathrm{b}}$, or equivalently $\mathrm{z}_{\mathrm{a}}$ and $\mathrm{z}_{\mathrm{b}}$, which is found by integrating $\mathrm{dN}$ :

$$
N\left(z_{b}, z_{a}\right)=\int_{z_{a}}^{z_{b}} d N=\frac{N_{0}}{K} \int_{z_{a}}^{z_{b}} e^{-z^{2}} d z=\frac{\sqrt{\pi} N_{0}}{2 K}\left[\operatorname{erf}\left(z_{b}\right)-\operatorname{erf}\left(z_{a}\right)\right]
$$

Also,

$$
\begin{aligned}
& N_{0} \equiv N\left(z_{2}, z_{1}\right)=\frac{\sqrt{\pi} N_{0}}{2 K}\left[\operatorname{erf}\left(z_{2}\right)-\operatorname{erf}\left(z_{1}\right)\right] \\
& \therefore \quad K=\frac{\sqrt{\pi}}{2}\left[\operatorname{erf}\left(z_{2}\right)-\operatorname{erf}\left(z_{1}\right)\right] \\
& \frac{d F}{d z}=\frac{2}{\sqrt{\pi}} \frac{e^{-z^{2}}}{\left[\operatorname{erf}\left(z_{2}\right)-\operatorname{erf}\left(z_{1}\right)\right]} \\
& d N=N_{0} d F=N_{0} \frac{d F}{d z} d z=\frac{2 N_{0}}{\sqrt{\pi}} \frac{e^{-z^{2}}}{\left[\operatorname{erf}\left(z_{2}\right)-\operatorname{erf}\left(z_{1}\right)\right]} d z
\end{aligned}
$$


The probability of finding particles with sizes between $\mathrm{x}_{\mathrm{a}}$ and $\mathrm{x}_{\mathrm{b}}$, or equivalently between the corresponding $z_{a}$ and $z_{b}$, is the number of particles in this size range divided by the total number of particles, where the total size range of the truncated distribution is from $x_{1}$ to $x_{2}$ or equivalently from $z_{1}$ to $z_{2}$. This is then

$$
F\left(z_{b}, z_{a} ; z_{2}, z_{1}, \mu, \sigma\right) \equiv=\frac{N\left(z_{b}, z_{a}\right)}{N\left(z_{2}, z_{1}\right)}=\frac{\int_{z_{a}}^{z_{b}} e^{-z^{2}} d z}{\int_{z_{1}}^{z_{2}} e^{-z^{2}} d z}=\frac{\operatorname{erf}\left(z_{b}\right)-\operatorname{erf}\left(z_{a}\right)}{\operatorname{erf}\left(z_{2}\right)-\operatorname{erf}\left(z_{1}\right)}
$$

The domain is truncated on the large end at $\mathrm{x}_{2}=5 / 8$ inch and we want to consider cases where we also truncate it on the small end by removing particles smaller than a certain size.

Also, given the two parameters, we can compute the number of particles appearing in a given size domain and compare this to the number of particles in a smaller domain contained within it. This corresponds to our data, which describe the number of particles appearing in each of the four size bins to the number of particles we counted. The particles fall in the domain from $1 / 16$ inch (the limit of visibility) to $5 / 8$ inch, the largest particles that we counted.

We fit the parameters $\mu$ and $\sigma$ by choosing the values that minimize the function

$$
\Gamma(\mu, \sigma)=\sum_{i}\left(\left.\frac{N\left(z_{i}, z_{i-1}\right)}{N\left(z_{2}, z_{1}\right)}\right|_{\text {calc }}-\left.\frac{N\left(z_{i}, z_{i-1}\right)}{N\left(z_{2}, z_{1}\right)}\right|_{\text {data }}\right)^{2}
$$

where as before $\mathrm{z}=\ln (\mathrm{x} / \mu) / \sigma$ where $\mathrm{x}$ is the particle size and the subscripts mean the following: 2 denotes the largest size of all particles, which is $5 / 8$ inch by our counting procedure; 1 denotes the smallest size of all particles, which we take to be $1 / 16$ inch, the limit of visibility; i denotes the upper boundary of size bin i, and i-1 denotes the lower boundary of size bin $\mathrm{i}$. Therefore, $\mathrm{N}\left(\mathrm{z}_{2}, \mathrm{z}_{1}\right)$ is the total number of counts.

The area of the particles in a differential size domain is

$$
d A=\frac{d A}{d N} d N=\beta x^{2} d N=\beta x^{2} \frac{2 N_{0}}{\sqrt{\pi}} \frac{e^{-z^{2}}}{\left[\operatorname{erf}\left(z_{2}\right)-\operatorname{erf}\left(z_{1}\right)\right]} d z=\beta \mu^{2} \frac{2 N_{0}}{\sqrt{\pi}} \frac{e^{-\left(z^{2}-2 \sigma z\right)}}{\left[\operatorname{erf}\left(z_{2}\right)-\operatorname{erf}\left(z_{1}\right)\right]} d z
$$

where $\beta$ is a shape factor for area assumed to describe all the particles and we have used $x \equiv \mu e^{\sigma z}$. Finally, the volume of the particles in a differential size domain is

$$
d V=\frac{d V}{d N} d N=\gamma x^{3} d N=\beta x^{3} \frac{2 N_{0}}{\sqrt{\pi}} \frac{e^{-z^{2}}}{\left[\operatorname{erf}\left(z_{2}\right)-\operatorname{erf}\left(z_{1}\right)\right]} d z=\beta \mu^{3} \frac{2 N_{0}}{\sqrt{\pi}} \frac{e^{-\left(z^{2}-3 \sigma z\right)}}{\left[\operatorname{erf}\left(z_{2}\right)-\operatorname{erf}\left(z_{1}\right)\right]} d z
$$

where $\gamma$ is a shape factor for volume. 
Given fitted values of $\mu$ and $\sigma$, the area of the particles in the truncated distribution is

$$
\begin{aligned}
& A\left(z_{2}, z_{1}\right)=\int_{z_{1}}^{z_{2}} d A=\beta \mu^{2} \frac{2 N_{0}}{\sqrt{\pi}} \frac{1}{\left[\operatorname{erf}\left(z_{2}\right)-\operatorname{erf}\left(z_{1}\right)\right]} \int_{z_{1}}^{z_{2}} e^{-\left(z^{2}-2 \sigma z\right)} d z \\
& =\beta \mu^{2} \frac{2 N_{0}}{\sqrt{\pi}} \frac{1}{\left[\operatorname{erf}\left(z_{2}\right)-\operatorname{erf}\left(z_{1}\right)\right]} \int_{z_{1}}^{z_{2}} e^{-(z-\sigma)^{2}+\sigma^{2}} d z=\beta \mu^{2} e^{\sigma^{2}} \frac{2 N_{0}}{\sqrt{\pi}} \frac{1}{\left[\operatorname{erf}\left(z_{2}\right)-\operatorname{erf}\left(z_{1}\right)\right]} \int_{z_{1}-\sigma}^{z_{2}-\sigma} e^{-w^{2}} d w \\
& =\beta \mu^{2} N_{0} e^{\sigma^{2}} \frac{\left[\operatorname{erf}\left(z_{2}-\sigma\right)-\operatorname{erf}\left(z_{1}-\sigma\right)\right]}{\left[\operatorname{erf}\left(z_{2}\right)-\operatorname{erf}\left(z_{1}\right)\right]}
\end{aligned}
$$

The cumulative fraction, $\phi$, of the area of particles up to normalize logarithmic size $\mathrm{z}$ in the truncated distribution is then

$$
\phi=\frac{A\left(z, z_{1}\right)}{A\left(z_{2}, z_{1}\right)}=\frac{\left[\operatorname{erf}(z-\sigma)-\operatorname{erf}\left(z_{1}-\sigma\right)\right]}{\left[\operatorname{erf}\left(z_{2}-\sigma\right)-\operatorname{erf}\left(z_{1}-\sigma\right)\right]}
$$

We recover the probability distribution function for area vs. normalized logarithm of particle size by differentiating $\phi$ with respect to $\mathrm{z}$ to give

$$
\frac{\partial \phi}{\partial z}=\frac{\frac{2}{\sqrt{\pi}} e^{-(z-\sigma)^{2}}}{\left[\operatorname{erf}\left(z_{2}-\sigma\right)-\operatorname{erf}\left(z_{1}-\sigma\right)\right]}
$$

Similarly, for the cumulative volume of the particles in the truncated distribution,

$$
\begin{aligned}
& V\left(z_{2}, z_{1}\right)=\int_{z_{1}}^{z_{2}} d V=\gamma \mu^{3} \frac{2 N_{0}}{\sqrt{\pi}} \frac{1}{\left[\operatorname{erf}\left(z_{2}\right)-\operatorname{erf}\left(z_{1}\right)\right]} \int_{z_{1}}^{z_{2}} e^{-\left(z^{2}-3 \sigma z\right)} d z \\
& =\gamma \mu^{3} \frac{2 N_{0}}{\sqrt{\pi}} \frac{1}{\left[\operatorname{erf}\left(z_{2}\right)-\operatorname{erf}\left(z_{1}\right)\right]} \int_{z_{1}}^{z_{2}} e^{-\left(z-\frac{3}{2} \sigma\right)^{2}+\frac{9}{4} \sigma^{2}} d z=\gamma \mu^{3} e^{\frac{9}{4} \sigma^{2}} \frac{2 N_{0}}{\sqrt{\pi}} \frac{1}{\left[\operatorname{erf}\left(z_{2}\right)-\operatorname{erf}\left(z_{1}\right)\right]} \int_{z_{1}-\frac{3}{2} \sigma}^{z_{2}-\frac{3}{2} \sigma} e^{-w^{2}} d w \\
& =N_{0} \gamma \mu^{3} e^{\frac{9}{4} \sigma^{2}}\left[\operatorname{erf}\left(z_{2}-\frac{3}{2} \sigma\right)-\operatorname{erf}\left(z_{1}-\frac{3}{2} \sigma\right)\right]
\end{aligned}
$$

The cumulative fraction, $\psi$, of the area of particles up to size $\mathrm{x}$ in the truncated distribution is then

$$
\psi=\frac{V\left(z, z_{1}\right)}{V\left(z_{2}, z_{1}\right)}=\frac{\left[\operatorname{erf}\left(z-\frac{3}{2} \sigma\right)-\operatorname{erf}\left(z_{1}-\frac{3}{2} \sigma\right)\right]}{\left[\operatorname{erf}\left(z_{2}-\frac{3}{2} \sigma\right)-\operatorname{erf}\left(z_{1}-\frac{3}{2} \sigma\right)\right]}
$$

We recover the probability distribution function for volume vs. normalized logarithm of particle size by differentiating $\psi$ with respect to $\mathrm{z}$ to give 


$$
\frac{\partial \psi}{\partial z}=\frac{\frac{2}{\sqrt{\pi}} e^{-\left(z-\frac{3}{2} \sigma\right)^{2}}}{\left[\operatorname{erf}\left(z_{2}-\frac{3}{2} \sigma\right)-e r f\left(z_{1}-\frac{3}{2} \sigma\right)\right]}
$$

An example distribution appears below in Figure F.1, which shows $\mathrm{F}, \mathrm{dF} / \mathrm{dz}, \mathrm{d} \phi / \mathrm{dz}$, and $\mathrm{d} \psi / \mathrm{dz}$ plotted vs. z. In this case, $\mu=0.16$ inch and $\sigma=1.3$ inches, whence $69 \%$ of the particles between $1 / 16$ inch and $5 / 8$ inch are smaller than $1 / 4$ inch.

The ratio of the area of all the particles to the volume of all the particles is

$$
\frac{A\left(z_{2}, z_{1}\right)}{V\left(z_{2}, z_{1}\right)}=\frac{\beta}{\gamma \mu} e^{-\frac{5}{4} \sigma^{2}} \frac{\operatorname{erf}\left(z_{2}-\sigma\right)-\operatorname{erf}\left(z_{1}-\sigma\right)}{\operatorname{erf}\left(z_{2}-\frac{3}{2} \sigma\right)-\operatorname{erf}\left(z_{1}-\frac{3}{2} \sigma\right)}
$$

A particle with the same area and volume shape factors as for the distribution of particles would have the area-to-volume ratio

$$
\left.\frac{A}{V}\right|_{\text {eff }}=\frac{\beta x_{e f f}^{2}}{\gamma x_{e f f}^{3}}=\frac{\beta}{\gamma x_{e f f}}
$$

where $\mathrm{X}_{\text {eff }}$ is the size of the effective particle. That is, if the particles were actually one size, $\mathrm{X}_{\mathrm{eff}}$ is the

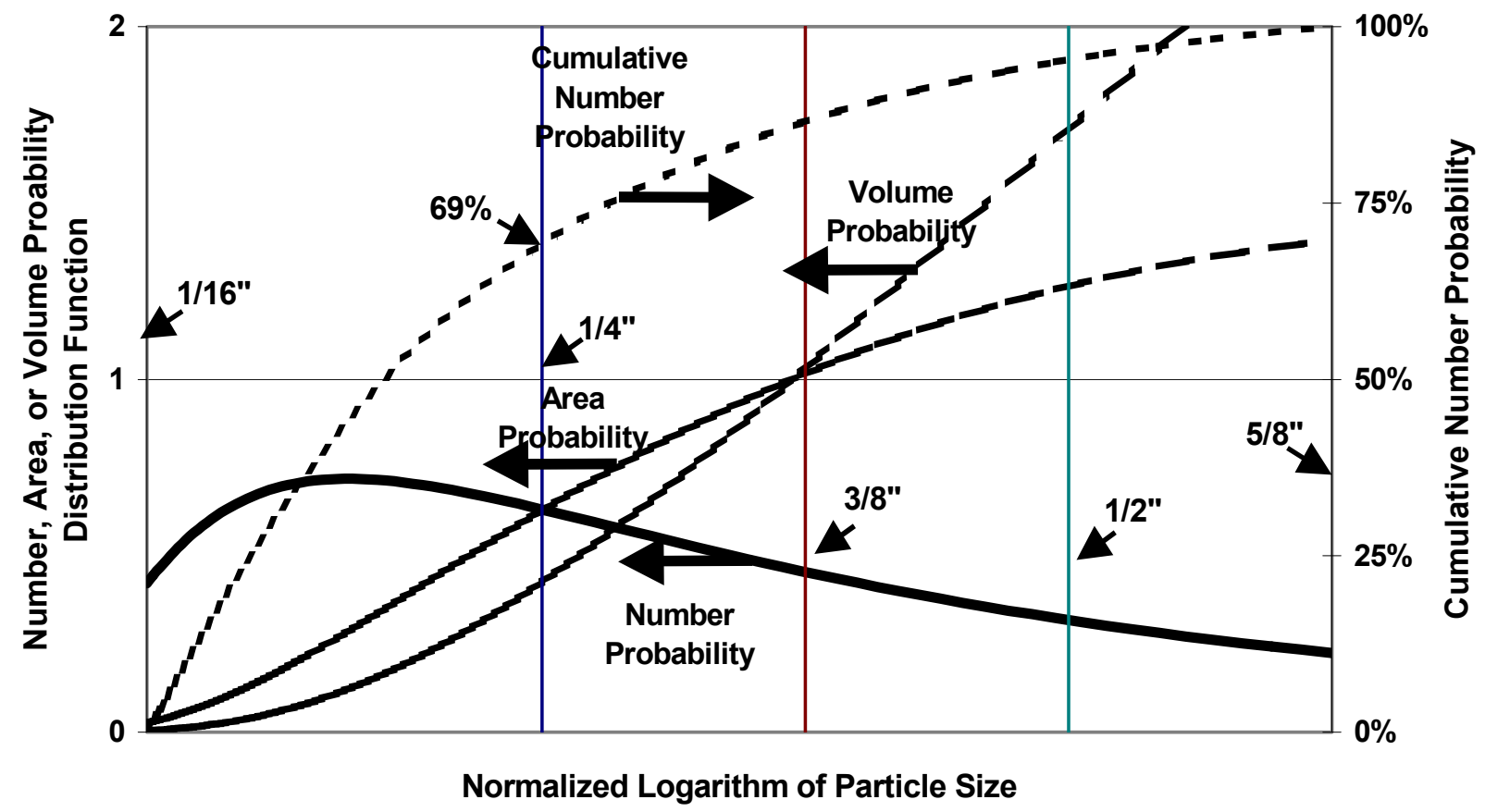

Figure F.1. Example Probability Distribution. 
size that would result in the same area-to-volume ratio as for the actual truncated distribution. This is given by

$$
\begin{aligned}
& \frac{\beta}{\gamma x_{\text {eff }}}=\frac{\beta}{\gamma \mu} e^{-\frac{5}{2} \sigma^{2}} \frac{\operatorname{erf}\left(z_{2}-\sigma\right)-\operatorname{erf}\left(z_{1}-\sigma\right)}{\operatorname{erf}\left(z_{2}-\frac{3}{2} \sigma\right)-\operatorname{erf}\left(z_{1}-\frac{3}{2} \sigma\right)} \\
& x_{\text {eff }}=\mu e^{\frac{5}{4} \sigma^{2}} \frac{\operatorname{erf}\left(z_{2}-\frac{3}{2} \sigma\right)-\operatorname{erf}\left(z_{1}-\frac{3}{2} \sigma\right)}{\operatorname{erf}\left(z_{2}-\sigma\right)-\operatorname{erf}\left(z_{1}-\sigma\right)}
\end{aligned}
$$

For the case of no lower bound on the distribution, i.e., $\mathrm{x}_{1} \rightarrow 0$ or equivalently $\mathrm{z}_{1} \rightarrow-\infty$, we have

$$
x_{e f f}=\mu e^{\frac{5}{4} \sigma^{2}} \frac{\operatorname{erf}\left(z_{2}-\frac{3}{2} \sigma\right)+1}{\operatorname{erf}\left(z_{2}-\sigma\right)+1}=\mu e^{\frac{5}{4} \sigma^{2}} \frac{\operatorname{erfc}\left(\frac{3}{2} \sigma-z_{2}\right)}{\operatorname{erfc}\left(\sigma-z_{2}\right)}
$$




\section{Distribution}

No. of

\section{Copies}

OFFSITE

M. G. Plys

Fauske \& Associates, Inc. 16W070 West 83rd Street,

Burr Ridge, IL 60521

J. D. Thomson

Holmes \& Narver

3250 Port of Benton Blvd.

Richland, Washington 99352

\section{ONSITE}

7 Flour Hanford, Inc.

R. M. Crawford

X3-79

D. R. Duncan

J. K. McClusky

A. L. Pitner

L. S. Semmens

J. A. Swenson (2)

$\mathrm{X} 3-79$

$\mathrm{X} 3-78$
No. of

Copies

Lucas Incorporated

V. Hoefer

X3-65

Numatec Hanford Corporation

J. P. Sloughter

X4-01

15 Pacific Northwest National Laboratories

J. Abrefah

P7-27

E. G. Baker

K2-12

D. W. Damschen

K7-15

D. E. Knutson

$\mathrm{P} 7-25$

W. L. Kuhn (5)

K7-15

S. C. Marschman

$\mathrm{P} 7-27$

R. K. Quinn

K2-20

A. J. Schmidt

$\mathrm{K} 2-12$

P. A. Scott

K9-46

T. L. Walton

K9-46

J. C. Wiborg

K7-68 